\title{
Clinical evaluation of pulsed electromagnetic field treatment for acute scaphoid fractures
}

Citation for published version (APA):

Hannemann, P. F. W. (2015). Clinical evaluation of pulsed electromagnetic field treatment for acute scaphoid fractures. [Doctoral Thesis, Maastricht University]. Maastricht University. https://doi.org/10.26481/dis.20150522ph

Document status and date:

Published: 01/01/2015

DOI:

10.26481/dis.20150522ph

Document Version:

Publisher's PDF, also known as Version of record

\section{Please check the document version of this publication:}

- A submitted manuscript is the version of the article upon submission and before peer-review. There can be important differences between the submitted version and the official published version of record.

People interested in the research are advised to contact the author for the final version of the publication, or visit the DOI to the publisher's website.

- The final author version and the galley proof are versions of the publication after peer review.

- The final published version features the final layout of the paper including the volume, issue and page numbers.

Link to publication

\footnotetext{
General rights rights.

- You may freely distribute the URL identifying the publication in the public portal. please follow below link for the End User Agreement:

www.umlib.nl/taverne-license

Take down policy

If you believe that this document breaches copyright please contact us at:

repository@maastrichtuniversity.nl

providing details and we will investigate your claim.
}

Copyright and moral rights for the publications made accessible in the public portal are retained by the authors and/or other copyright owners and it is a condition of accessing publications that users recognise and abide by the legal requirements associated with these

- Users may download and print one copy of any publication from the public portal for the purpose of private study or research.

- You may not further distribute the material or use it for any profit-making activity or commercial gain

If the publication is distributed under the terms of Article $25 \mathrm{fa}$ of the Dutch Copyright Act, indicated by the "Taverne" license above, 


\section{CLINICAL EVALUATION OF PULSED ELECTROMAGNETIC FIELD TREATMENT FOR ACUTE SCAPHOID FRACTURES}

Pascal F.W. Hannemann 
Copyright $(0) 2015$ by P.F.W. Hannemann. All rights reserved. ISBN/EAN 978-90-8590-060-3

Cover illustration: John Derwall

Thesis layout: www.dlgraphics.nl

Photography: Sandra Hubers

Printed by: Schrijen-Lippertz Media B.V.

The scientific work in this thesis was funded by the Netherlands Organisation for Health Research and Development (ZonMW).

Reproduction of this thesis was supported by the Dutch Trauma Society (Nederlandse Vereniging voor Traumachirurgie, NVT), Clinical Trial Center Maastricht (CTCM) and Pro-Motion Medical B.V. 


\section{CLINICAL EVALUATION OF PULSED ELECTROMAGNETIC FIELD TREATMENT FOR ACUTE SCAPHOID FRACTURES}

\section{PROEFSCHRIFT}

ter verkrijging van de graad van doctor aan de Universiteit Maastricht, op het gezag van de Rector Magnificus, Prof. dr. L.L.G. Soete, volgens het besluit van het College van Decanen, in het openbaar te verdedigen op vrijdag 22 mei 2015 om 12.00 uur

door

Pascal Franciscus Wilhelmus Hannemann Geboren op 13 september 1974 te Heerlen, Nederland 


\section{Promotor}

Prof. dr. P.R.G. Brink

\section{Copromotor}

Dr. M. Poeze

\section{Beoordelingscommissie}

Prof. dr. R.R.W.J. van der Hulst (voorzitter)

Prof. dr. R. Arora (Universitätsklinik für Unfallchirurgie Innsbruck, Österreich) Dr. G.A. Buijze (Academisch Medisch Centrum Amsterdam, Nederland) Prof. dr. L.W. van Rhijn 


\section{Contents}

$\begin{array}{lll}\text { Chapter } 1 \text { General introduction and outline of the thesis } & 8\end{array}$

Chapter 2 The clinical and radiological outcome of pulsed 24 electromagnetic field treatment for acute scaphoid fractures: a first report

Chapter 3 Determining scaphoid waist fracture union by conventional radiographic examination: an analysis of reliability and validity

Chapter 4 Multiplanar reconstruction computed tomography for diagnosis of scaphoid waist fracture union:

a prospective cohort analysis of accuracy and precision

Chapter 5 CT scan-evaluated outcome of pulsed electromagnetic 70 fields in the treatment of acute scaphoid fractures: a follow-up study

Chapter 6 Functional outcome and cost-effectiveness of 86 pulsed electromagnetic fields in the treatment of acute scaphoid fractures.

Chapter 7 The effects of low intensity pulsed ultrasound and 108 pulsed electromagnetic fields bone growth stimulation in acute fractures: a systematic review and meta-analysis of randomized controlled trials

Chapter 8 General discussion

Chapter 9 Summary

Chapter 10 Nederlandse samenvatting (Summary in Dutch)

Chapter 11 Valorization

Appendix Dankwoord 


Sind 51 $110.71=$ ine 12

(1) 111$)$

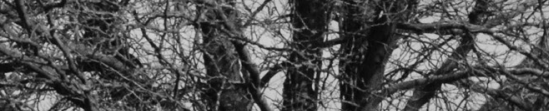

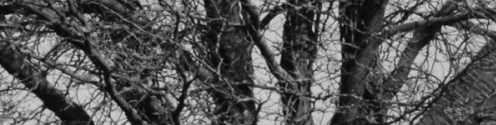

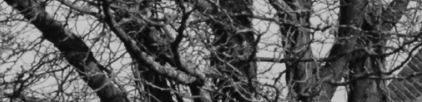

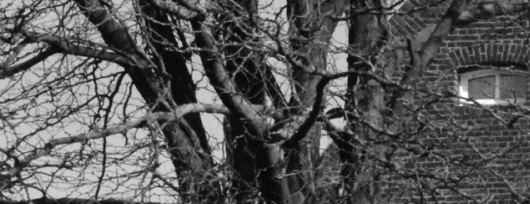

$\cos (x)=0.5$

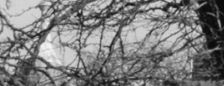

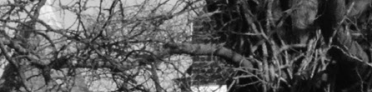
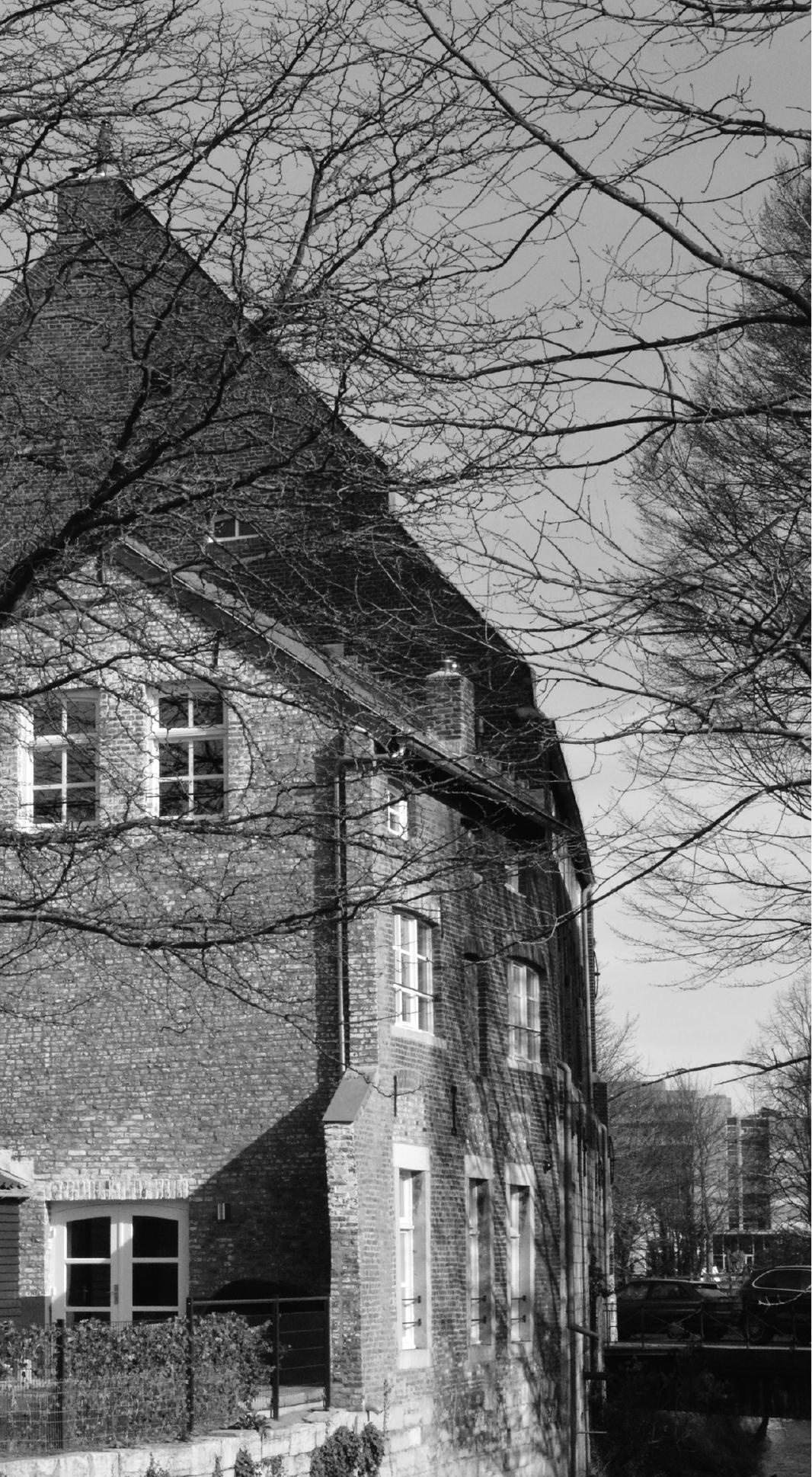

a che

$-1$

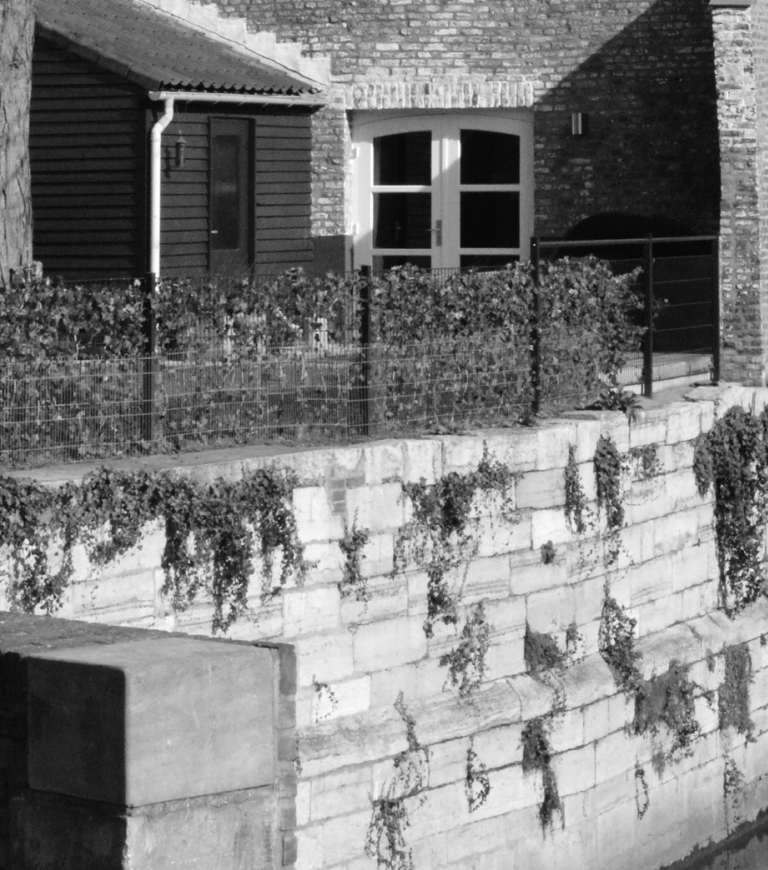

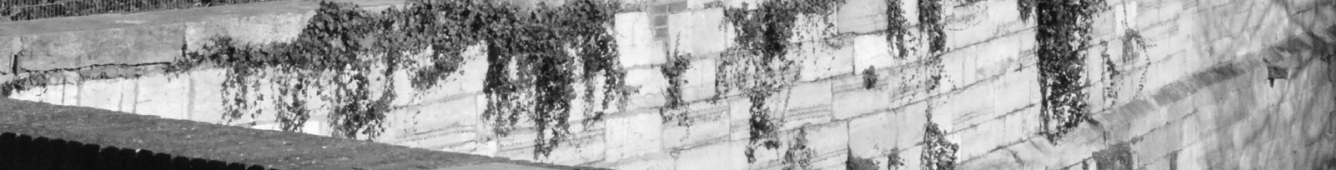

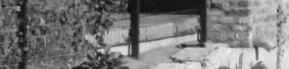

(4)

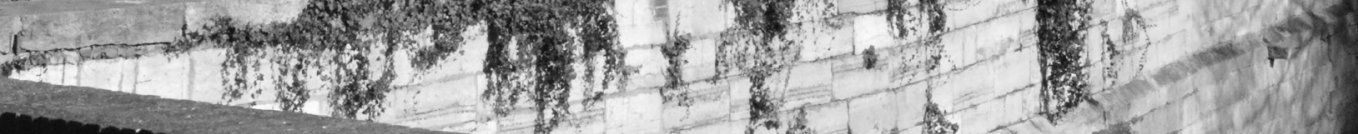




\section{Chapter 1}

\section{GENERAL INTRODUCTION AND OUTLINE OF THE THESIS}

Hannemann PFW

Göttgens KW

van Wely BJ

Kolkman KA

Werre AJ

Poeze M

Brink PRG

BMC Musculoskelet Disord. 2011 May 6;12:90 



\section{BACKGROUND}

Fractures of the scaphoid bone represent $2 \%$ to $6 \%$ of all fractures and typically occur in young, active patients aged 15 to $40 .{ }^{1}$ Of all carpal fractures in the Netherlands, $90 \%$ concern fractures of the scaphoid. ${ }^{2}$ A total of 21,000 scaphoid fractures are suspected and subsequently treated in the Netherlands each year. ${ }^{3,4}$ Evidence from the literature suggests that the incidence of radiographically proven scaphoid fractures lies between $15 \%$ and $20 \%$ of all suspected scaphoid fractures, ${ }^{5-7}$ i.e. 3150 to 4200 cases in the Netherlands per year. However, given that many patients do not seek medical attention or present years after the fracture occurred, the exact incidence of scaphoid fractures is unknown. ${ }^{8}$

\section{SCAPHOID FRACTURE HEALING}

The scaphoid bone articulates with 5 surrounding bones in the wrist and therefore plays an essential role in the functionality of the wrist, acting as a pivot. Due to this demanding functional requirement, failed treatment of scaphoid fractures can lead to serious pain and impairment. Frequently reported complications of failed scaphoid healing include nonunion of the fracture and subsequent early degenerative changes of the wrist. ${ }^{9,10}$

Many factors may contribute to the development of scaphoid nonunion, including clinical and biological factors. ${ }^{11}$ Clinical factors include failure to adequately diagnose the fracture, delay in treatment and inadequate immobilization. Biological factors include localization of the fracture, instability due to displacement of the fracture fragments, and co-occurrence of the scaphoid fracture with ligamentous injury of the carpus. Another important biological reason for problematic or failed healing of scaphoid fractures can be attributed to the specific blood supply to the scaphoid bone. The scaphoid has a retrograde blood supply; branches of the radial artery enter the scaphoid bone dorsally at the distal part, supplying the bone from distal to proximal. The proximal pole is thus entirely dependent on intra-osseous blood supply. Therefore, fractures of the mid or distal third of the scaphoid bone can disrupt blood supply to the proximal pole and subsequently cause avascular necrosis and nonunion. 


\section{Chapter 1}

\section{Challenges in SCAPhoid fracture treatment}

The primary goals of scaphoid fracture treatment, regardless of treatment mode, are to achieve consolidation and maximize functional outcome, while minimizing socioeconomic consequences. Scaphoid fractures can be treated either conservatively, with immobilization in a cast, or operatively. Given the high risk of nonunion, functional treatment of radiographically proven scaphoid fractures is not recommended.

There is evidence that early and accurate diagnosis and adequate conservative treatment of scaphoid waist fractures lead to high union rates and satisfactory wrist function. ${ }^{12}$ Following immobilization of undisplaced scaphoid fractures in a below-elbow cast, a substantial number of fractures unite within 8 weeks, with overall union rates for non-operatively treated scaphoid fractures of $88 \%$ to $95 \% .{ }^{13-15}$ Recent evidence shows that immobilization of the thumb is unnecessary for treatment of scaphoid fractures in a below-elbow cast. ${ }^{16}$ The main reasons for failure of conservative treatment are displacement of the scaphoid fracture, localization of the fracture in the proximal pole and delayed treatment. ${ }^{11,17,18}$ Untreated nonunion of the scaphoid has been shown to lead to osteoarthritis in $75 \%$ of all cases within 6 to 9 years and up to $100 \%$ of cases within 10 years, usually leading to severe impairment in wrist function and permanent disability. ${ }^{19}$ Therefore, treatment failure of scaphoid fractures may have severe consequences. In addition, impaired consolidation of scaphoid fractures results in longer immobilization. Since the patient population consists mainly of young, productive people, prolonged immobilization and therefore protracted return to normal function leads to more days of lost work, with severe socioeconomic consequences. A Dutch study showed that carpal fractures with normal healing result in a mean absence from work of 155 days (22 weeks). In the case of complicated healing conditions, such as nonunion of a scaphoid fracture, this figure rises to 296 days (42 weeks). ${ }^{2}$

Still, in some cases the current treatment strategies for scaphoid fractures remain unsatisfactory. Although union rates are satisfactory in most cases, the number of complications following conservative treatment in a cast can be high, with osteoarthritis in up to $32 \%$ and residual symptoms in $34 \%$ of patients despite fracture consolidation. ${ }^{10}$ Furthermore, compared to undisplaced waist fractures, displaced scaphoid waist fractures and proximal pole fractures have a significantly higher risk of nonunion when treated in a cast. ${ }^{17,18}$ This might indicate the need for operative treatment of scaphoid fractures in some cases. . $^{9,10,20}$ 
Operative treatment of undisplaced fractures of the scaphoid waist has been shown to lead to earlier return of function and to sport and full work compared to nonoperative treatment. ${ }^{21,22}$ However, a statistically significant difference in union rates between surgery and conservative treatment of acute minimally displaced and undisplaced scaphoid waist fractures has not been reported in the literature to date. ${ }^{23}$ In addition, surgery of scaphoid waist fractures is associated with a significantly higher risk of complications. ${ }^{23,24} \mathrm{~A}$ recent meta-analysis on surgical versus conservative treatment of minimally displaced and undisplaced scaphoid waist fractures revealed a significantly increased risk of complications of surgical treatment, with a pooled odds ratio of 7.69 (95\% confidence interval: 2.16-27.4, $\left.p=0.02, I^{2}=0 \%\right) .{ }^{23}$ Therefore, controversy still surrounds the best treatment for minimally displaced and undisplaced scaphoid waist fractures, and other adjunct treatment options should be investigated.

Adjunct interventions such as electrophysical bone growth stimulation are frequently used to facilitate and accelerate fracture repair and healing of long-bone fractures..$^{25} \mathrm{~A} 2008$ survey of 450 Canadian trauma surgeons revealed that $45 \%$ of surgeons incorporated bone growth stimulators into their treatment regimes for long-bone fractures. ${ }^{26}$ Despite the severe socioeconomic impact of scaphoid fractures in the young population at risk for this fracture, the efficacy of electrophysical bone growth stimulation in fresh scaphoid fractures remains to be investigated. ${ }^{2}$

\section{THE PRINCIPLES OF ELECTROPHYSICAL BONE GROWTH STIMULATION}

Reports on clinical experiments concerning the effects of electricity on the healing of fractures date back to the $19^{\text {th }}$ century. In 1816, French surgeon Alexis Boyer reported on the effect of electricity on the healing of a tibial fracture. ${ }^{27}$ In 1892, German surgeon Julius Wolff (Figure 1) provided an early scientific basis for the hypothesis that the structure of bone adapts to changes in its environment. His description of the restructuring of bone trabeculae, followed by cortical changes in response to an external stimulus, is known as Wolff's law. ${ }^{28}$ However, it was not until the $20^{\text {th }}$ century that the study of electricity and bone regeneration began to receive considerably more attention. In their 1964 study, Bassett, Pawluk and Becker reported on significantly increased endosteal bone formation around the cathode of insulated battery implants whose electrodes were implanted in the femurs of 12 dogs. ${ }^{29}$ In 1968 Anderson and Eriksson reported on the electrical properties of collagen, followed in 1970 by their publication on the piezoelectric properties of bone, which provided a scientific foundation for Wolff's law. ${ }^{30,31}$ Since 


\section{Chapter 1}

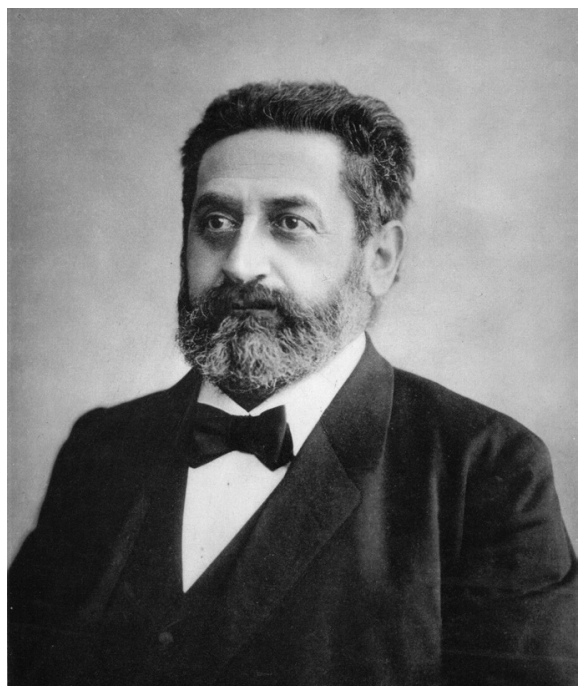

Figure 1. German surgeon Julius Wolff,

pictured in 1868.

(C) Universitätsbibliothek der Humboldt-Universität, Berlin.

then, many forms of electrophysical bone growth stimulation have been studied to test its capacity to induce bone healing in nonunions and later on in fresh fractures.

Modern bone growth stimulators can roughly be divided into two groups: ultrasound stimulators and electromagnetic stimulators.

Ultrasound stimulators produce a low-intensity pulsed ultrasound (LIPUS) signal that increases the levels of prostaglandin E-2 at the fracture site and stimulates mineralization. ${ }^{32}$ This results in enhanced endochondreal ossification and the conversion of fibrous callus into mineralized callus.

Electromagnetic stimulators, in turn, can be divided into inductive or capacitive coupling devices. ${ }^{33}$ Inductive coupling, also known as pulsed electromagnetic fields (PEMF), was introduced in the 1970s and its efficacy has since been investigated in numerous studies. ${ }^{34}$ A PEMF bone growth stimulator delivers a lowlevel electromagnetic signal through a coil placed over, in or under a plaster cast at the site of the fracture. When it reaches the fracture site, the low-level electromagnetic signal is converted into electric currents in the bone. ${ }^{35}$ PEMF exposure of human bone marrow-derived stromal cells has been shown to induce differentiation and enhance the mineralization of bone, which supports the theory that PEMF induces an osteogenic response in vivo and may therefore stimulate fracture healing. ${ }^{36}$ 


\section{Rationale for the use of PEMF bone growth stimulation IN ACUTE SCAPHOID FRACTURES}

To date, the debate on diagnostic and therapeutic strategies for (undisplaced) scaphoid fractures has been subject to controversy. The aim of this thesis is to investigate a noninvasive method of bone growth stimulation that has been used to induce or accelerate fracture repair since $1974 .{ }^{37}$ Although the first clinical report on pulsed electromagnetic fields (PEMF) - the technique used in this thesis - was published in 1977, the efficacy of this technique in fresh scaphoid fractures has never been thoroughly investigated. ${ }^{38}$

The first double-blind study of PEMF in bone healing concluded that the technique significantly improved healing in long-bone fractures with delayed union, although baseline imbalance may limit the impact of this trial. ${ }^{39}$ In 1992, Gossling, Bernstein and Abbott reviewed 44 articles assessing the effectiveness of PEMF versus surgical therapy for tibial nonunions. ${ }^{40}$ They found that PEMF was more successful than previous noninvasive treatment, and at least equally effective as surgery. Considering the costs and potential dangers of surgery in these cases, they concluded that PEMF should be regarded as an effective alternative for the treatment of tibial nonunion. ${ }^{40}$

With regard to scaphoid fractures specifically, Bora, Osterman and Brighton reported a $71 \%$ healing rate in previously conservatively treated scaphoid nonunions after 12 weeks of electrical stimulation using a semi-invasive technique. ${ }^{41}$ In a 1992 follow-up study, Adams, Frykman and Taleisnik reported on the treatment of 54 scaphoid nonunions treated with PEMF, with an overall successful union rate of $69 \% .^{42}$ They concluded that PEMF treatment should be considered an alternative to bone-grafting procedures in scaphoid nonunion. ${ }^{42}$

The literature on PEMF for ununited fractures is characterized by a lack of highquality level I data and high prevalence of level IV studies. In 2011 a meta-analysis on electromagnetic field stimulation for the treatment of delayed union or nonunion in long bone fractures in adults was conducted, including four randomized controlled trials involving 125 participants. ${ }^{43}$ According to the authors, the pooled available evidence suggested that the effect of electromagnetic field stimulation was small and not statistically significant. The limited number of studies included and heterogeneity in study design and outcome measures contributed to this conclusion. 


\section{Chapter 1}

Interest in using electrophysical forces to accelerate bone healing in fresh fractures dates back to the 1950s, when the effect of high-intensity ultrasound on callus formation in animals was studied. ${ }^{44}$ Unfortunately, this study did not show accelerated bone healing, but instead demonstrated the damaging effect of ultrasound on bone. After it became clear that the intensity of the ultrasound signal had to be decreased to stimulate bone growth and fracture healing, several trials revealed accelerated healing in fresh fractures. ${ }^{45,46}$ This gave rise to the assumption that low-intensity pulsed ultrasound is a useful method to accelerate fracture healing. ${ }^{45,46}$ Since the 1990s, several trials have been conducted to test whether electrophysical forces can also be applied to accelerate healing in fresh fractures. In their 1994 randomized controlled trial, Heckman et al. reported on the treatment of 96 patients with 97 closed or grade I open, conservatively treated diaphyseal tibia fractures with either LIPUS bone growth stimulation or a placebo. ${ }^{47}$ The intervention group showed a significantly faster overall healing time compared to the placebo group. Similarly, Kristiansen et al. randomly allocated 83 patients with 85 conservatively treated fresh extra-articular distal radius fractures to either LIPUS treatment or placebo. ${ }^{48}$ They reported a significantly faster time to union and decreased loss of reduction in the patients treated with LIPUS compared to the placebo group.

Only one randomized controlled trial on the treatment of fresh scaphoid fractures with electrophysical bone growth stimulation has been published. ${ }^{49}$ In their 2000 study, Mayr et al. randomly allocated 28 patients with 30 acute undisplaced fractures of the scaphoid to either LIPUS treatment or placebo. ${ }^{49}$ The authors reported significantly faster scaphoid fracture healing in the ultrasound group, and after six weeks of treatment confirmed $81 \%$ healing in the group treated with LIPUS versus $55 \%$ in the control group.

Only two randomized clinical trials have reported on the effects of PEMF in acute fractures. ${ }^{50,51}$ Faldini et al. reported on 77 patients with a femoral neck fracture who underwent osteosynthesis with screws. ${ }^{51}$ Patients were randomly allocated to active PEMF treatment or placebo treatment. Fracture healing was achieved in $94 \%$ of the compliant patients receiving PEMF treatment compared to $69 \%$ in the placebo group, a statistically significant difference. The authors concluded that PEMF stimulation accelerates fracture repair in patients with femoral neck fractures. ${ }^{51}$ Adie et al., however, reported no improvement in radiographic union or functional outcomes after adjuvant PEMF stimulation in patients with acute tibial shaft fractures. ${ }^{50}$ 
In summary, electromagnetic field stimulation has been used widely to accelerate fracture repair and has been shown to reduce osteoclast resorption, increase the rate of osteoid formation and enhance bone mineralization in vivo. However, evidence from randomized trials on its efficacy in treating fresh fractures is very limited. ${ }^{25,52}$ Given this lack of evidence, PEMF is currently not recommended for use in fresh fractures.

\section{OUtLINE OF THIS THESIS}

As outlined above, debate on the therapeutic management of minimally displaced and undisplaced scaphoid waist fractures is ongoing. Missed diagnosis, delayed or incorrect treatment and complicated healing of scaphoid fractures may have severe personal, economic and social consequences in the mainly young, working population affected. ${ }^{2}$ Although the potential efficacy of PEMF bone growth stimulation is supported by numerous clinical and basic research studies, level I or II evidence to support the addition of PEMF to the conservative treatment of acute scaphoid fractures to accelerate bone healing is lacking.

We hypothesized that the use of PEMF bone growth stimulation would significantly improve healing in acute scaphoid fractures. The following research objectives were formulated:

1. To determine whether the use of bone-growth stimulation by means of PEMF in acute scaphoid fractures accelerates fracture healing both clinically and radiologically.

2. To determine whether the use of PEMF in acute scaphoid fractures decreases the incidence of nonunions and avascular necrosis of the scaphoid and, therefore, the number of secondary surgical interventions.

3. To investigate the effect of PEMF on functional outcome in acute scaphoid fractures.

4. To investigate the cost-effectiveness of PEMF from a societal perspective compared to care as usual.

These four research objectives are addressed in different chapters of this thesis. In chapter 2, we describe a randomized, double-blind, placebo-controlled, multicentre trial designed to test the hypothesis that the use of PEMF in acute scaphoid fractures significantly accelerates time to union. Radiological follow-up was performed by assessment of normal scaphoid radiographs. 


\section{Chapter 1}

An important question remains whether conventional radiographic imaging of the scaphoid can accurately and reliably diagnose scaphoid waist fracture union. For this reason, chapter 3 assesses the reliability and validity of conventional radiographic imaging in determining scaphoid waist fracture union.

Although computed tomography is not an integral part of common practice to evaluate the healing process of scaphoid waist fractures, there is evidence that it is superior to conventional techniques for determining union in scaphoid fractures. Therefore, chapter 4 examines the reliability and validity of multiplanar reconstruction computed tomography in determining scaphoid waist fracture union.

The results of the trial described in chapter 2 and the study described in chapter 4 warranted a larger and improved randomized trial on the effect of PEMF bone growth stimulation in the treatment of scaphoid fractures. Therefore, in chapter 5 we describe the CT scan-evaluated outcome of PEMF treatment of acute scaphoid fractures in a randomized, multicentre, double-blind, placebo-controlled trial. Subsequently, chapter $\mathbf{6}$ analyses the functional outcomes and cost-effectiveness of PEMF.

To put the results of our research in perspective, chapter 7 reports on a systematic review and meta-analysis of randomized controlled trials on the effects of the two most common forms of electrophysical bone growth stimulation (LIPUS and PEMF) on fresh fractures.

Finally, chapter 8 provides a general discussion of the results of the studies described in this thesis, along with recommendations for future research and prospects for the use of bone growth stimulation in scaphoid fractures. A summary of the thesis is presented in chapter $\mathbf{9}$. 


\section{RefERENCES}

1. Tiel-van Buul MM, van Beek EJ, Broekhuizen AH, Bakker AJ, Bos KE, van Royen EA. Radiography and scintigraphy of suspected scaphoid fracture. A long-term study in 160 patients. The Journal of bone and joint surgery British volume 1993;75:61-5.

2. van der Molen AB, Groothoff JW, Visser GJ, Robinson PH, Eisma WH. Time off work due to scaphoid fractures and other carpal injuries in The Netherlands in the period 1990 to 1993. J Hand Surg Br 1999;24:193-8.

3. Beeres FJ, Rhemrev SJ, Hogervorst M, den Hollander P, Jukema GN. [Scaphoid fractures: diagnosis and therapy]. Ned Tijdschr Geneeskd 2007;151:742-7.

4. Tiel-van Buul MM, Roolker W, Broekhuizen AH, Van Beek EJ. The diagnostic management of suspected scaphoid fracture. Injury 1997;28:1-8.

5. Jenkins PJ, Slade K, Huntley JS, Robinson CM. A comparative analysis of the accuracy, diagnostic uncertainty and cost of imaging modalities in suspected scaphoid fractures. Injury 2008;39:768-74.

6. Murphy D, Eisenhauer M. The utility of a bone scan in the diagnosis of clinical scaphoid fracture. J Emerg Med 1994;12:709-12.

7. Nguyen Q, Chaudhry S, Sloan R, Bhoora I, Willard C. The clinical scaphoid fracture: early computed tomography as a practical approach. Ann R Coll Surg Engl 2008;90: 488-91.

8. Kozin SH. Incidence, mechanism, and natural history of scaphoid fractures. Hand clinics 2001;17:515-24.

9. Rajagopalan BM, Squire DS, Samuels LO. Results of Herbert-screw fixation with bonegrafting for the treatment of nonunion of the scaphoid. The Journal of bone and joint surgery American volume 1999;81:48-52.

10. Raudasoja L, Rawlins M, Kallio P, Vasenius J. Conservative treatment of scaphoid fractures: a follow up study. Ann Chir Gynaecol 1999;88:289-93.

11. Wong K, von Schroeder HP. Delays and poor management of scaphoid fractures: factors contributing to nonunion. The Journal of hand surgery 2011;36:1471-4.

12. Geoghegan JM, Woodruff MJ, Bhatia $R$, et al. Undisplaced scaphoid waist fractures: is 4 weeks' immobilisation in a below-elbow cast sufficient if a week 4 CT scan suggests fracture union? The Journal of hand surgery, European volume 2009;34:631-7.

13. Rhemrev SJ, van Leerdam RH, Ootes D, Beeres FJ, Meylaerts SA. Non-operative treatment of non-displaced scaphoid fractures may be preferred. Injury 2009;40:638-41.

14. Desai VV, Davis TR, Barton NJ. The prognostic value and reproducibility of the radiological features of the fractured scaphoid. J Hand Surg Br 1999;24:586-90.

15. Dias JJ, Brenkel IJ, Finlay DB. Patterns of union in fractures of the waist of the scaphoid. The Journal of bone and joint surgery British volume 1989;71:307-10.

16. Buijze GA, Goslings JC, Rhemrev SJ, et al. Cast immobilization with and without immobilization of the thumb for nondisplaced and minimally displaced scaphoid waist 


\section{Chapter 1}

fractures: a multicenter, randomized, controlled trial. The Journal of hand surgery 2014; 39:621-7.

17. Singh HP, Taub N, Dias JJ. Management of displaced fractures of the waist of the scaphoid: meta-analyses of comparative studies. Injury 2012;43:933-9.

18. Eastley N, Singh H, Dias JJ, Taub N. Union rates after proximal scaphoid fractures; meta-analyses and review of available evidence. The Journal of hand surgery, European volume 2013;38:888-97.

19. Inoue G, Sakuma M. The natural history of scaphoid non-union. Radiographical and clinical analysis in 102 cases. Archives of orthopaedic and trauma surgery 1996;115:1-4.

20. Divelbiss BJ, Adams BD. Electrical and ultrasound stimulation for scaphoid fractures. Hand clinics 2001;17:697-701, x-xi.

21. McQueen MM, Gelbke MK, Wakefield A, Will EM, Gaebler C. Percutaneous screw fixation versus conservative treatment for fractures of the waist of the scaphoid: a prospective randomised study. The Journal of bone and joint surgery British volume 2008;90: 66-71.

22. Bond CD, Shin AY, McBride MT, Dao KD. Percutaneous screw fixation or cast immobilization for nondisplaced scaphoid fractures. The Journal of bone and joint surgery American volume 2001;83-A:483-8.

23. Ibrahim T, Qureshi A, Sutton AJ, Dias JJ. Surgical versus nonsurgical treatment of acute minimally displaced and undisplaced scaphoid waist fractures: pairwise and network meta-analyses of randomized controlled trials. The Journal of hand surgery 2011;36: 1759-68 e1.

24. Buijze GA, Doornberg JN, Ham JS, Ring D, Bhandari M, Poolman RW. Surgical compared with conservative treatment for acute nondisplaced or minimally displaced scaphoid fractures: a systematic review and meta-analysis of randomized controlled trials. The Journal of bone and joint surgery American volume 2010;92:1534-44.

25. Mollon B, da Silva V, Busse JW, Einhorn TA, Bhandari M. Electrical stimulation for longbone fracture-healing: a meta-analysis of randomized controlled trials. The Journal of bone and joint surgery American volume 2008;90:2322-30.

26. Busse JW, Morton E, Lacchetti C, Guyatt GH, Bhandari M. Current management of tibial shaft fractures: a survey of 450 Canadian orthopedic trauma surgeons. Acta orthopaedica 2008;79:689-94.

27. Boyer. A treatise on surgical diseases, and the operations suited to them. T and J Swords, New York 1816.

28. Frost HM. Wolff's Law and bone's structural adaptations to mechanical usage: an overview for clinicians. The Angle orthodontist 1994;64:175-88.

29. Bassett CA, Pawluk RJ, Becker RO. Effects of Electric Currents on Bone in Vivo. Nature 1964;204:652-4.

30. Anderson JC, Eriksson C. Electrical properties of wet collagen. Nature 1968;218:166-8. 
31. Anderson JC, Eriksson C. Piezoelectric properties of dry and wet bone. Nature 1970; 227:491-2.

32. Unsworth J, Kaneez S, Harris S, et al. Pulsed low intensity ultrasound enhances mineralisation in preosteoblast cells. Ultrasound in medicine \& biology 2007;33:1468-74.

33. Aaron RK, Ciombor DM, Simon BJ. Treatment of nonunions with electric and electromagnetic fields. Clin Orthop Relat Res 2004:21-9.

34. Ryaby JT. Clinical effects of electromagnetic and electric fields on fracture healing. Clinical orthopaedics and related research 1998:S205-15.

35. Aaron RK, Steinberg ME. Electrical stimulation of osteonecrosis of the femoral head. Seminars in arthroplasty 1991;2:214-21.

36. Jansen $\mathrm{JH}$, van der Jagt OP, Punt BJ, et al. Stimulation of osteogenic differentiation in human osteoprogenitor cells by pulsed electromagnetic fields: an in vitro study. BMC musculoskeletal disorders 2010;11:188.

37. Bassett CA, Pawluk RJ, Pilla AA. Acceleration of fracture repair by electromagnetic fields. A surgically noninvasive method. Annals of the New York Academy of Sciences 1974;238:242-62.

38. Bassett CA, Pilla AA, Pawluk RJ. A non-operative salvage of surgically-resistant pseudarthroses and non-unions by pulsing electromagnetic fields. A preliminary report. Clinical orthopaedics and related research 1977:128-43.

39. Sharrard WJ. A double-blind trial of pulsed electromagnetic fields for delayed union of tibial fractures. The Journal of bone and joint surgery British volume 1990;72:347-55.

40. Gossling HR, Bernstein RA, Abbott J. Treatment of ununited tibial fractures: a comparison of surgery and pulsed electromagnetic fields (PEMF). Orthopedics 1992;15:711-9.

41. Bora FW, Jr., Osterman AL, Brighton CT. The electrical treatment of scaphoid nonunion. Clin Orthop Relat Res 1981:33-8.

42. Adams BD, Frykman GK, Taleisnik J. Treatment of scaphoid nonunion with casting and pulsed electromagnetic fields: a study continuation. The Journal of hand surgery 1992; 17:910-4.

43. Griffin XL, Costa ML, Parsons N, Smith N. Electromagnetic field stimulation for treating delayed union or non-union of long bone fractures in adults. The Cochrane database of systematic reviews 2011:CD008471.

44. Ardan NI, Jr., Janes JM, Herrick JF. Changes in bone after exposure to ultrasonic energy. Minnesota medicine 1954;37:415-20.

45. Borsalino G, Bagnacani M, Bettati E, et al. Electrical stimulation of human femoral intertrochanteric osteotomies. Double-blind study. Clinical orthopaedics and related research 1988:256-63.

46. Azuma $\mathrm{Y}$, Ito $\mathrm{M}$, Harada $\mathrm{Y}$, Takagi $\mathrm{H}$, Ohta T, Jingushi S. Low-intensity pulsed ultrasound accelerates rat femoral fracture healing by acting on the various cellular reactions in the fracture callus. Journal of bone and mineral research: the official journal of the American Society for Bone and Mineral Research 2001;16:671-80. 


\section{Chapter 1}

47. Heckman JD, Ryaby JP, McCabe J, Frey JJ, Kilcoyne RF. Acceleration of tibial fracturehealing by non-invasive, low-intensity pulsed ultrasound. The Journal of bone and joint surgery American volume 1994;76:26-34.

48. Kristiansen TK, Ryaby JP, McCabe J, Frey JJ, Roe LR. Accelerated healing of distal radial fractures with the use of specific, low-intensity ultrasound. A multicenter, prospective, randomized, double-blind, placebo-controlled study. The Journal of bone and joint surgery American volume 1997;79:961-73.

49. Mayr E, Rudzki MM, Rudzki M, Borchardt B, Hausser H, Ruter A. [Does low intensity, pulsed ultrasound speed healing of scaphoid fractures?]. Handchir Mikrochir Plast Chir 2000;32:115-22.

50. Adie S, Harris IA, Naylor JM, et al. Pulsed electromagnetic field stimulation for acute tibial shaft fractures: a multicenter, double-blind, randomized trial. The Journal of bone and joint surgery American volume 2011;93:1569-76.

51. Faldini C, Cadossi M, Deianira L, Betti E, Chiarello E, Giannini S. Electromagnetic bone growth stimulation in patients with femoral neck fractures treated with screws: prospective randomized double-blind study. Current Orthopaedic Practice 2010;21:282-87.

52. Otter MW, McLeod KJ, Rubin CT. Effects of electromagnetic fields in experimental fracture repair. Clin Orthop Relat Res 1998:S90-104. 
General introduction 


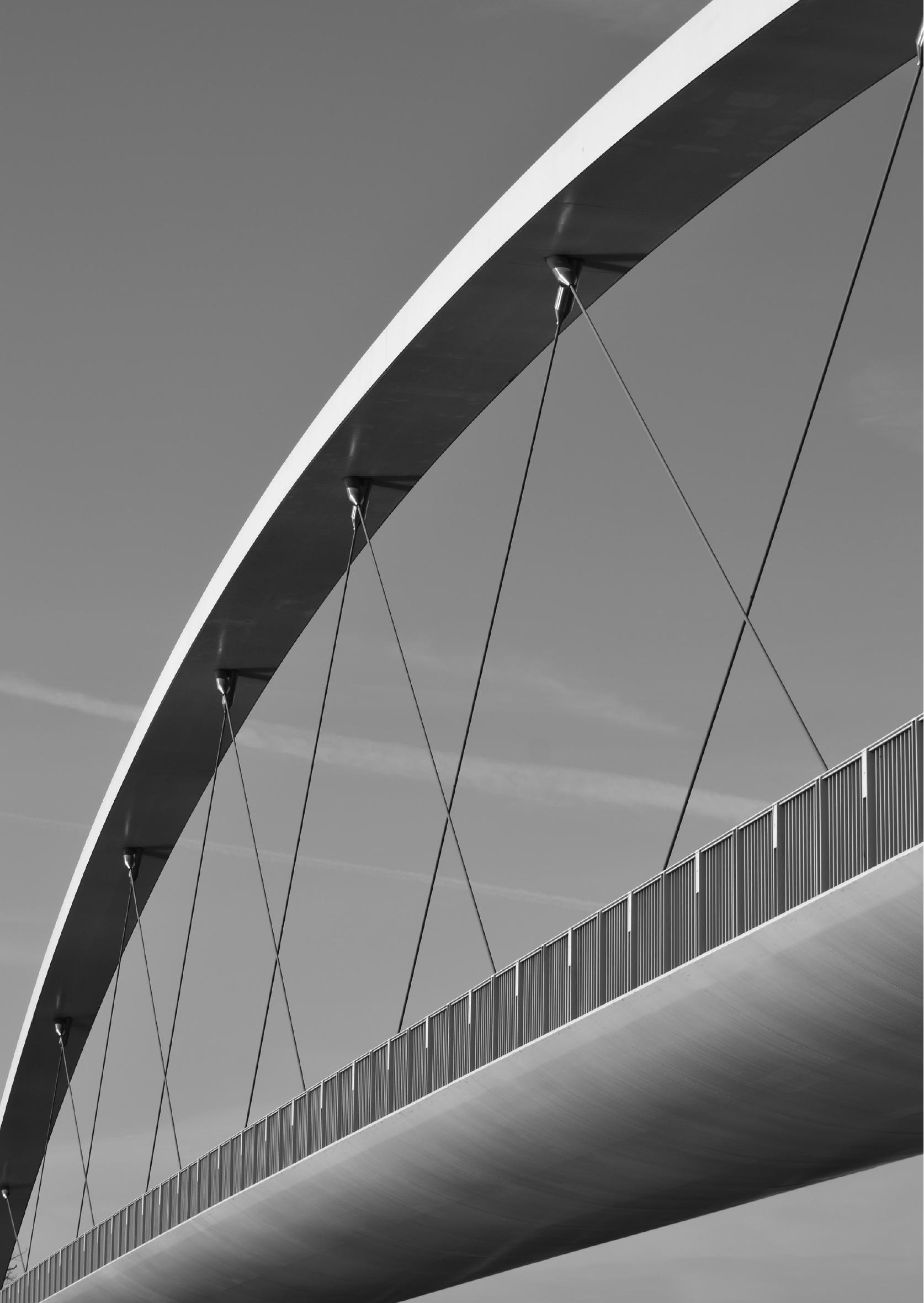




\section{Chapter 2}

THE CLINICAL AND RADIOLOGICAL OUTCOME OF PULSED ELECTROMAGNETIC FIELD TREATMENT FOR ACUTE SCAPHOID FRACTURES:

A FIRST REPORT

Hannemann PFW

Göttgens KWA

van Wely BJ

Kolkman KA

Werre AJ

Poeze M

Brink PRG

J Bone Joint Surg Br. 2012 Oct;94(10):1403-8 


\section{Chapter 2}

\section{Abstract}

The use of pulsed electromagnetic fields (PEMF) to stimulate bone growth has been recommended as an alternative to the surgical treatment of ununited scaphoid fractures, but has never been examined in acute fractures. We hypothesized that the use of PEMF in acute scaphoid fractures would accelerate the time to union by $30 \%$ in a randomized, double-blind, placebo-controlled, multicenter trial. A total of 53 patients in three different medical centers with a unilateral undisplaced acute scaphoid fracture were randomly assigned to receive either treatment with PEMF $(n=24)$ or a placebo $(n=29)$. The clinical and radiological outcomes were assessed at four, six, nine, 12, 24 and 52 weeks.

A log-rank analysis showed that neither time to clinical and radiological union nor the functional outcome differed significantly between the groups. The clinical assessment of union indicated that at six weeks tenderness in the anatomic snuffbox $(p=0.03)$ as well as tenderness on longitudinal compression of the scaphoid ( $p=0.008$ ) differed significantly in favor of the placebo group.

We conclude that stimulation of bone growth by PEMF has no additional value in the conservative treatment of acute scaphoid fractures. 


\section{Clinical and radiological outcome of PEMF}

\section{INTRODUCTION}

Fractures of the scaphoid, which is the most commonly fractured carpal bone, represent $2 \%$ to $6 \%$ of all fractures and typically occur in young, active patients between 15 to 40 years of age. ${ }^{1}$ In The Netherlands, $90 \%$ of all fractures of the carpus involve the scaphoid. ${ }^{2}$ The exact incidence is unknown because this injury often remains undiagnosed, but 21000 scaphoid fractures are suspected to occur in The Netherlands each year, ${ }^{3,4}$ of which a potential $15 \%$ to $20 \%$ represent actual fractures. ${ }^{5}$

The scaphoid has an essential function in the wrist, acting as a pivot articulating with five surrounding bones. Failed treatment of scaphoid fractures can result in avascular necrosis in up to $40 \%$, nonunion in up to $21 \%$ and early osteoarthritis in up to $32 \%,{ }^{1,6-8}$ Treatment of unstable fractures is associated with further complications. ${ }^{9}$

In addition, delayed union of scaphoid fractures leads to longer immobilization and greater loss of function which, in the mainly young working population affected, leads to more days of lost work with significant economic and social consequences. ${ }^{2}$ It has been shown that even uncomplicated healing leads to a mean interruption of employment of 21 weeks. In those whose healing is complicated, for instance, by nonunion, the mean disability period increases to 42 weeks. $^{2}$

Current treatment strategies remain unsatisfactory. The number of complications following conservative treatment in a cast is high, and surgery is usually only performed if complications arise. ${ }^{6-8}$ The outcome following conservative treatment is variable. ${ }^{10}$ There is evidence that surgical treatment of Herbert types B1 and $\mathrm{B} 2{ }^{11}$ scaphoid fractures leads to earlier return to normal function, work and sport than non-operative treatment. ${ }^{12}$ However, there is no evidence that surgical treatment of undisplaced scaphoid fractures leads to a lower rate of nonunion, ${ }^{12,13}$ and the complications of surgery may be more common than is generally reported, especially when fixation is performed percutaneously. ${ }^{13}$

Electromagnetic field stimulation has been widely used to accelerate fracture repair ${ }^{14}$ : it reduces osteoclast resorption, induces osteoid formation and stimulates angiogenesis. ${ }^{15}$ In particular, the use of pulsed electromagnetic fields (PEMF) aids healing of fractures of the tibia and may offer an effective alternative to surgery in the treatment of nonunions in general. ${ }^{16,17}$ 


\section{Chapter 2}

Since the 1990s, evidence has emerged that physical forces can also enhance the healing of fresh fractures. ${ }^{18,19}$ Although there is some experience concerning the treatment of scaphoid nonunion, there is no evidence from randomized trials to evaluate the use of PEMF stimulation in the treatment of acute fractures of the scaphoid. 5,20,21 However, treatment of acute scaphoid fractures by low-intensity pulsed ultrasound (LIPUS) may accelerate healing by up to $30 \% .{ }^{22}$

We hypothesized that PEMF would reduce the time to union of acute scaphoid fractures by up to $30 \%$.

\section{Patients and Methods}

This was a double-blind, randomized, placebo-controlled, multicenter study involving three centers in the Netherlands (Figure 1). Approval was obtained from each local ethics committee and written informed consent for participation was obtained from all patients.

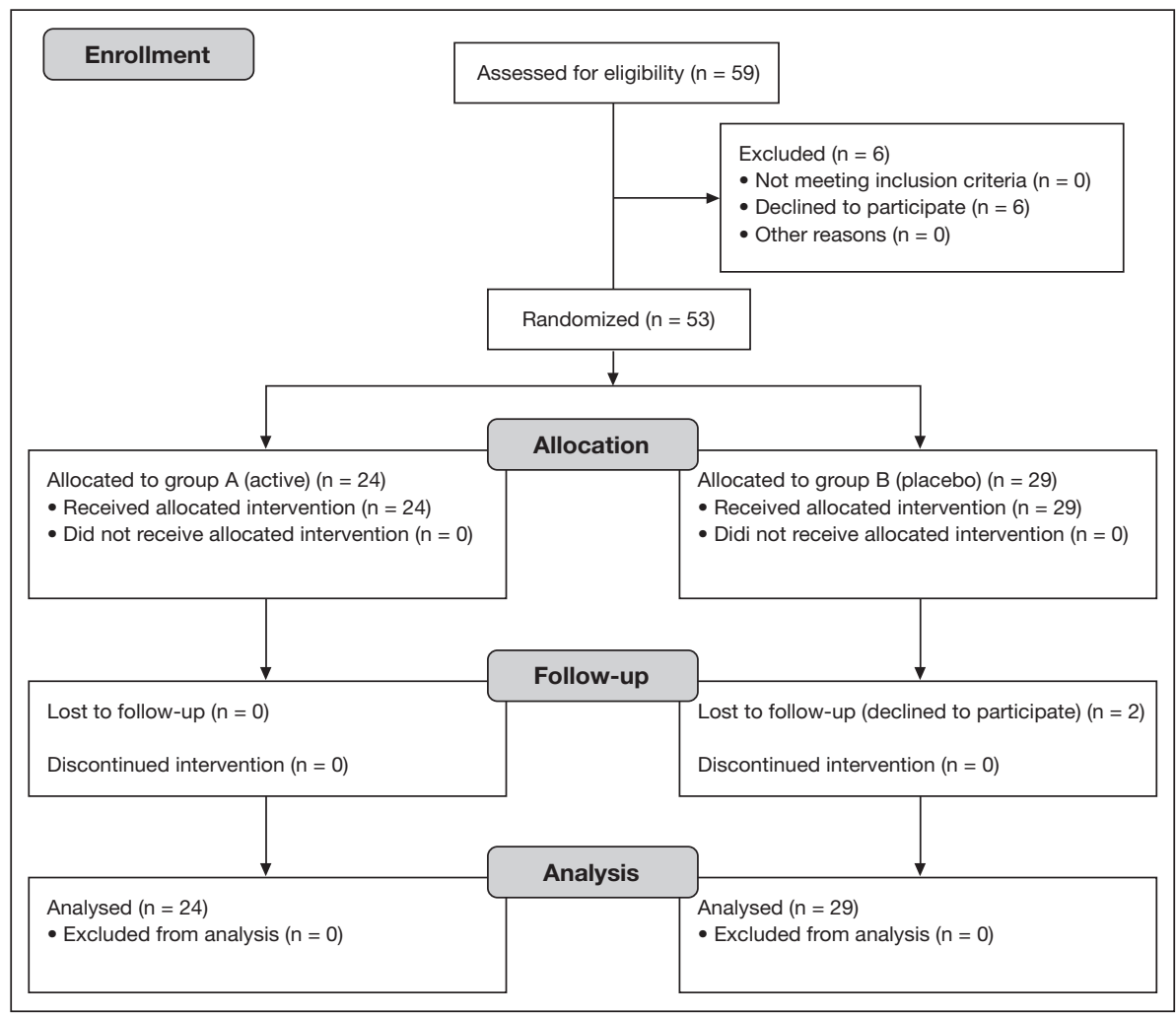

Figure 1. CONSORT flow diagram. 
All adults $\geq 18$ years of age presenting between 1 June 2006 and 31 August 2009 with a unilateral fracture of the scaphoid, type A1, A2, B1, B2 and B3 according to the Herbert classification, ${ }^{11}$ were included. Type B4 and B5 fractures (fracture dislocations of the carpus and comminuted fractures) were excluded. B2 fractures were classified as displaced or mobile fractures of the waist of the scaphoid.

Exclusion criteria were presentation $>$ five days after injury, pregnancy, presence of a life-supporting implanted electronic device, additional fractures of the wrist, carpal or metacarpal bones, and a pre-existing impairment of wrist function.

The diagnosis of a scaphoid fracture was made by a combination of clinical and radiological examination. The radiographs consisted of four views: posterioranterior view, posterior-anterior view in full ulnar deviation, lateral view and oblique, semi-pronated view. If no apparent fracture was seen on the initial radiographs, a bone scan was performed.

All fractures were treated with immobilization in a forearm cast with the first metacarpal and both phalanges immobilized. Electromagnetic stimulation was administered continuously for 24 hours a day using a PEMF (Ossatec ${ }^{\circledR}$, Uden, The Netherlands) bone growth stimulator, which consists of a flexible coil incorporated into the plaster at the site of the fracture. The coil is attached to a batterypowered signal processor placed on the cast. (Figures 2 and 3 ) It has been shown that attenuation of PEMF signal through dense materials is limited, making it suitable for many clinical applications, including the placement of coils over plaster casts. ${ }^{23}$ Table 1 shows the signal characteristics of the device used.

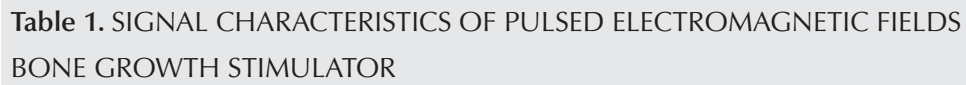

\section{Characteristic}

Pulse amplitude

Pulse width

$50 \mathrm{mV}$

Burst width

$5 \mu \mathrm{s}$

Burst refractory period

$5 \mathrm{~ms}$

Repeat repetition rate

$62 \mathrm{~ms}$

$15 \mathrm{~Hz}$

Half of the devices were disabled at random in the factory and gave outward signs of normal function, but did not generate a signal. Neither the investigators nor the patients were aware of the device's functionality. 


\section{Chapter 2}

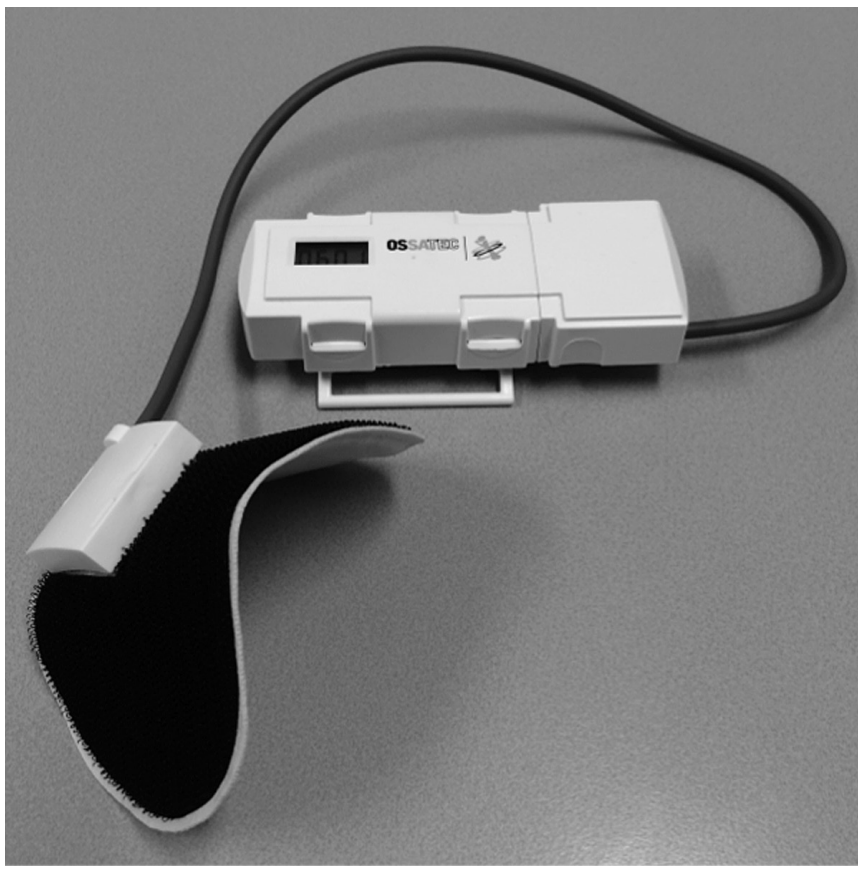

Figure 2. The PEMF

bone growth stimulator consisting of a batterypowered signal processor and a flexible flat coil.

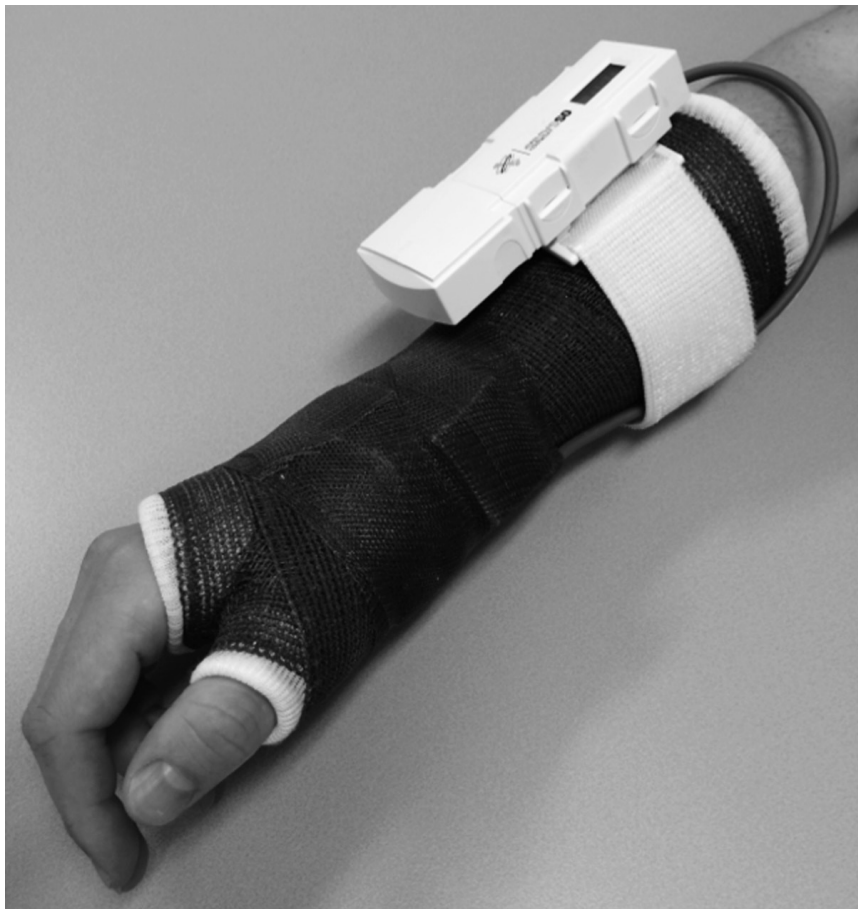

Figure 3. The PEMF bone growth stimulator with the signal processor placed on the cast and the coil incorporated into the plaster. 


\section{Clinical and radiological outcome of PEMF}

The patients were reviewed at four, six, nine, 12, 24 and 52 weeks after diagnosis of the fracture. At these times, the cast was removed and clinical and radiological examination was performed. In patients with complete clinical and radiological union the PEMF device was removed at six or 12 weeks after the start of treatment, depending on the time of union.

Clinical examination included testing for tenderness in the anatomical snuff box (ASB) and with longitudinal compression of the scaphoid (LC), both being criteria for determining clinical union. The range of active dorsiflexion, palmar flexion, radial and ulnar deviation was determined using a handheld goniometer. The sum was expressed as a percentage of that of the opposite, unaffected wrist. ${ }^{24}$ A loss of movement by $>25 \%$ is considered to be significant when determining functional outcome..$^{25}$ Grip strength was measured using a JAMAR dynamometer (Sammons Preston Rolyan, Bolingbrook, Illinois, USA) and expressed as a percentage of the value on the unaffected side. ${ }^{26} \mathrm{~A}$ reduction in strength by $>10 \%$ in the injured dominant hand or $>20 \%$ in the injured non-dominant hand in comparison with the unaffected side was considered significant. ${ }^{27-29}$

Assessment of healing on the radiographs was based on signs of trabecular bridging. Two consultant surgeons and a radiologist, all blinded from the treatment allocation, assessed the radiographs, and categorized the appearances as nonunion, possible union or complete union. Nonunion was defined as the presence of trabecular bridging on two views or less, possible union as the presence of bridging on three views and complete union as bridging on all views. For radiological union, the weighted average of the interobserver agreement for the three observers, Fleiss $\kappa$, was calculated for all radiographs.

The primary endpoint was clinical and radiological evidence of union of the fracture, the secondary outcome parameter related to functional outcome. The minimum, median, maximum and interquartile range (IQR) were calculated for the time to both clinical and radiological union. Finally, the percentage of nonunions in both groups was calculated. Nonunion was defined as above and determined at 24 weeks follow-up.

Based on a previous study, ${ }^{22}$ a power analysis was conducted with an expected outcome difference of $30 \%$, i.e. a $30 \%$ reduction in the time to union assuming a mean of 9 weeks (SD 4) until union in the placebo group. The alpha error level was set at 5\% (two-sided significance level); power was set at $80 \%$. Including an anticipated dropout rate of $10 \%$, this resulted in a sample size of 23 patients per group. 


\section{Chapter 2}

\section{Statistical Analysis}

This was performed using proprietary statistical software (SPSS statistical package version 18.0; SPSS inc., Chicago, Illinois, USA) with advanced statistics add-on modules. A statistician was recruited for analysis of the data. Statistical significance was assumed when $p<0.05$. When comparing means between the two groups, an independent student's t-test was used in the case of normality, or the non-parametric Mann-Whitney $U$ test in cases where normality could not be assumed. Categorical data were analyzed using the chi-squared test, or Fisher's exact test if the assumptions for this test were not met. The cumulative incidence of clinical and radiological evidence of union was estimated using the KaplanMeier method and compared using log-rank. All variables were evaluated for prognostic significance in an extensive regression analysis using Cox's proportional hazards model (including age, type of fracture according to the Herbert classification, ${ }^{11}$ hand dominance, time interval between fracture and start of treatment, and comorbidities) with clinical and radiological union as dependent factors. Several analyses were performed to test the accuracy of the model, but this did not change the level of significance (data not shown). The hazard ratio (HR) and 95\% confidence intervals $(95 \% \mathrm{Cl})$ were calculated from the regression analysis.

All patients were analyzed according to the intention-to-treat principle.

\section{ResULTS}

A total of 59 patients were eligible for inclusion during the period of study; six patients withdrew, leaving 53 patients with a clinically and radiologically proven fracture of the scaphoid in the study. After randomization, 24 patients $(45 \%)$ were placed in group A (active) and 29 in group B (placebo) (55\%). Baseline characteristics of both groups are shown in Table 2. All Herbert type B2 fractures had $<2 \mathrm{~mm}$ of displacement on initial radiographs. Two patients were lost to follow-up, both in group B. Scaphoid fractures, in two patients, one in each group were initially diagnosed only on bone scintigraphy. Both fractures were confirmed by follow-up radiographs.

No significant difference in clinical evidence of union was seen during follow-up using log-rank analysis $\left(\chi^{2}=0.03, p>0.05\right)$ (Table 3$)$, except at six weeks, when $11(46 \%)$ patients in group A still had tenderness in the ASB compared with five $(17 \%)$ in group $B, p=0.03$ (Table 3 ) and nine $(38 \%)$ in group A still had tenderness with LC compared to two $(7 \%)$ in group $B, p=0.008$. The time to clinical union was a median of nine weeks (4 to 52 , IQR 4 to 12) in group A, compared with a median of nine weeks (4 to 24, IQR 6 to 12 ) in group B. 
Table 2. BASELINE CHARACTERISTICS

\begin{tabular}{lll}
\hline & Group A (active) & Group B (placebo) \\
\hline Number & 24 & 29 \\
Mean age (yrs) (range) & $44.3(18$ to 84) & $37.7(18$ to 71$)$ \\
Male $(\mathrm{n}, \%)$ & $18(75)$ & $23(79)$ \\
Fracture in dominant hand $(\mathrm{n}, \%)$ & $14(58)$ & $14(48)$ \\
Fracture types ( $\mathrm{n}, \%)$ & & \\
A1 & $4(17)$ & $3(10)$ \\
A2 & $16(67)$ & $18(62)$ \\
B1 & $2(8)$ & $3(10)$ \\
B2 & $1(4)$ & $4(14)$ \\
B3 & $1(4)$ & $1(3)$ \\
Comorbidities (,$\%)$ & & $17(59)$ \\
None & $17(71)$ & $11(38)$ \\
Smoking & $7(29)$ & $1(3)$ \\
Corticosteroids & $0(0)$ & $29(100)$ \\
Anatomical snuff box tenderness $(n, \%)$ & $24(100)$ & $26(90)$ \\
Tenderness on longitudinal compression $(n, \%)$ & $21(88)$ &
\end{tabular}

Table 3. CLINICAL ASSESSMENT OF FRACTURE CONSOLIDATION

\begin{tabular}{llll}
\hline & $\begin{array}{l}\text { Group A } \\
\text { (active) }\end{array}$ & $\begin{array}{l}\text { Group B } \\
\text { (placebo) }\end{array}$ & $\begin{array}{l}\text { p-value } \\
\text { (Fisher's exact test) }\end{array}$ \\
\hline Number & 24 & 29 & \\
Anatomical snuff box tenderness (n, \%) & & & \\
$\quad 4$ weeks & $13(54)$ & $11(38)$ & 0.49 \\
6 weeks & $11(46)$ & $5(17)$ & 0.03 \\
9 weeks & $6(25)$ & $6(21)$ & 0.85 \\
12 weeks & $4(17)$ & $3(10)$ & 1 \\
24 weeks & $1(4)$ & 0 & - \\
52 weeks & 0 & 0 & - \\
Pain with longitudinal compression $(n, \%)$ & & & \\
4 weeks & $10(42)$ & $9(31)$ & 0.63 \\
6 weeks & $9(38)$ & $2(7)$ & 0.008 \\
9 weeks & $4(17)$ & $2(7)$ & 0.41 \\
12 weeks & $3(13)$ & $1(3)$ & 0.61 \\
24 weeks & $2(8)$ & 0 & - \\
52 weeks & 0 & 0 & -
\end{tabular}




\section{Chapter 2}

The range of movement of the wrist returned to normal with no significant difference between the groups (difference $<25 \%$ ) at 12 weeks (Table 4 ).

Table 4. ASSESSMENT OF FUNCTIONAL OUTCOME IN TERMS OF LOSS OF WRIST MOVEMENT (Cl, CONFIDENCE INTERVAL)

\begin{tabular}{llll}
\hline \multicolumn{4}{l}{ Loss of wrist movement (\%, 95\% Cl) } \\
Interval & Group A (active) & Group B (placebo) & p-value \\
\hline 4 weeks & $43 \%(34$ to 51$)$ & $44 \%(36$ to 52$)$ & 0.82 \\
6 weeks & $35 \%(23$ to 48$)$ & $38 \%(29$ to 48$)$ & 0.62 \\
9 weeks & $30 \%(15$ to 44$)$ & $30 \%(18$ to 42$)$ & 0.93 \\
12 weeks & $21 \%(6$ to 36$)$ & $20 \%(5$ to 35$)$ & 0.92 \\
24 weeks & $10 \%(-2$ to 25$)$ & $3 \%(-2$ to 8$)$ & 0.97 \\
52 weeks & - & - & - \\
\hline${ }^{*}$ wrist movement returned to normal levels & &
\end{tabular}

Grip strength returned to normal with no significant difference between the groups at 24 weeks (Table 5).

Table 5. ASSESSMENT OF FUNCTIONAL OUTCOME IN TERMS OF LOSS OF GRIP STRENGTH BY FRACTURE SITE (Cl, CONFIDENCE INTERVAL)

\begin{tabular}{|c|c|c|c|c|c|c|}
\hline \multirow[b]{3}{*}{ Interval } & \multicolumn{6}{|c|}{ Loss of wrist movement $(\%, 95 \% \mathrm{Cl})$} \\
\hline & \multicolumn{3}{|c|}{ Fracture at dominant side ${ }^{*}$} & \multicolumn{3}{|c|}{ Fracture at non-dominant side ${ }^{\dagger}$} \\
\hline & $\begin{array}{l}\text { Group A } \\
\text { (active) }\end{array}$ & $\begin{array}{l}\text { Group B } \\
\text { (placebo) }\end{array}$ & $\mathrm{p}$-value & $\begin{array}{l}\text { Group A } \\
\text { (active) }\end{array}$ & $\begin{array}{l}\text { Group B } \\
\text { (placebo) }\end{array}$ & $\mathrm{p}$-value \\
\hline 4 weeks & $54 \%(27$ to 81$)$ & $47 \%$ (32 to 62$)$ & 0.58 & $52 \%(25$ to 79$)$ & $46 \%$ (33 to 59$)$ & 0.65 \\
\hline 6 weeks & $32 \%(-3$ to 66$)$ & $32 \%(12$ to 53$)$ & 0.92 & $48 \%(25$ to 71$)$ & $46 \%$ (25 to 66$)$ & 0.85 \\
\hline 9 weeks & $24 \%(10$ to 38$)$ & $33 \%(17$ to 48$)$ & 0.29 & $28 \%$ (1 to 55$)$ & $39 \%(17$ to 61$)$ & 0.46 \\
\hline 12 weeks & $22 \%(10$ to 34$)$ & $10 \%(-15$ to 35$)$ & 0.26 & $26 \%(-2$ to 54$)$ & $28 \%(-11$ to 66$)$ & 0.83 \\
\hline 24 weeks $^{\ddagger}$ & $0 \%(-16$ to 16$)$ & $-8 \% \S(-25$ to 24$)$ & 0.62 & $7 \%(-6$ to 21$)$ & $15 \%(-6$ to 36$)$ & 0.42 \\
\hline 52 weeks & - & - & - & - & - & - \\
\hline \multicolumn{7}{|c|}{${ }^{*}$ normal strength at loss $<10 \%$} \\
\hline \multicolumn{7}{|c|}{$\dagger$ normal strength at loss $<20 \%$} \\
\hline \multicolumn{7}{|c|}{$\ddagger$ grip strength returned to normal levels } \\
\hline \multicolumn{7}{|c|}{$\S$ strength higher than healthy side } \\
\hline
\end{tabular}




\section{Clinical and radiological outcome of PEMF}

The weighted average interobserver agreement for radiological union showed a $\kappa$ of $0.59(95 \% \mathrm{Cl} 0.47$ to $0.71 ; \mathrm{p}<0.001)$ at six weeks after injury for all radiographs.

Throughout the follow-up period no significant difference was observed between the groups by log-rank analysis $\left(\chi^{2}=0.03, p>0.05\right)$. In both groups radiological union took a median of nine weeks ( 4 to 52, IQR 6 to 24$)(p=0.32$ ). The confounding factors of age, hand dominance, comorbidities (smoking, use of corticosteroids), type of fracture (Herbert types A1, A2, B1, B2 and B3) ${ }^{11}$ and time between fracture and treatment had no significant influence on the effect of the PEMF treatment with respect to either clinical or radiological union (Table 6). There was one nonunion in group $A$ and none in group $B(p=0.57)$.

Table 6. COX REGRESSION ANALYSIS FOR CLINICAL AND RADIOLOGICAL ANALYSIS.

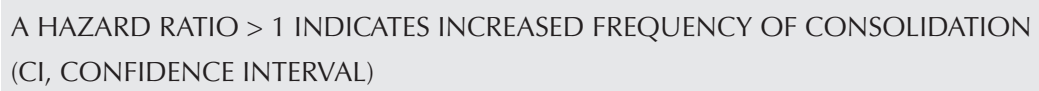

\begin{tabular}{|c|c|c|c|c|}
\hline & Loss Clinical union & & Radiological union & \\
\hline Parameters ${ }^{*}$ & Hazard ratio $(95 \% \mathrm{Cl})$ & $p$-value & Hazard ratio $(95 \% \mathrm{Cl})$ & $p$-value \\
\hline Group & 1.20 (0.56 to 2.58$)$ & 0.6 & $0.73(0.36$ to 1.50$)$ & 0.4 \\
\hline Age & $0.98(0.95$ to 1.00$)$ & 0.1 & 1.02 (0.99 to 1.04$)$ & 0.1 \\
\hline Fracture type & 0.88 (0.62 to 1.26$)$ & 0.5 & 0.85 (0.58 to 1.24$)$ & 0.4 \\
\hline Interval time & $1.09(0.91$ to 1.30$)$ & 0.3 & $1.03(0.85$ to 1.25$)$ & 0.8 \\
\hline Hand dominance & 1.09 (0.49 to 2.43) & 0.8 & $0.86(0.41$ to 1.82$)$ & 0.7 \\
\hline Comorbidities & $0.57(0.26$ to 1.25$)$ & 0.2 & $0.55(0.26$ to 1.19$)$ & 0.1 \\
\hline
\end{tabular}

\section{Discussion}

This is the first double-blind, randomized, placebo-controlled trial to investigate the effect of PEMF on the time to union and functional outcome of acute fractures of the scaphoid.

Observational studies by Frykman and Adams on 44 and 54 scaphoid nonunions, respectively, showed that $69 \%$ to $80 \%$ of ununited fractures that presented more 


\section{Chapter 2}

than six months after injury, healed using PEMF stimulation and a thumb spica cast. $^{20,21}$ Patients were treated for at least three months or until the fracture had united. Even nonunions with associated radiological evidence of avascular necrosis healed with success rates of $73 \%$ to $89 \% .^{20,21}$ Furthermore, there is evidence that LIPUS may accelerate union of acute scaphoid fractures by up to $30 \% .^{22}$ Our study, however, found no positive effect of adding PEMF to conservative treatment of these fractures. There are several reasons why the use of non-invasive techniques for bone growth stimulation, such as PEMF could be considered. Conservative treatment often leads to a long period of absenteeism. ${ }^{2}$ Furthermore, operative treatment for delayed or nonunion often starts months after the fracture has occurred, with inevitable socioeconomic consequences. ${ }^{2}$

Several clinical trials have considered the place of physical forces in the treatment of acute fractures. The healing of tibial and radial fractures was found to be significantly accelerated in two prospective, randomized, double-blind trials using LIPUS as an adjunct to conventional treatment. ${ }^{18,19}$ A recent systematic review concerning the effects of LIPUS and PEMF in the treatment of acute tibial fractures was not able to compare the effects of these interventions. ${ }^{30}$ However, after analyzing five studies on LIPUS and three on PEMF, the authors concluded that LIPUS accelerates acute fracture healing and that both promote healing in ununited fractures. LIPUS has also been shown to accelerate the healing of acute scaphoid fractures. In a prospective randomized trial, where union was assessed by CT scans every two weeks, Mayr et al. concluded that LIPUS accelerated the healing of acute scaphoid fractures by $30 \%{ }^{22}$

However, our study found no evidence supporting the addition of PEMF to conservative treatment. There was no reduction in the time to either clinical or radiological union and there was no effect on either the functional outcome or the range of movement.

Given that this study was not designed to detect differences in the number of nonunions, no conclusion can be made as to the prevention of this complication. Radiological follow-up was performed by assessment of normal scaphoid radiographs, in accordance with current practice. However, these may not always provide reliable and reproducible evidence of healing. ${ }^{31-34}$ Trabeculae crossing the fracture line, sclerosis of the fracture line and avascularity of the proximal part of the scaphoid are signs that can be used in the assessment of union of a scaphoid fracture. ${ }^{34}$ Dias $^{33}$ showed that when assessing union, the reproducibility and interobserver agreement were too poor to rely on in the first 12 weeks after injury. However, radiographs usually give some indication of 
union or nonunion. Reproducibility and interobserver variability tend to be better with regard to these assessments. ${ }^{33}$ In our series, interobserver variability showed an acceptable $\kappa$ of $0.59(95 \% \mathrm{Cl} 0.47$ to 0.71$)$ at six weeks after injury for all radiographs. CT scanning in the longitudinal axis may allow for a more accurate assessment of union of a scaphoid fracture. ${ }^{35,36}$ Recent studies concerning operative versus conservative treatment of scaphoid fractures, however, use standard radiographs for the assessment of union. ${ }^{2,37}$ In our study the clinical parameters of union and the functional outcome did not differ between treatment arms.

In conclusion, adding PEMF to the conservative treatment of acute scaphoid fractures does not accelerate union or improve the functional outcome. 


\section{Chapter 2}

\section{REFERENCES}

1. Tiel-van Buul MM, van Beek EJ, Broekhuizen AH, Bakker AJ, Bos KE, van Royen EA. Radiography and scintigraphy of suspected scaphoid fracture. A long-term study in 160 patients. The Journal of bone and joint surgery British volume 1993;75:61-5.

2. van der Molen AB, Groothoff JW, Visser GJ, Robinson PH, Eisma WH. Time off work due to scaphoid fractures and other carpal injuries in The Netherlands in the period 1990 to 1993. J Hand Surg Br 1999;24:193-8.

3. Tiel-van Buul MM, Roolker W, Broekhuizen AH, Van Beek EJ. The diagnostic management of suspected scaphoid fracture. Injury 1997;28:1-8.

4. Beeres FJ, Rhemrev SJ, Hogervorst M, den Hollander P, Jukema GN. [Scaphoid fractures: diagnosis and therapy]. Ned Tijdschr Geneeskd 2007;151:742-7.

5. Jenkins PJ, Slade K, Huntley JS, Robinson CM. A comparative analysis of the accuracy, diagnostic uncertainty and cost of imaging modalities in suspected scaphoid fractures. Injury 2008;39:768-74.

6. Divelbiss BJ, Adams BD. Electrical and ultrasound stimulation for scaphoid fractures. Hand clinics 2001;17:697-701, x-xi.

7. Rajagopalan BM, Squire DS, Samuels LO. Results of Herbert-screw fixation with bonegrafting for the treatment of nonunion of the scaphoid. The Journal of bone and joint surgery American volume 1999;81:48-52.

8. Raudasoja L, Rawlins M, Kallio P, Vasenius J. Conservative treatment of scaphoid fractures: a follow up study. Ann Chir Gynaecol 1999;88:289-93.

9. Szabo RM, Manske D. Displaced fractures of the scaphoid. Clin Orthop Relat Res 1988:30-8.

10. Kozin SH. Incidence, mechanism, and natural history of scaphoid fractures. Hand clinics 2001;17:515-24.

11. Herbert TJ, Fisher WE. Management of the fractured scaphoid using a new bone screw. The Journal of bone and joint surgery British volume 1984;66:114-23.

12. McQueen MM, Gelbke MK, Wakefield A, Will EM, Gaebler C. Percutaneous screw fixation versus conservative treatment for fractures of the waist of the scaphoid: a prospective randomised study. The Journal of bone and joint surgery British volume 2008;90: 66-71.

13. Bushnell BD, McWilliams AD, Messer TM. Complications in dorsal percutaneous cannulated screw fixation of nondisplaced scaphoid waist fractures. The Journal of hand surgery 2007;32:827-33.

14. Mollon B, da Silva V, Busse JW, Einhorn TA, Bhandari M. Electrical stimulation for longbone fracture-healing: a meta-analysis of randomized controlled trials. The Journal of bone and joint surgery American volume 2008;90:2322-30.

15. Otter MW, McLeod KJ, Rubin CT. Effects of electromagnetic fields in experimental fracture repair. Clin Orthop Relat Res 1998:S90-104. 


\section{Clinical and radiological outcome of PEMF}

16. Gossling HR, Bernstein RA, Abbott J. Treatment of ununited tibial fractures: a comparison of surgery and pulsed electromagnetic fields (PEMF). Orthopedics 1992;15:711-9.

17. Ito $\mathrm{H}$, Shirai $\mathrm{Y}$. The efficacy of ununited tibial fracture treatment using pulsing electromagnetic fields: relation to biological activity on nonunion bone ends. J Nippon Med Sch 2001;68:149-53.

18. Heckman JD, Ryaby JP, McCabe J, Frey JJ, Kilcoyne RF. Acceleration of tibial fracturehealing by non-invasive, low-intensity pulsed ultrasound. The Journal of bone and joint surgery American volume 1994;76:26-34.

19. Kristiansen TK, Ryaby JP, McCabe J, Frey JJ, Roe LR. Accelerated healing of distal radial fractures with the use of specific, low-intensity ultrasound. A multicenter, prospective, randomized, double-blind, placebo-controlled study. The Journal of bone and joint surgery American volume 1997;79:961-73.

20. Adams BD, Frykman GK, Taleisnik J. Treatment of scaphoid nonunion with casting and pulsed electromagnetic fields: a study continuation. The Journal of hand surgery 1992; 17:910-4.

21. Frykman GK, Taleisnik J, Peters G, et al. Treatment of nonunited scaphoid fractures by pulsed electromagnetic field and cast. The Journal of hand surgery 1986;11:344-9.

22. Mayr E, Rudzki MM, Rudzki M, Borchardt B, Hausser H, Ruter A. [Does low intensity, pulsed ultrasound speed healing of scaphoid fractures?]. Handchir Mikrochir Plast Chir 2000;32:115-22.

23. Zborowski M, Kligman B, Midura RJ, et al. Decibel attenuation of pulsed electromagnetic field (PEMF) in blood and cortical bone determined experimentally and from the theory of ohmic losses. Ann Biomed Eng 2006;34:1030-41.

24. Dias JJ, Wray CC, Jones JM, Gregg PJ. The value of early mobilisation in the treatment of Colles' fractures. The Journal of bone and joint surgery British volume 1987;69:463-7.

25. Roolker W, Maas M, Broekhuizen AH. Diagnosis and treatment of scaphoid fractures, can non-union be prevented? Archives of orthopaedic and trauma surgery 1999;119: 428-31.

26. Hamilton GF, McDonald C, Chenier TC. Measurement of grip strength: validity and reliability of the sphygmomanometer and jamar grip dynamometer. J Orthop Sports Phys Ther 1992;16:215-9.

27. Crosby CA, Wehbe MA, Mawr B. Hand strength: normative values. The Journal of hand surgery 1994; 19:665-70.

28. Czitrom AA, Lister GD. Measurement of grip strength in the diagnosis of wrist pain. The Journal of hand surgery 1988;13:16-9.

29. Schmidt RT, Toews JV. Grip strength as measured by the Jamar dynamometer. Arch Phys Med Rehabil 1970;51:321-7.

30. Walker NA, Denegar CR, Preische J. Low-intensity pulsed ultrasound and pulsed electromagnetic field in the treatment of tibial fractures: a systematic review. J Athl Train 2007; 42:530-5. 


\section{Chapter 2}

31. Barton NJ. The late consequences of scaphoid fractures. The Journal of bone and joint surgery British volume 2004;86:626-30.

32. Schuind F, Haentjens P, Van Innis F, Vander Maren C, Garcia-Elias M, Sennwald G. Prognostic factors in the treatment of carpal scaphoid nonunions. The Journal of hand surgery 1999;24:761-76.

33. Dias JJ, Taylor M, Thompson J, Brenkel IJ, Gregg PJ. Radiographic signs of union of scaphoid fractures. An analysis of inter-observer agreement and reproducibility. The Journal of bone and joint surgery British volume 1988;70:299-301.

34. Dias JJ. Definition of union after acute fracture and surgery for fracture nonunion of the scaphoid. J Hand Surg Br 2001;26:321-5.

35. Sanders WE. Evaluation of the humpback scaphoid by computed tomography in the longitudinal axial plane of the scaphoid. The Journal of hand surgery 1988;13:182-7.

36. Bain GI, Bennett JD, Richards RS, Slethaug GP, Roth JH. Longitudinal computed tomography of the scaphoid: a new technique. Skeletal Radiol 1995;24:271-3.

37. Dias JJ, Wildin CJ, Bhowal B, Thompson JR. Should acute scaphoid fractures be fixed? A randomized controlled trial. The Journal of bone and joint surgery American volume 2005;87:2160-8. 
Clinical and radiological outcome of PEMF 


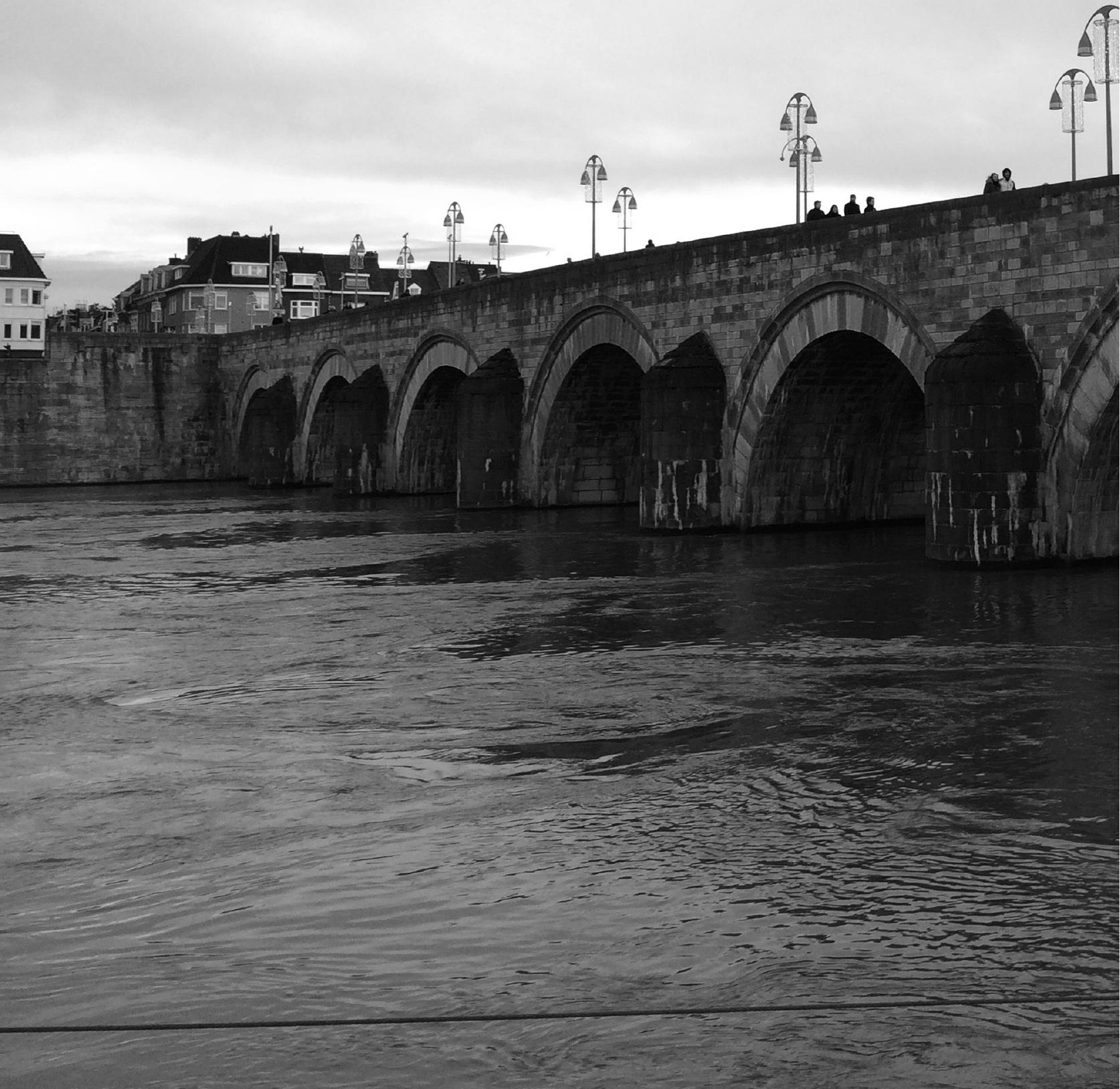




\section{Chapter 3}

\section{DETERMINING SCAPHOID WAIST}

FRACTURE UNION BY CONVENTIONAL RADIOGRAPHIC EXAMINATION:

\section{AN ANALYSIS OF RELIABILITY AND VALIDITY}

Hannemann PFW

Brouwers L

Dullaert K

Van der Linden ES

Poeze M

Brink PRG

Arch Orthop Trauma Surg. 2015 Feb;135(2):291-6 


\section{Chapter 3}

\section{Abstract}

Conventional radiographic imaging is the first imaging tool of choice in scaphoid fractures. The majority of undisplaced scaphoid waist fractures unite after six weeks of cast immobilization. We hypothesized that conventional radiographic imaging at 6 weeks after injury can both accurately and reliably predict union in undisplaced scaphoid waist fractures.

Fleiss' kappa statistics were used concerning the opinions of four observers reviewing 47 sets of good-quality scaphoid radiographs of undisplaced scaphoid waist fractures. As reference standard for union, radiographs were taken at a minimum of six months after injury to determine validity.

Overall agreement was defined as moderate. $(\kappa=0.583)$ "No consolidation" $(\kappa=0.816)$, "full consolidation" $(\kappa=0.517)$ and "partial consolidation" $(\kappa=0.390)$ were defined as good, moderate and fair agreement, respectively. The average sensitivity and specificity of diagnosing scaphoid waist fracture union on standard scaphoid radiographs were 0.65 and 0.67 , respectively. The positive predictive value for diagnosing union was 0.93 and the negative predictive value was 0.22 .

We conclude that conventional radiographic imaging is accurate and moderately reliable in diagnosing union, and reliable but inaccurate in diagnosing nonunion of scaphoid waist fractures at 6 weeks follow-up. 


\section{Accuracy and precision of conventional radiographic examination}

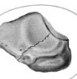

\section{INTRODUCTION}

Scaphoid fractures are the most common carpal bone fractures. ${ }^{1}$ Conventional radiographic imaging is the first imaging tool of choice in scaphoid fractures. ${ }^{2}$ For scaphoid fractures, usually trabecular bridging and sclerosis at the fracture line are used to assess bony union. ${ }^{3}$ Radiological diagnosis and evaluation of scaphoid fracture union are difficult, because of the unique shape, size and orientation of the bone. ${ }^{3}$ In case of a scaphoid fracture, the appearance of trabecular overcrossing of the fracture line may be incorrect as a result of overlapping of fracture fragments in the direction of the X-ray beam. ${ }^{4,5}$

When considering non-operative treatment of undisplaced scaphoid fractures, most fractures unite within 8 weeks. ${ }^{6,7}$ However, some studies use cast immobilization up to 12 weeks in undisplaced scaphoid waist fractures because of the above-mentioned difficulties with identifying the extent of radiological union of the scaphoid fracture by using conventional radiographic imaging techniques. ${ }^{1,8-11}$ The length of immobilization therefore, however notoriously unreliable, is often dictated by clinical signs of consolidation of the scaphoid and less by a radiographic observed union., ${ }^{4,12}$ Although the risk of scaphoid nonunion is substantial for some fractures, overall union rates for non-operatively treated scaphoid fractures are 88 to $95 \% .4,8,13,14$

An important question remains whether conventional radiographic imaging of the scaphoid at 6 weeks is able to accurately and reliably diagnose scaphoid waist fracture union or not. Rhemrev showed that more than $80 \%$ of undisplaced scaphoid fractures were clinically united after 6 weeks of cast immobilization. ${ }^{6}$ Dias showed poor inter-observer agreement concerning union for the use of conventional radiographic views determined at 12 weeks after injury. ${ }^{4}$ Computed Tomography (CT) imaging of the scaphoid for identification of occult fractures and evaluation of the healing process is being performed more frequently and often considered as gold standard, but is yet not common practice in the Netherlands as it is impractical to perform CT scans at each follow-up visit in every patient. ${ }^{15}$ Therefore, it is important to know whether or not radiographic diagnosis of union by conventional radiographic imaging is a reliable method for determining union at 6 weeks after injury.

We hypothesized that conventional radiographic imaging at 6 weeks after injury can both accurately and reliably predict union in undisplaced scaphoid waist fractures. Therefore, in addition to determining inter-observer reliability (precision), in this study the accuracy (or validity) of conventional imaging was deter- 


\section{Chapter 3}

mined using diagnostic performance characteristics in a group of patients with acute, undisplaced scaphoid waist fractures.

\section{Materials AND Methods}

Between May 2006 and March 2008, 47 consecutive patients (39 males, eight females, mean age 35 (18-72 years)) with acute unilateral undisplaced scaphoid waist fractures were prospectively included in this study. Fracture dislocations of the carpus, comminuted scaphoid fractures and displaced waist fractures of the scaphoid were excluded. Approval was obtained from the medical ethical committee of the participating center and written informed consent for participation and registration of the data was obtained from all patients. All research was conducted in accordance with the Declaration of Helsinki. The presence of a scaphoid fracture was determined by a combination of physical and radiographic examination. If no apparent fracture line was seen on the initial X-rays (scaphoid series), a CT scan was performed within 5 days after trauma to confirm the diagnosis.

For the analysis, 47 sets of good-quality digital radiographs of the scaphoid fractures were taken at 6 weeks after injury. Each set included four views: posterioranterior view, posterior-anterior view in full ulnar deviation, lateral view and oblique, semi-pronated view. ${ }^{1}$ Each radiograph was taken using the appropriate exposure settings (contrast, noise and spatial resolution) and checked for visibility of all gross necessary image details. ${ }^{16}$

In accordance with the current consensus reference standard for the endpoint union, scaphoid radiographs were taken at a minimum of 6 months after injury to confirm or exclude union by determining the presence of trabecular bridging. ${ }^{3,14}$ As reference standard for nonunion, a persistent lucency determined by a senior orthopedic trauma consultant and a musculoskeletal radiologist on the radiographs obtained at a minimum of 6 months after injury was used. ${ }^{3,14}$ All fractures were treated conservatively in a lower arm cast with the first metacarpal and proximal phalanx immobilized.

The results of four observers were analyzed: Two senior orthopedic trauma consultants and two radiologists with special interest in musculoskeletal radiology. We presented each clinician the 47 sets of randomly ordered radiographs, labeled 1 to 47 . They were asked to determine whether there was union, no union or partial union of the scaphoid fracture of each patient. 


\section{Accuracy and precision of conventional radiographic examination}

Trabecular crossing of the fracture line and sclerosis at the fracture line were classified as signs of scaphoid union on the radiographs. ${ }^{3}$ Union was defined as signs of consolidation on at least three out of four views. ${ }^{5}$ Partial union was defined as signs of consolidation on one or two views. ${ }^{5}$ No union was defined as signs of consolidation on none of the views. ${ }^{5}$ (See table 1 for criteria used for different ratings of union.) After two months, all four observers were asked again to judge the radiographs concerning the above-mentioned degree of consolidation. The previously numbered radiographs were again presented in a random order.

Table 1. CRITERIA USED FOR DIFFERENT RATINGS OF UNION

\begin{tabular}{llll}
\hline & Trabecular crossing & Sclerosis & Seen on number of views \\
\hline Union & yes & yes & $3-4$ \\
Partial union & yes & yes & $1-2$ \\
No union & no & no & 0
\end{tabular}

Data were analyzed and expressed in terms of intra- and inter-observer agreement in total and by stage of consolidation. A statistician was recruited for analysis of the data. A level of significance of $\alpha=0.05$ was used. Calculations were performed using 95\% confidence intervals (Cl). Calculation was done using Fleiss' kappa statistics in such a way that the reliability of agreement between a fixed number of observers when assigning categorical ratings to a number of items was assessed. ${ }^{17}$

We interpreted the multirater kappa statistics as follows; values of $0.01-0.20$ indicate slight agreement, $0.21-0.40$ fair agreement, $0.41-0.60$ moderate agreement, $0.61-0.80$ substantial agreement and more than 0.80 good agreement. ${ }^{18} \mathrm{~A}$ kappa value of 1 would indicate a perfect agreement between categorical ratings. Sensitivity and specificity were estimated with use of $95 \%$ confidence intervals $(\mathrm{Cl})$. For estimation of sensitivity and specificity the pretest probability of union of scaphoid fractures was set at $90 \%$, as literature shows that an overall union rate of scaphoid fractures of $88-95 \%$ is achieved after 6 weeks of cast immobilization. ${ }^{4,8,13,14,19}$ 


\section{Chapter 3}

\section{Results}

We included 47 patients with unilateral undisplaced scaphoid waist fractures in this study. All fractures were diagnosed by conventional radiographic imaging. No additional CT scans were made to confirm the presence of a scaphoid waist fracture since all fractures were visible on initial radiographs, independently diagnosed by an orthopedic trauma consultant and a musculoskeletal radiologist. All fractures were treated conservatively. At the endpoint, six patients developed a nonunion (13\%).

The observers agreed in 24 of a total of 47 patients (51\%). In 14 patients, 3 observers agreed (30\%) and in 9 patients 2 observers agreed (19\%). We calculated the degree of agreement in total for all 47 sets of radiographs. The total interobserver agreement could be defined as a moderate agreement $(\kappa=0.583)(95 \%$ confidence interval (Cl): 0.371-0.795, $\mathrm{P}<0.001)$.

We also calculated the inter-observer agreement for each type of consolidation. There was an almost perfect agreement $(\kappa=0.816)(95 \% \mathrm{Cl}: 0.321-0.999$, $p=0.001$ ) between the observers concerning no union for all scaphoid fractures. The inter-observer agreement regarding union showed a moderate agreement $(\kappa=0.517)(95 \% \mathrm{Cl}: 0.077-0.999, \mathrm{p}=0.02)$ and the observers agreed less on partial union $(\kappa=0.390)(95 \% \mathrm{Cl}: 0.048-0.832, \mathrm{p}=0.08)$. The results for the inter-observer agreements are presented in table 2.

All four observers were tested again after 2 months. The capability to reproduce their own opinion regarding the degree of consolidation was measured. The total intra-observer agreements were substantial for two observers $(\kappa=0.775$ and 0.623 , respectively) and moderate for the other two observers ( $\kappa=0.469$ and 0.542 , respectively). The average total intra-observer agreement for all four observers was moderate $(\kappa=0.602)$. Obviously, inter-observer agreements for each type of consolidation obtained after 2 months differed from the first time and are presented in table 3. No significant differences between inter-observer agreements were seen, except for partial union. $(\kappa=0.447$, see table 3 )

The average sensitivity of scaphoid series for diagnosing union of scaphoid waist fractures was 0.65 (95\% Cl: 0.54-0.75). The average specificity was 0.67 (95\% $\mathrm{Cl}$ : 0.39-0.86). Positive predictive value (PPV) for this test was $0.93(95 \% \mathrm{Cl}$ : 0.83-0.97) and negative predictive value (NPV) was 0.22 (95\% Cl: 0.12-0.38). 
Accuracy and precision of conventional radiographic examination

Table 2. INTER-OBSERVER AGREEMENTS FOR EACH TYPE OF CONSOLIDATION

\begin{tabular}{|c|c|c|c|c|c|c|c|}
\hline $\begin{array}{l}\text { Patient } \\
\text { no. }\end{array}$ & $\begin{array}{l}\text { Non- } \\
\text { union }\end{array}$ & Union & $\begin{array}{l}\text { Partial } \\
\text { union }\end{array}$ & $\begin{array}{l}\text { Patient } \\
\text { no. }\end{array}$ & $\begin{array}{l}\text { Non- } \\
\text { union }\end{array}$ & Union & $\begin{array}{l}\text { Partial } \\
\text { union }\end{array}$ \\
\hline 1 & 0 & 2 & 2 & 25 & 0 & 0 & 4 \\
\hline 2 & 3 & 0 & 1 & 26 & 0 & 0 & 4 \\
\hline 3 & 3 & 0 & 1 & 27 & 3 & 0 & 1 \\
\hline 4 & 4 & 0 & 0 & 28 & 2 & 0 & 2 \\
\hline 5 & 4 & 0 & 0 & 29 & 0 & 4 & 0 \\
\hline 6 & 0 & 4 & 0 & 30 & 0 & 4 & 0 \\
\hline 7 & 0 & 2 & 2 & 31 & 0 & 3 & 1 \\
\hline 8 & 0 & 0 & 4 & 32 & 4 & 0 & 0 \\
\hline 9 & 4 & 0 & 0 & 33 & 4 & 0 & 0 \\
\hline 10 & 4 & 0 & 0 & 34 & 0 & 3 & 1 \\
\hline 11 & 0 & 3 & 1 & 35 & 0 & 1 & 3 \\
\hline 12 & 0 & 0 & 4 & 36 & 0 & 4 & 0 \\
\hline 13 & 0 & 3 & 1 & 37 & 0 & 4 & 0 \\
\hline 14 & 0 & 4 & 0 & 38 & 2 & 0 & 2 \\
\hline 15 & 1 & 0 & 3 & 39 & 0 & 4 & 0 \\
\hline 16 & 1 & 0 & 3 & 40 & 2 & 0 & 2 \\
\hline 17 & 4 & 0 & 0 & 41 & 0 & 2 & 2 \\
\hline 18 & 0 & 2 & 2 & 42 & 0 & 4 & 0 \\
\hline 19 & 0 & 2 & 2 & 43 & 0 & 2 & 2 \\
\hline 20 & 0 & 1 & 3 & 44 & 0 & 0 & 4 \\
\hline 21 & 4 & 0 & 0 & 45 & 3 & 0 & 1 \\
\hline 22 & 4 & 0 & 0 & 46 & 1 & 0 & 3 \\
\hline 23 & 0 & 4 & 0 & 47 & 0 & 4 & 0 \\
\hline 24 & 0 & 3 & 1 & & & & \\
\hline & & & & Totals & 57 & 69 & 62 \\
\hline & & & & Kappa & 0.816 & 0.517 & 0.390 \\
\hline & & & & $95 \% \mathrm{Cl}$ & $0.321-0.999$ & 0.077-0.999 & $0.048-0.832$ \\
\hline & & & & $p$-value & $p=0.001$ & $p=0.02$ & $p=0.08$ \\
\hline & & & & \multicolumn{3}{|c|}{ Overall kappa } & 0.583 \\
\hline & & & & \multicolumn{3}{|l|}{$95 \% \mathrm{Cl}$} & $0.371-0.795$ \\
\hline & & & & \multicolumn{3}{|l|}{$p$-value } & $p<0.001$ \\
\hline
\end{tabular}

Numbers indicate frequencies of chosen types of consolidation for each patient 


\section{Chapter 3}

Table 3. INTER-OBSERVER AGREEMENTS FOR EACH TYPE OF CONSOLIDATION OBTAINED THE SECOND TIME, AT 2 MONTHS AFTER THE OBSERVERS WERE TESTED THE FIRST TIME

\begin{tabular}{|c|c|c|c|c|c|c|c|}
\hline $\begin{array}{l}\text { Patient } \\
\text { no. }\end{array}$ & $\begin{array}{l}\text { Non- } \\
\text { union }\end{array}$ & Union & $\begin{array}{l}\text { Partial } \\
\text { union }\end{array}$ & $\begin{array}{l}\text { Patient } \\
\text { no. }\end{array}$ & $\begin{array}{l}\text { Non- } \\
\text { union }\end{array}$ & Union & $\begin{array}{l}\text { Partial } \\
\text { union }\end{array}$ \\
\hline 1 & 0 & 2 & 2 & 25 & 0 & 0 & 4 \\
\hline 2 & 4 & 0 & 0 & 26 & 0 & 0 & 4 \\
\hline 3 & 4 & 0 & 0 & 27 & 2 & 0 & 2 \\
\hline 4 & 4 & 0 & 0 & 28 & 2 & 0 & 2 \\
\hline 5 & 4 & 0 & 0 & 29 & 0 & 4 & 0 \\
\hline 6 & 2 & 0 & 2 & 30 & 0 & 4 & 0 \\
\hline 7 & 0 & 3 & 1 & 31 & 0 & 3 & 1 \\
\hline 8 & 0 & 0 & 4 & 32 & 4 & 0 & 0 \\
\hline 9 & 4 & 0 & 0 & 33 & 4 & 0 & 0 \\
\hline 10 & 4 & 0 & 0 & 34 & 0 & 3 & 1 \\
\hline 11 & 0 & 3 & 1 & 35 & 0 & 1 & 3 \\
\hline 12 & 0 & 0 & 4 & 36 & 0 & 4 & 0 \\
\hline 13 & 0 & 3 & 1 & 37 & 0 & 4 & 0 \\
\hline 14 & 0 & 4 & 0 & 38 & 4 & 0 & 0 \\
\hline 15 & 1 & 0 & 3 & 39 & 0 & 4 & 0 \\
\hline 16 & 2 & 0 & 2 & 40 & 2 & 0 & 2 \\
\hline 17 & 4 & 0 & 0 & 41 & 0 & 2 & 2 \\
\hline 18 & 0 & 2 & 2 & 42 & 0 & 4 & 0 \\
\hline 19 & 0 & 2 & 2 & 43 & 0 & 2 & 2 \\
\hline 20 & 0 & 2 & 2 & 44 & 0 & 0 & 4 \\
\hline 21 & 4 & 0 & 0 & 45 & 4 & 0 & 0 \\
\hline 22 & 4 & 0 & 0 & 46 & 1 & 0 & 3 \\
\hline 23 & 0 & 4 & 0 & 47 & 0 & 4 & 0 \\
\hline 24 & 0 & 3 & 1 & & & & \\
\hline & & & & Totals & 64 & 67 & 57 \\
\hline & & & & Kappa & 0.812 & 0.542 & 0.447 \\
\hline & & & & $95 \% \mathrm{Cl}$ & $0.319-0.999$ & 0.081-0.999 & $0.055-0.948$ \\
\hline & & & & $\mathrm{p}$-value & $p=0.001$ & $p=0.01$ & $p=0.04$ \\
\hline & & & & \multicolumn{3}{|c|}{ Overall kappa } & 0.596 \\
\hline & & & & \multicolumn{3}{|l|}{$95 \% \mathrm{Cl}$} & $0.384-0.807$ \\
\hline & & & & \multicolumn{3}{|l|}{$\mathrm{p}$-value } & $p<0.001$ \\
\hline
\end{tabular}

Numbers indicate frequencies of chosen types of consolidation for each patient 


\section{Discussion}

Diagnostic tests could be interpreted to be of high quality if both reliability and validity or accuracy are of substantial value. The results of our study suggest that, although the confidence intervals were wide for diagnosing union and nonunion, conventional radiographic imaging is very accurate (PPV 0.93) and moderately reliable $(\kappa=0.517)$ in diagnosing union and inaccurate (NPV 0.22$)$ but very reliable $(\kappa=0.816)$ in diagnosing nonunion of scaphoid waist fractures at 6 weeks follow-up.

Concerning reliability (inter-observer agreement), the results of this study showed that at 6 weeks after injury, conventional radiographic imaging can be reliably used to prove that a scaphoid waist fracture has not united. To determine whether a scaphoid waist fracture has partially or fully united, the use of conventional radiographic imaging shows far less inter-observer agreement.

Dias suggested that it is difficult to identify union of the scaphoid fracture on conventional radiographs in the early period after injury, since radiographs are considered not to provide reliable evidence for determination of trabecular crossing of the fracture and sclerosis of the fracture line or proximal part of the scaphoid as signs of union of the fracture. ${ }^{3}$ In a retrospective study by the same author at 12 weeks after injury, the inter-observer agreement and reproducibility concerning consolidation was too poor to reliably assess union of the scaphoid fracture. ${ }^{4}$ Indeed, also in our study there was less agreement concerning partial union or complete union. Trabecular crossing of the fracture line and sclerosis of the fracture can be difficult to identify because of the possibility of wrong positioning of the hand on the radiographs. ${ }^{3}$ This is in contrast to the findings in our study at 6 weeks after injury where a good agreement between the observers for no consolidation was found.

Inter-observer agreements for each type of consolidation, obtained again 2 months after the observers were tested the first time, showed a small but significant improvement of inter-observer agreement regarding partial union. Apparently, the training effect of re-evaluation of the 47 sets of radiographs improves reliability to some extent. The same effect was described by Buijze et al. in a study where they concluded that training improved inter-observer reliability for the diagnosis of scaphoid fracture displacement, determined by conventional radiographs and CT scans. ${ }^{20}$ 


\section{Chapter 3}

Concerning validity (the level of accuracy in diagnosing union), when compared to CT scanning as reference standard, standard scaphoid radiographs are far less sensitive (0.65) and specific (0.67) for diagnosing union of scaphoid waist fractures. ${ }^{21}$

This is in contrast to the findings from a meta-analysis by Yin et al., where high sensitivity (91.1\%) and specificity $(99.8 \%)$ were found for standard scaphoid radiographs, albeit for the diagnosis of suspected scaphoid fractures, not fracture union. ${ }^{22}$ Still, the authors of this study also noticed significant between-study heterogeneity regarding sensitivity, most likely as a result of poor inter-observer agreement of follow-up radiographs for the diagnosis of occult scaphoid fractures. However, positive predictive value was high in our study (0.93), while negative predictive value was low (0.22), which means that standard radiographs are accurate in diagnosing union of scaphoid waist fractures at 6 weeks after injury and inaccurate in diagnosing nonunion. Apparently, there is an inverse relationship between reliability and validity in determining union and nonunion of acute scaphoid fractures when using standard radiographic views for evaluation. An improved accuracy comes to the expense of less precision and vice versa.

A number of limitations must be considered when interpreting our results. Union is a physiologically continuous process of bone reconstruction, but there is no commonly accepted cut-off point for union of scaphoid fractures. ${ }^{3}$ Partial consolidation, usually dorsal, could be defined when there is still a gap on 1 of the 4 radiographic views. ${ }^{3}$ This kind of partial union is usually sufficient for most wrist and hand function. ${ }^{3}$ Therefore in our study full consolidation was defined as the presence of union on 3 out of 4 views. Although this definition may be debated, the use of such predefined criteria for union makes reliable assessment between different observers and between different points in time possible.

Presently, CT-scan has been shown to be a more reliable option for determination of the level of union in scaphoid fractures. ${ }^{2,21,23}$ Buijze investigated the inter-observer reliability of CT-scan for determination of union in scaphoid waist fractures, using any degree of bony bridging between fragments as definition of union and demonstrated there was substantial inter-observer agreement $(\kappa=0.660) .{ }^{21}$ Therefore, CT scanning may be more accurate in determining the level of consolidation. Furthermore, CT scanning is more accurate in visualizing translation, distraction, rotation and angulation of displaced scaphoid waist fractures than plain radiographs and therefore has a prominent role in deciding whether scaphoid fractures should be treated operatively or not. ${ }^{24}$ However, Farnell and Dickson emphasized the practical problems of performing a CT-scan 


\section{Accuracy and precision of conventional radiographic examination}

for every patient with a scaphoid fracture, because of higher costs, less availability, and greater radiation exposure compared to standard radiographic examination. ${ }^{1,21}$

We conclude that conventional radiographic imaging is accurate and moderately reliable in diagnosing scaphoid waist fracture union, but reliable in diagnosing nonunion at 6 weeks follow-up, although it lacks accuracy for the diagnosis of nonunion at this time frame in treatment. Because the majority of undisplaced scaphoid waist fractures heal without any complications, we do not feel there is a role for early routine CT evaluation of the healing process in every scaphoid waist fracture; however it may be part of a diagnostic strategy in selected cases for prevention of unnecessary long immobilization. ${ }^{21}$ 


\section{Chapter 3}

\section{REFERENCES}

1. Farnell RD. The assessment and management of acute scaphoid fractures and nonunion. Orthopaedics and Trauma 2010;24.

2. Hackney LA, Dodds SD. Assessment of scaphoid fracture healing. Current reviews in musculoskeletal medicine 2011;4:16-22.

3. Dias JJ. Definition of union after acute fracture and surgery for fracture nonunion of the scaphoid. J Hand Surg Br 2001;26:321-5.

4. Dias JJ, Taylor M, Thompson J, Brenkel IJ, Gregg PJ. Radiographic signs of union of scaphoid fractures. An analysis of inter-observer agreement and reproducibility. The Journal of bone and joint surgery British volume 1988;70:299-301.

5. Singh HP, Forward D, Davis TR, Dawson JS, Oni JA, Downing ND. Partial union of acute scaphoid fractures. J Hand Surg Br 2005;30:440-5.

6. Rhemrev SJ, van Leerdam RH, Ootes D, Beeres FJ, Meylaerts SA. Non-operative treatment of non-displaced scaphoid fractures may be preferred. Injury 2009;40:638-41.

7. Alshryda S, Shah A, Odak S, Al-Shryda J, Ilango B, Murali SR. Acute fractures of the scaphoid bone: Systematic review and meta-analysis. Surgeon 2012;10:218-29.

8. Desai VV, Davis TR, Barton NJ. The prognostic value and reproducibility of the radiological features of the fractured scaphoid. J Hand Surg Br 1999;24:586-90.

9. Bond CD, Shin AY, McBride MT, Dao KD. Percutaneous screw fixation or cast immobilization for nondisplaced scaphoid fractures. The Journal of bone and joint surgery American volume 2001;83-A:483-8.

10. Mack GR, Bosse MJ, Gelberman RH, Yu E. The natural history of scaphoid non-union. The Journal of bone and joint surgery American volume 1984;66:504-9.

11. Russe O. Fracture of the carpal navicular. Diagnosis, non-operative treatment, and operative treatment. The Journal of bone and joint surgery American volume 1960;42-A: 759-68.

12. Rhemrev SJ, Beeres FJ, van Leerdam RH, Hogervorst M, Ring D. Clinical prediction rule for suspected scaphoid fractures: A prospective cohort study. Injury 2010;41:1026-30.

13. Ford DJ, Khoury G, el-Hadidi S, Lunn PG, Burke FD. The Herbert screw for fractures of the scaphoid. A review of results and technical difficulties. J Bone Joint Surg Br 1987;69: 124-7.

14. Dias JJ, Brenkel IJ, Finlay DB. Patterns of union in fractures of the waist of the scaphoid. The Journal of bone and joint surgery British volume 1989;71:307-10.

15. Mallee WH, Veltman ES, Doornberg JN, Blankevoort L, van Dijk CN, Goslings JC. [Variations in management of suspected scaphoid fractures]. Ned Tijdschr Geneeskd 2012;156: A4514.

16. Tingberg A, Eriksson F, Medin J, et al. Inter-observer variation in masked and unmasked images for quality evaluation of clinical radiographs. Radiation protection dosimetry 2005; 114:62-8. 


\section{Accuracy and precision of conventional radiographic examination}

17. Fleiss JL. Meassuring nominal scale agreement among many raters. Psychological bulletin 1971;76:378-82.

18. Landis JR, Koch GG. The measurement of observer agreement for categorical data. Biometrics 1977;33:159-74.

19. Clay NR, Dias JJ, Costigan PS, Gregg PJ, Barton NJ. Need the thumb be immobilised in scaphoid fractures? A randomised prospective trial. The Journal of bone and joint surgery British volume 1991;73:828-32.

20. Buijze GA, Guitton TG, van Dijk CN, Ring D. Training improves interobserver reliability for the diagnosis of scaphoid fracture displacement. Clin Orthop Relat Res 2012;470: 2029-34.

21. Buijze GA, Wijffels MM, Guitton TG, Grewal R, van Dijk CN, Ring D. Interobserver reliability of computed tomography to diagnose scaphoid waist fracture union. The Journal of hand surgery 2012;37:250-4.

22. Yin ZG, Zhang JB, Kan SL, Wang XG. Diagnostic accuracy of imaging modalities for suspected scaphoid fractures: meta-analysis combined with latent class analysis. The Journal of bone and joint surgery British volume 2012;94:1077-85.

23. Ring $\mathrm{D}$, Jupiter JB, Herndon JH. Acute fractures of the scaphoid. The Journal of the American Academy of Orthopaedic Surgeons 2000;8:225-31.

24. Dias JJ, Singh HP. Displaced fracture of the waist of the scaphoid. The Journal of bone and joint surgery British volume 2011;93:1433-9. 


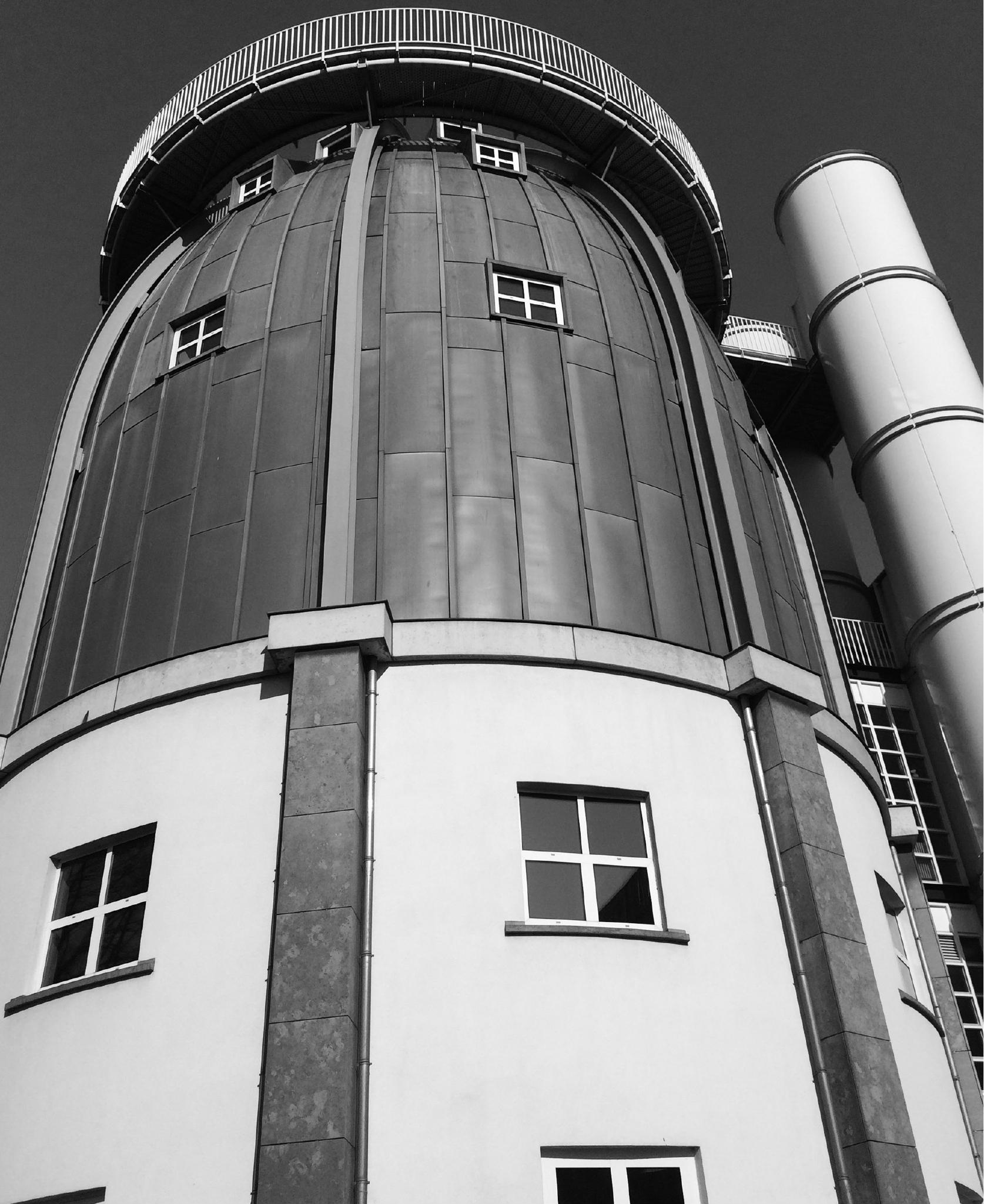




\section{Chapter 4}

\section{MULTIPLANAR RECONSTRUCTION COMPUTED TOMOGRAPHY FOR DIAGNOSIS OF SCAPHOID WAIST FRACTURE UNION: A PROSPECTIVE COHORT ANALYSIS OF ACCURACY AND PRECISION}

Hannemann PFW

Brouwers L

Van der Zee D

Stadler A

Göttgens KWA

Weijers R

Poeze M

Brink PRG

Skeletal Radiol. 2013 Oct;42(10):1377-82 


\section{Chapter 4}

\section{Abstract}

Our objective was to examine reliability and validity concerning union of scaphoid fractures determined by multiplanar reconstruction computed tomography randomized at 6, 12 and 24 weeks after injury.

We used Fleiss' kappa to measure the opinions of three observers reviewing 44 sets of computed tomographic scans of 44 conservatively treated scaphoid waist fractures. We calculated kappa for the extent of consolidation $(0-24 \%$, $25-49 \%, 50-74 \%$ or $75-100 \%$ ) on the transverse, sagittal and coronal views. We also calculated kappa for no union, partial union and union, and grouped the results for 6, 12 and 24 weeks after injury. As the reference standard for union, CT scans were performed at a minimum of 6 months after injury to determine validity.

Overall inter-observer agreement was found to be moderate $(\kappa=0.576)$. No union $(\kappa=0.791)$, partial union $(\kappa=0.502)$ and union $(\kappa=0.683)$ showed substantial, moderate and substantial agreement respectively. The average sensitivity of multiplanar reconstruction CT for diagnosing union of scaphoid waist fractures was $73 \%$. The average specificity was $80 \%$.

Our results suggest that multiplanar reconstruction computed tomography is a reliable and accurate method for diagnosing union or nonunion of scaphoid fractures. However, inter-observer agreement was lower with respect to partial union. 


\section{INTRODUCTION}

Fractures of the scaphoid, being the most commonly fractured carpal bone, represent $2-6 \%$ of all fractures and typically occur in young and active patients. ${ }^{1}$ The majority of undisplaced scaphoid fractures will heal within 8 weeks if treated in a cast. ${ }^{2}$ However, immobilization up to 12 weeks is not uncommon in undisplaced scaphoid waist fractures, due to difficulties identifying the extent of radiological consolidation using conventional radiographic imaging techniques. ${ }^{2-4}$ For example, Dias et al. demonstrated poor inter-observer reliability in diagnosing union on standard scaphoid radiographs 12 weeks after injury. ${ }^{5}$

Nowadays, computed tomography has proven to be a better option for determining union in scaphoid fractures. ${ }^{6-8}$ Scanning along the longitudinal axis of the scaphoid and multiplanar reconstructions of sagittal and coronal views has been demonstrated to be more accurate than conventional radiography in assessing scaphoid fracture union and displacement. ${ }^{9-11}$ However, to date, the evidence promoting the use of $\mathrm{CT}$ scanning in the assessment and quantification of union amounts to only two published studies concerning undisplaced scaphoid fractures and one published study concerning displaced scaphoid fractures. ${ }^{8,12,13}$ Furthermore, CT imaging of the scaphoid to identify occult fractures and evaluate the healing process is still not common practice. ${ }^{14}$

We hypothesized that multiplanar reconstruction computed tomography can both accurately and reliably diagnose scaphoid waist fracture union. Therefore, in addition to determining inter-observer reliability (precision), in this study the accuracy (or validity) of multiplanar reconstruction computed CT for the diagnosis of union was compared to the reference standard in a pool of patients with acute scaphoid waist fractures.

\section{MAterial AND METHODS}

All adult patients aged over 18 presenting in one medical center in the Netherlands with a unilateral undisplaced and minimally displaced scaphoid waist fracture between November 2009 and February 2012 were prospectively included in the study. Approval was obtained from the medical ethical committee of the participating center and written informed consent for participation and registration of the data was obtained from all patients. 


\section{Chapter 4}

The presence of a scaphoid fracture was determined by a combination of physical and radiographic examination. If no apparent fracture line was seen on the initial X-rays (scaphoid series), a CT scan was performed within 5 days of trauma to confirm the diagnosis. Based on the initial radiographs and CT scans, we classified all fractures according to the Herbert classification. ${ }^{15}$ All fractures were treated conservatively in a lower arm cast with the first metacarpal and proximal phalanx immobilized. In each patient, CT scans of the fractured scaphoid were performed at 6,12 and 24 weeks after injury. These three different follow-up points allowed for good visualization of the consolidation process. We randomized the inclusion of one CT scan at one of the three time points (6,12 or 24 weeks) for each patient to quantify the extent of union, as described by Singh et al. ${ }^{16}$ Of the CT scans ultimately reviewed, 14 were taken at 6 weeks, 17 at 12 weeks and 13 at 24 weeks after injury.

The CT scans were obtained using three comparable scanners (Brilliance 64, Philips Healthcare ${ }^{\circledR}$, Eindhoven, the Netherlands; Definition Flash, Siemens ${ }^{\circledR}$, Erlangen, Germany; Sensation 16, Siemens ${ }^{\circledR}$, Forchheim, Germany). The technique described by Sanders was used ${ }^{10}$, in which the patient lies prone on the table with the arm overhead and the forearm crossing the gantry of the CT unit at a $45^{\circ}$ angle. The hand is placed flat on the table, with the wrist in neutral position in the lower arm fiberglass cast. A set of scans consisted of the $1.0 \mathrm{~mm}$ source transverse images and sagittal- and coronal multiplanar reconstructions (MPR) in the central longitudinal axis of the scaphoid with contiguous slice thickness as described by Sanders et al. ${ }^{10}$ Observers were able to view all images and multiplanar reconstructions on high-definition medical-diagnostic displays. Multiplanar reconstruction CT scans were performed at a minimum of 6 months after injury to confirm or exclude union. The current consensus reference standard for union of scaphoid waist fractures is the presence of trabecular bridging on CT obtained at least 6 months after injury. ${ }^{17,18}$ The reference standard for nonunion is a persistent gap across the whole fracture site with no signs of restoration of the trabecular bone pattern on a CT scan obtained at least at 6 to 12 months after the initial CT scan. ${ }^{17,18}$

The three observers were a senior consultant in orthopedic trauma surgery, a senior musculoskeletal radiologist and a senior radiology resident with a special interest in musculoskeletal radiology. We presented each observer with 44 randomized sets of computed tomography views from the patients included, labeled 1 to 44 . Based on the original transversal views, they were asked to indicate the amount of consolidation $(0-24 \%, 25-49 \%, 50-74 \%$ or $75-100 \%)$ for 
each patient, as described by Singh et al. ${ }^{16}$ The same procedure was performed for the sagittal- and coronal reconstructions. Ultimately, the observers were asked to come up with a final conclusion regarding union (no union, partial union or union) for each patient. Union was defined as continuity of the trabecular pattern across the whole width of the scaphoid. Partial union indicated a visible gap across some of the fracture site, with presence of trabecular bridging in other areas. No union was defined as a visible gap across the whole fracture site with no sign of physiological restoration of bony architecture. ${ }^{16,17}$ Additionally, we asked the observers to come up with a final conclusion regarding union for each patient with only two possible outcomes: union or no union.

After 6 weeks, intra-observer reliability was assessed for the two senior observers (the senior consultant in orthopedic trauma surgery and the senior musculoskeletal radiologist) using the above-mentioned criteria for no union, partial union, and union.

Data were analyzed and expressed in terms of intra- and inter-observer agreement in total and by type of view (transverse, coronal and sagittal). Calculations using Fleiss' kappa were performed with 95\% confidence intervals. Reliability of agreement was assessed between a fixed number of observers who assigned categorical ratings to a number of items. ${ }^{19}$ We interpreted the multi-rater kappa statistics as follows: values of 0.01-0.20 indicated slight agreement, 0.21-0.40 fair agreement, 0.41-0.60 moderate agreement, 0.61-0.80 substantial agreement, and more than 0.80 almost perfect agreement. ${ }^{20}$ Statistical analyses were performed using SPSS (version 18.0; Chicago, Illinois, USA). A statistician was recruited for analysis of the data.

Sample size analysis was conducted to establish the number of observations required. A level of significance of $\alpha=0.05$ was used. Power was set at 0.99 $(1-\beta)$. A sample size of 44 was obtained for an estimated correlation coefficient of 0.61 (substantial agreement) with a confidence interval from 0.382 to 0.768 . Sensitivity, specificity, positive likelihood ratio and negative likelihood ratio for diagnosing union were estimated using 95\% confidence intervals. For the determination of sensitivity, specificity and likelihood ratios, pretest probability of union of scaphoid waist fractures was set at $90 \%$, since nonunion occurs on average in $10 \%$ of patients with scaphoid waist fractures treated conservatively. ${ }^{21}$ 


\section{Chapter 4}

\section{RESULTS}

A total of 48 patients were eligible for inclusion during the study period. Four patients declined to participate, leaving a total of 44 patients with a radiologically proven unilateral scaphoid fracture. The median age of the patients was 44 (range: 19-80 years) of whom 34 (77\%) were male. Patient demographics are presented in table 1. All fractures were diagnosed on initial radiographs performed within 48 hours after trauma. Seventeen patients were classified as having an A2 fracture, 17 a B1 fracture and ten a B2 fracture (Table 1). We determined inter-observer agreement for transverse views and coronal and sagittal reconstructions for all 44 sets of CT scans.

Table 1. PATIENT DEMOGRAPHICS AND CLASSIFICATION OF FRACTURES

\begin{tabular}{llr}
\hline Demographic data & & \\
\hline Sex & $34(77 \%)$ & \\
Male & $10(23 \%)$ & \\
Female & & \\
Median age & 37 (range: 19-80 years) \\
Male & 57 (range: 22-71 years) \\
Female & 44 (range: 19-80 years) \\
Overall & & \\
\hline Herbert classification of scaphoid fractures & A1 Tubercle & 0 \\
\hline Type A (stable acute fractures) & A2 Incomplete waist & 17 \\
& B1 Distal oblique & 17 \\
Type B (unstable acute fractures) & B2 Complete waist & 10 \\
& B3 Proximal pole & 0 \\
& B4 Trans-scaphoid-perilunate & \\
& fracture dislocation of carpus & 0 \\
& Total patients: & 44
\end{tabular}

The observers' final conclusions for all views combined (transversal, coronal and sagittal) regarding no union, partial union, or union showed moderate overall inter-observer agreement $(\kappa=0.576)(95 \% \mathrm{Cl}$ : 0.399-0.753) (Table 2). Interobserver reliability for union and no union showed substantial agreement $(\kappa=0.683$ and 0.791 respectively). The kappa value for partial union was 0.502 , representing moderate agreement. 
Table 2. INTER-OBSERVER AGREEMENT

\begin{tabular}{|c|c|c|c|c|c|}
\hline \multicolumn{6}{|c|}{ All views combined, 3 possible outcomes } \\
\hline No union & & Partial & Union & Overall & $95 \% \mathrm{Cl}$ \\
\hline 0.791 & & 0.502 & 0.683 & 0.576 & $0.399-0.753$ \\
\hline \multicolumn{6}{|c|}{ All views combined, 2 possible outcomes } \\
\hline No union & & & Union & Overall & $95 \% \mathrm{Cl}$ \\
\hline 0.793 & & & 0.793 & 0.699 & $0.529-0.870$ \\
\hline \multicolumn{6}{|c|}{ Transverse views } \\
\hline $0-24 \%$ & $25-49 \%$ & $50-74 \%$ & $75-100 \%$ & Overall & $95 \% \mathrm{Cl}$ \\
\hline 0.699 & 0.243 & 0.260 & 0.549 & 0.458 & $0.277-0.640$ \\
\hline \multicolumn{6}{|c|}{ Coronal reconstructions } \\
\hline $0-24 \%$ & $25-49 \%$ & $50-74 \%$ & $75-100 \%$ & Overall & $95 \% \mathrm{Cl}$ \\
\hline 0.794 & 0.418 & 0.216 & 0.613 & 0.430 & $0.249-0.612$ \\
\hline \multicolumn{6}{|c|}{ Sagittal reconstructions } \\
\hline $0-24 \%$ & $25-49 \%$ & $50-74 \%$ & $75-100 \%$ & Overall & $95 \% \mathrm{Cl}$ \\
\hline 0.797 & 0.361 & 0.075 & 0.637 & 0.512 & $0.319-0.704$ \\
\hline
\end{tabular}

Additionally, we asked the three observers to come up with a final conclusion for all views combined with only two possible outcomes: union or no union. This resulted in a substantial overall inter-observer agreement $(\kappa=0.699$, 95\% Cl: 0.529-0.870). Inter-observer reliability for union and no union showed substantial agreement as well ( $\kappa=0.793$ for union and no union) (Table 2$)$.

Concerning the transverse views, there was moderate agreement $(\kappa=0.458)$ (95\% Cl: $0.277-0.640)$ among the observers (Table 2). No (0-24\%) and full $(75-100 \%)$ consolidation on the transverse views showed substantial $(\kappa=0.699)$ and moderate agreement $(\kappa=0.549)$, respectively. Fair agreement was found for $25-49 \%$ and $50-74 \%$ consolidation ( $\kappa=0.243$ and 0.260 , respectively).

Inter-observer agreement on the coronal reconstructions also showed moderate overall agreement $(\kappa=0.430)(95 \% \mathrm{Cl}$ : $0.249-0.612)$ (Table 2$)$. The observers agreed substantially on $0-24 \%$ and $75-100 \%$ consolidation $(\kappa=0.794$ and 0.613 respectively). Moderate and fair agreement was reached for $25-49 \%$ and $50-74 \%$ consolidation ( $\kappa=0.418$ and 0.216 , respectively).

The observers showed moderate agreement concerning the sagittal reconstructions ( $\kappa=0.512)(95 \% \mathrm{Cl}$ : 0.319-0.704) (Table 2). Substantial agreement was reached for $0-24 \%$ and $75-100 \%$ consolidation $(\kappa=0.797$ and 0.637 respec- 


\section{Chapter 4}

tively) while there was fair and slight agreement for 25-49\% and 50-74\% consolidation ( $\kappa=0.361$ and 0.075 respectively).

Post-hoc analysis was performed for three different follow-up moments (Table 3). Six weeks after injury, the combined inter-observer reliability regarding no union, partial union and union was moderate $(\kappa=0.427)(95 \% \mathrm{Cl}: 0.170-0.684)$; 12 weeks after injury, agreement was again moderate $(\kappa=0.600)(95 \% \mathrm{Cl}: 0.269$ $0.932)$; and 24 weeks after injury substantial agreement was found $(\kappa=0.654)$ (95\% Cl: 0.218-0.999).

Table 3. INTER-OBSERVER AGREEMENT FOR ALL VIEWS COMBINED FOR THREE DIFFERENT FOLLOW-UP MOMENTS.

\begin{tabular}{llllll}
\hline & No union & Partial & Union & Overall & $95 \% \mathrm{Cl}$ \\
\hline 6 weeks & 0.574 & 0.521 & 0.705 & 0.427 & $0.170-0.684$ \\
12 weeks & 0.778 & 0.455 & 0.647 & 0.600 & $0.269-0.932$ \\
24 weeks & 1.000 & 0.312 & 0.620 & 0.654 & $0.218-0.999$
\end{tabular}

The two senior observers were tested again after 6 weeks to determine intraobserver agreement. We measured their final opinions as well as their accuracy in reproducing their original opinions regarding the transverse, coronal, sagittal views. For 37 and 34 of the 44 patients ( $84 \%$ and $77 \%$ respectively), the final conclusion on grading of consolidation was the same. The total intra-observer agreement was therefore substantial $(\kappa=0.672)(95 \% \mathrm{Cl}: 0.368-0.976)$ and moderate $(\kappa=0.525)(95 \% \mathrm{Cl}: 0.271-0.780)$ (Table 4$)$.

Table 4. INTRA-OBSERVER AGREEMENT FOR SENIOR OBSERVERS

\begin{tabular}{llllll}
\hline Final conclusion & No union & Partial & Union & Overall & $95 \% \mathrm{Cl}$ \\
\hline Observer 1 & 1.000 & 0.562 & 0.640 & 0.672 & $0.368-0.976$ \\
Observer 2 & 0.734 & 0.435 & 0.676 & 0.525 & $0.271-0.780$
\end{tabular}

There were five nonunions ( $11 \%$ ). The average sensitivity of multiplanar reconstruction CT for diagnosing union of scaphoid waist fractures was $73 \%(95 \% \mathrm{Cl}$ : $66-79 \%$ ), while the average specificity was $80 \%$ (95\% Cl: $68-92 \%)$. Positive likelihood ratio of multiplanar reconstruction CT for diagnosing union was 3.65 
(95\% Cl: 1.51-6.82) and negative likelihood ratio was 0.34 (95\% Cl: 0.24-0.47). Diagnostic odds ratio was 10.9 (95\% Cl: 3.43-34.3).

\section{Discussion}

The results of this study show that computed tomography can be used reliably to determine union and nonunion of scaphoid waist fractures when scanning in the longitudinal axis of the scaphoid with sagittal and coronal reconstructions from the transverse source images. ${ }^{10,22}$ The related multi-rater kappa statistics could be interpreted as substantial agreement ( $\kappa=0.683$ and 0.791 , respectively). In addition to substantial reliability, computed tomography shows an acceptable degree of accuracy with fairly good diagnostic performance characteristics for determination of scaphoid waist fracture union.

The inter-observer agreement concerning multiplanar reconstruction CT scans for determination of scaphoid fracture union at 12 weeks after injury $(\kappa=0.647)$ was substantially higher in this study than that found by Dias et al. using standard radiographs $(\kappa=0.39) .{ }^{5}$ Our study also showed even better agreement for determination of union at 6 weeks $(\kappa=0.705)$, making multiplanar reconstruction CT a reliable method for determination of union in the first 6-12 weeks after injury. As this study shows, however, computed tomography is less reliable in determining partial consolidation.

In our study, sagittal plane reconstructed images of the scaphoid were superior to the original transverse and coronal plane reconstructed images in determining consolidation. Furthermore, the inter-observer agreement for no $(0-25 \%)$ and full $(75-100 \%)$ consolidation on transverse, coronal and sagittal plane images was substantially better than the agreement for intermediate $(25-49 \%$ and $50-74 \%$ ) consolidation. This shows that it is difficult to determine the extent of partial union on CT scans of the scaphoid.

Observers rated the extent of consolidation of scaphoid fractures on CT scans without knowing whether the scans were taken 6, 12 or 24 weeks after injury. The ratings from the different follow-up times were analyzed separately. The results showed more consensus on the state of consolidation at 12 and 24 weeks after injury compared with 6 weeks after injury. This might support the notion that diagnoses of nonunion should be avoided within 6 months of injury. Dias suggested an interval of up to 1 year after injury to diagnose nonunion, although this timeframe is controversial. ${ }^{17,23}$ 


\section{Chapter 4}

The present results also show that multiplanar reconstruction computed tomography is specific $(80 \%)$ but somewhat less sensitive $(73 \%)$ in diagnosing union of scaphoid waist fractures. This is in accordance with the findings of Buijze et al. ${ }^{8}$ Since most uncomplicated scaphoid waist fractures heal with conservative treatment (in our study 89\%), CT scans are superior in predicting union (positive likelihood ratio 3.65) as compared to predicting nonunion. ${ }^{8,24}$

Our results are subject to certain caveats. Multiplanar reconstruction computed tomographic scans at multiple timepoints to evaluate the fracture-healing process is presently not common practice due to concerns about radiation exposure and costs. ${ }^{8,25}$ Although computerized tomography of the skeleton is associated with substantially elevated radiation exposure, the effective dose is relatively low given the distance of the wrist from the torso. ${ }^{25}$ Buijze et al. demonstrated substantial inter-observer agreement of CT $(\kappa=0.66)$ for determination of scaphoid waist fracture union using exclusively sagittal (single-plane) views. ${ }^{8}$ Our study has shown that additional reconstruction and assessment of all planes improves inter-observer reliability. Fractures parallel to the scanned plane will be detected more easily and accurately using a multiplanar reconstruction technique (Figure 1).
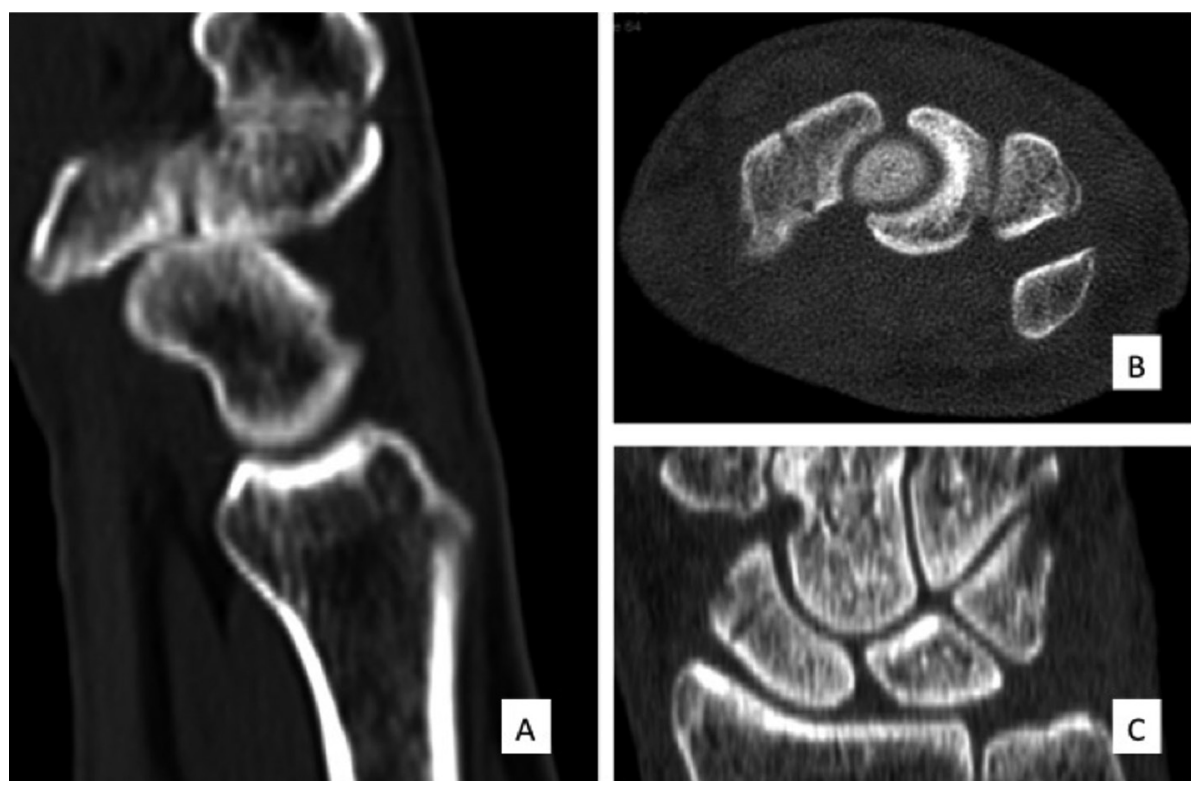

Figure 1. Demonstration of importance of viewing all planes when assessing union of scaphoid waist fractures. A. Sagittal view: no fracture visible. B. Transverse view, same patient: scaphoid waist fracture visible, no full consolidation. C. Coronal view, same patient: scaphoid waist fracture visible, no full consolidation. 
Furthermore, it may be more practical for observers to diagnose union or nonunion only, excluding partial union. Buijze et al., for example, did not use partial union as a separate option. ${ }^{8}$ Since the decision to stop, continue, or alter treatment is based on whether union is observed or not, we also performed an interobserver analysis with union or no union as the only possible outcomes.

However, since the designation 'incomplete consolidation' is used in daily practice, we included partial union in our analysis. Although bony union is a continuous process of bone reconstruction and there is no commonly accepted cut-off point for union of scaphoid fractures, we used an ordinal scale to define complete and partial union. ${ }^{17}$ Dias suggested that, at some stage during the process of bone reconstruction, bony architecture has healed to an extent that most of the previous functions can be performed within the physiological limits of the new bone. ${ }^{17}$ Therefore, it is important to assess the process of bone reconstruction and union as shown in this study. Further investigation is required to differentiate between 'clinically united' (when some function is restored) and radiologically united.

In conclusion, for follow-up after a scaphoid fracture, multiplanar reconstruction computed tomography is a reliable and accurate method to assess union or nonunion of scaphoid fractures. Observers show less agreement with respect to partial union. Still, it is our view that CT scanning should be given a place in early follow-up after scaphoid fractures. 


\section{Chapter 4}

\section{REFERENCES}

1. Tiel-van Buul MM, van Beek EJ, Broekhuizen AH, Bakker AJ, Bos KE, van Royen EA. Radiography and scintigraphy of suspected scaphoid fracture. A long-term study in 160 patients. The Journal of bone and joint surgery British volume 1993;75:61-5.

2. Bond CD, Shin AY, McBride MT, Dao KD. Percutaneous screw fixation or cast immobilization for nondisplaced scaphoid fractures. The Journal of bone and joint surgery American volume 2001;83-A:483-8.

3. Desai VV, Davis TR, Barton NJ. The prognostic value and reproducibility of the radiological features of the fractured scaphoid. J Hand Surg Br 1999;24:586-90.

4. Mack GR, Bosse MJ, Gelberman RH, Yu E. The natural history of scaphoid non-union. The Journal of bone and joint surgery American volume 1984;66:504-9.

5. Dias JJ, Taylor M, Thompson J, Brenkel IJ, Gregg PJ. Radiographic signs of union of scaphoid fractures. An analysis of inter-observer agreement and reproducibility. The Journal of bone and joint surgery British volume 1988;70:299-301.

6. Hackney LA, Dodds SD. Assessment of scaphoid fracture healing. Current reviews in musculoskeletal medicine 2011;4:16-22.

7. Ring D, Jupiter JB, Herndon JH. Acute fractures of the scaphoid. The Journal of the American Academy of Orthopaedic Surgeons 2000;8:225-31.

8. Buijze GA, Wijffels MM, Guitton TG, Grewal R, van Dijk CN, Ring D. Interobserver reliability of computed tomography to diagnose scaphoid waist fracture union. The Journal of hand surgery 2012;37:250-4.

9. Bain GI, Bennett JD, MacDermid JC, Slethaug GP, Richards RS, Roth JH. Measurement of the scaphoid humpback deformity using longitudinal computed tomography: intraand interobserver variability using various measurement techniques. The Journal of hand surgery 1998;23:76-81.

10. Sanders WE. Evaluation of the humpback scaphoid by computed tomography in the longitudinal axial plane of the scaphoid. The Journal of hand surgery 1988;13:182-7.

11. Lozano-Calderon S, Blazar P, Zurakowski D, Lee SG, Ring D. Diagnosis of scaphoid fracture displacement with radiography and computed tomography. The Journal of bone and joint surgery American volume 2006;88:2695-703.

12. Amirfeyz R, Bebbington A, Downing ND, Oni JA, Davis TR. Displaced scaphoid waist fractures: the use of a week $4 \mathrm{CT}$ scan to predict the likelihood of union with nonoperative treatment. The Journal of hand surgery, European volume 2011;36:498-502.

13. Geoghegan JM, Woodruff MJ, Bhatia R, et al. Undisplaced scaphoid waist fractures: is 4 weeks' immobilisation in a below-elbow cast sufficient if a week 4 CT scan suggests fracture union? The Journal of hand surgery, European volume 2009;34:631-7.

14. Mallee WH, Veltman ES, Doornberg JN, Blankevoort L, van Dijk CN, Goslings JC. [Variations in management of suspected scaphoid fractures]. Ned Tijdschr Geneeskd 2012;156:A4514. 


\section{Accuracy and precision of MRCT}

15. Herbert TJ, Fisher WE. Management of the fractured scaphoid using a new bone screw. The Journal of bone and joint surgery American volume 1984;66:114-23.

16. Singh HP, Forward D, Davis TR, Dawson JS, Oni JA, Downing ND. Partial union of acute scaphoid fractures. J Hand Surg Br 2005;30:440-5.

17. Dias JJ. Definition of union after acute fracture and surgery for fracture nonunion of the scaphoid. J Hand Surg Br 2001;26:321-5.

18. Dias JJ, Brenkel IJ, Finlay DB. Patterns of union in fractures of the waist of the scaphoid. The Journal of bone and joint surgery British volume 1989;71:307-10.

19. Fleiss JL. Measuring nominal scale agreement among many raters. Psychological Bulletin 1971;76:378-82.

20. Landis JR, Koch GG. The measurement of observer agreement for categorical data. Biometrics 1977;33:159-74.

21. Raudasoja L, Rawlins M, Kallio P, Vasenius J. Conservative treatment of scaphoid fractures: a follow up study. Ann Chir Gynaecol 1999;88:289-93.

22. Bain GI, Bennett JD, Richards RS, Slethaug GP, Roth JH. Longitudinal computed tomography of the scaphoid: a new technique. Skeletal Radiol 1995;24:271-3.

23. Maudsley RH, Chen SC. Screw fixation in the management of the fractured carpal scaphoid. The Journal of bone and joint surgery British volume 1972;54:432-41.

24. Buijze GA, Doornberg JN, Ham JS, Ring D, Bhandari M, Poolman RW. Surgical compared with conservative treatment for acute nondisplaced or minimally displaced scaphoid fractures: a systematic review and meta-analysis of randomized controlled trials. The Journal of bone and joint surgery American volume;92:1534-44.

25. Biswas D, Bible JE, Bohan M, Simpson AK, Whang PG, Grauer JN. Radiation exposure from musculoskeletal computerized tomographic scans. The Journal of bone and joint surgery American volume 2009;91:1882-9. 
is.

tow

$6+2 x+2$

cisists

cosint

s.t.

atson

(3) $x^{2}+x^{3}$

(3)

2. $-2,+1$

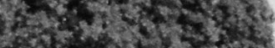

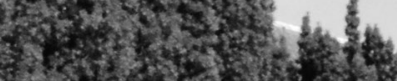

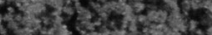

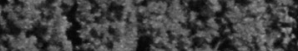

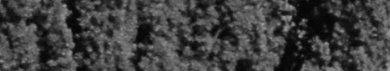
anty ats 5 .

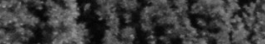

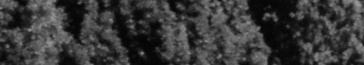

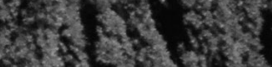
3.

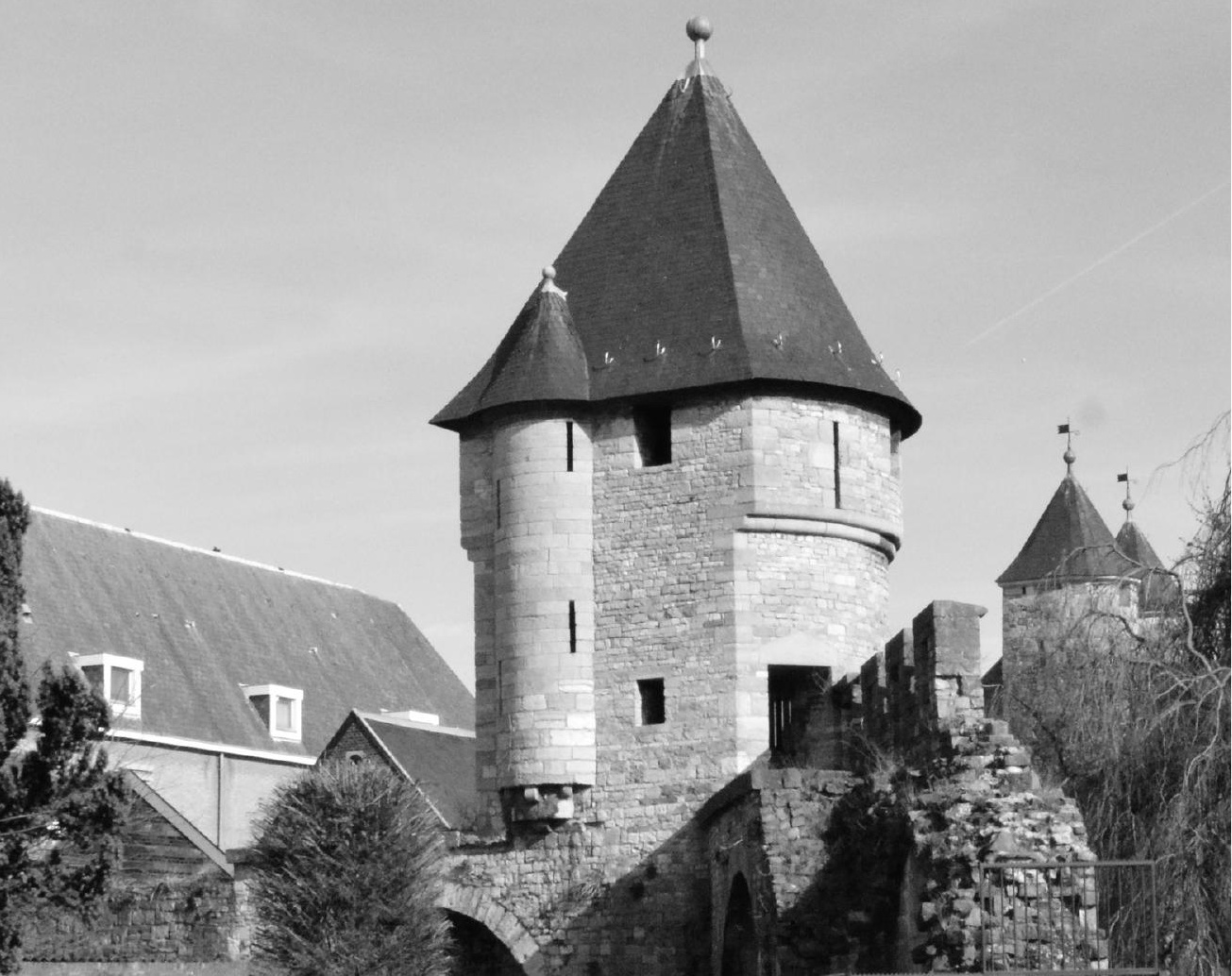

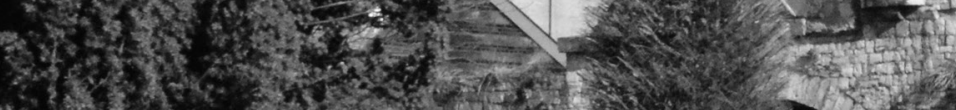
4.3. X.

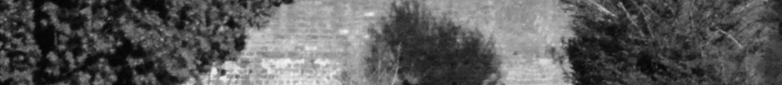

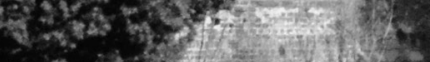

(⿻)

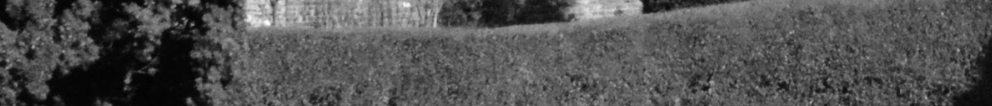

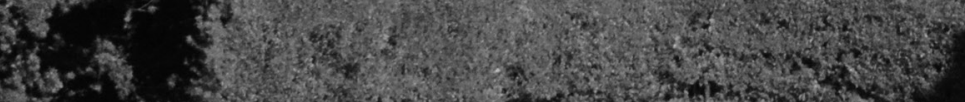
5 ato

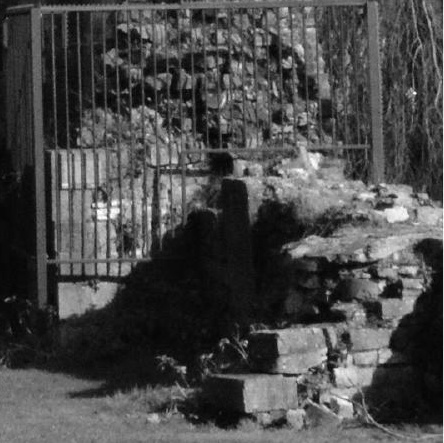




\section{Chapter 5}

\section{CT SCAN-EVALUATED OUTCOME OF PULSED ELECTROMAGNETIC FIELDS IN THE TREATMENT OF ACUTE SCAPHOID FRACTURES: A FOLLOW-UP STUDY}

Hannemann PFW

Van Wezenbeek MR

Kolkman KA

Twiss ELL

Berghmans $\mathrm{CHJ}$

Dirven PAMGM

Brink PRG

Poeze M

Bone Joint J. 2014 Aug;96-B(8):1070-6 


\section{Chapter 5}

\section{Abstract}

We hypothesized that the use of pulsed electromagnetic field (PEMF) bone growth stimulation in acute scaphoid fractures would significantly shorten the time to union and reduce the number of nonunions in a randomized, double-blind, placebo-controlled multicenter trial.

A total of 102 patients ( 78 male, 24 female; mean age 35 years (18 to 77)) from five different medical centers with a unilateral undisplaced acute scaphoid fracture were randomly allocated to PEMF $(n=51)$ or placebo $(n=51)$ and assessed with regard to functional and radiological outcomes (multiplanar reconstructed CT scans) at six, nine, 12, 24 and 52 weeks.

The overall time to clinical and radiological healing did not differ significantly between the active PEMF group and the placebo group.

We concluded that the addition of PEMF bone growth stimulation to the conservative treatment of acute scaphoid fractures does not accelerate bone healing. 


\section{CT scan-evaluated outcome of PEMF}

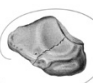

\section{INTRODUCTION}

Fractures of the scaphoid represent $2 \%$ to $6 \%$ of all fractures ${ }^{1}$ and typically occur in active people between 15 and 40 years of age. ${ }^{1,2}$ It has been estimated that up to $22 \%$ of all scaphoid fractures remain undiagnosed..$^{3,4}$ In the Netherlands, 21000 suspected scaphoid fractures occur each year, of which potentially $15 \%$ to $20 \%$ represent actual fractures. ${ }^{2,5}$

Treatment of scaphoid fractures can be conservative using a cast but in some circumstances surgery might be subsequently required. ${ }^{6-8}$ It has been shown that the surgical treatment of Herbert types B1 and B2 ${ }^{9}$ scaphoid fractures leads to earlier return to normal function, work and sports than non-operative treatment. ${ }^{10,11}$ However, there is no evidence to suggest that surgical treatment of all scaphoid fractures leads to a lower rate of nonunion or early osteoarthritis (OA), and discussion about the treatment of undisplaced stable fractures at the waist of the scaphoid remains controversial. ${ }^{12,13}$ Furthermore, the surgical treatment of scaphoid fractures is associated with more complications (including prominent hardware, intra-operative technical difficulties, infection, complex regional pain syndrome, scar-related complications and a higher rate of scaphotrapezial osteoarthritis) than conservative treatment. ${ }^{13,14}$

Electrical bone growth stimulation has been used to promote and accelerate fracture repair. ${ }^{15}$ Recent studies have shown that pulsed electromagnetic field (PEMF) exposure enhances the mineralization of bone and induces differentiation of human bone marrow-derived stromal cells. ${ }^{16} \mathrm{PEMF}$ has been used in the treatment of tibial nonunion. ${ }^{17,18}$ It has also been shown that physical forces such as pulsed ultrasound can be used in the treatment of fresh fractures, so that by 12 weeks after starting therapy, healing has accelerated by $30 \%$ and the rate of nonunion has reduced by $71 \%$ in patients treated with low-intensity pulsed ultrasound (LIPUS). ${ }^{19,20}$

In a recent pilot study, we found that PEMF added limited benefit to the conservative treatment of acute scaphoid fractures. ${ }^{21}$ However, the radiological followup in the pilot study was performed by assessing conventional scaphoid radiographs, which may not always provide reliable and reproducible evidence of healing. ${ }^{22-24} \mathrm{CT}$, however, has been shown to be better at demonstrating union in scaphoid fractures. ${ }^{25-27}$ Furthermore, evidence that the treatment of scaphoid fractures by PEMF and LIPUS may accelerate healing by up to $30 \%$ warranted a larger randomized trial because the number of patients in that study was too 


\section{Chapter 5}

small a cohort either to detect differences in the number of nonunions, or to perform subgroup analyses. ${ }^{19}$ We therefore hypothesized that PEMF would reduce the time to union of scaphoid fractures by up to $30 \%$, while also reducing the incidence of scaphoid nonunion or osteonecrosis as assessed by CT.

\section{Patients and Methods}

This was a randomized multicenter double-blind placebo-controlled trial, for which recruitment took place in five different centers in the Netherlands (Figure 1). Approval was obtained from the relevant local ethics committees and written informed consent for participation was obtained from every patient. All patients $\geq 18$ years of age presenting between 1 January 2010 and 31 December 2011 with a unilateral undisplaced fracture of the scaphoid, Herbert types A1, A2, B1 and B2, were included. ${ }^{9}$ Exclusion criteria were displaced scaphoid fractures;

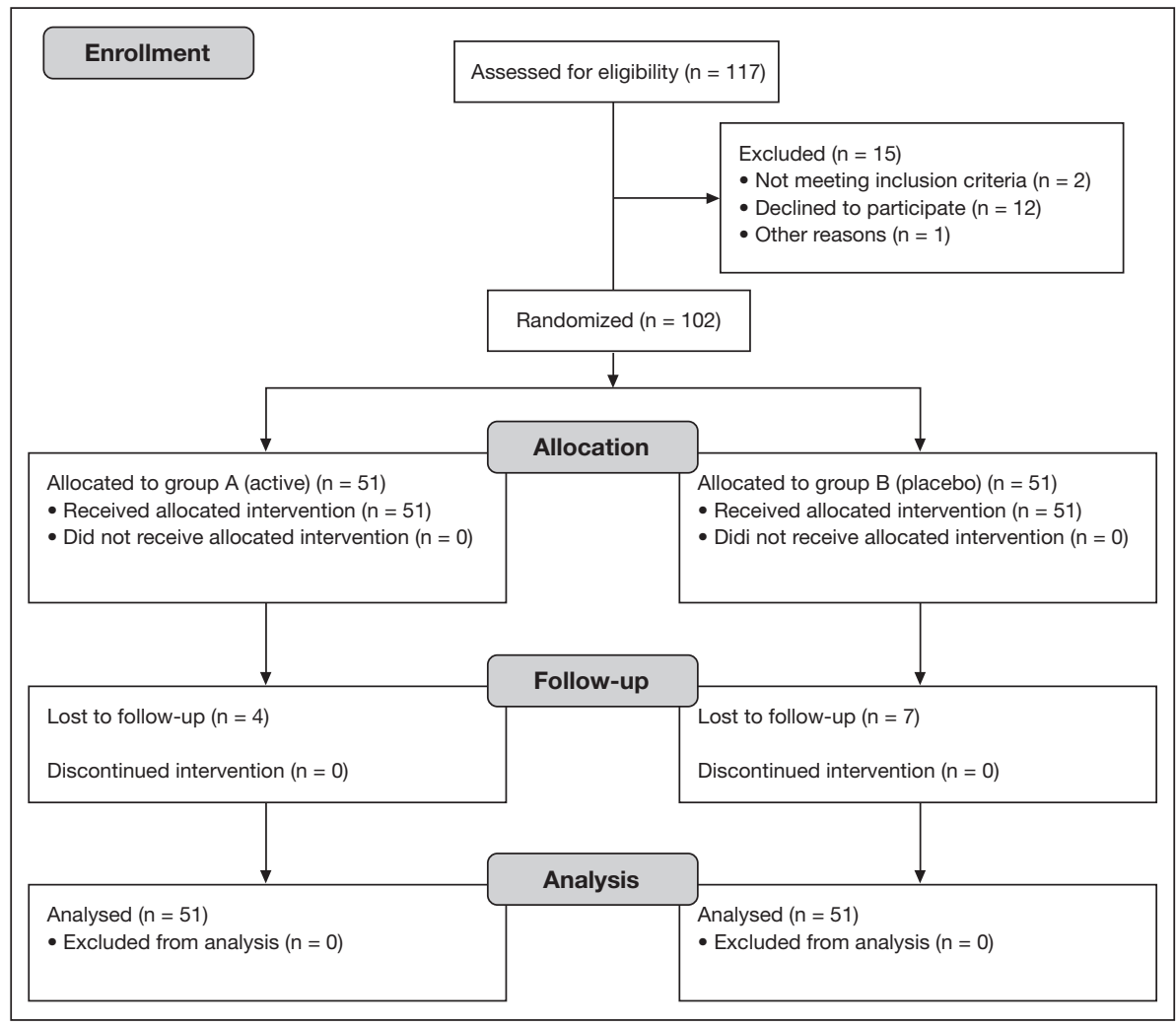

Figure 1. CONSORT flow diagram. 
proximal pole scaphoid fractures (Herbert type B3); fracture dislocations of the carpus or comminuted scaphoid fractures (Herbert type B4 and B5 fractures); presentation more than five days after injury; pregnancy; the presence of a life-supporting implanted electronic device; additional fractures of the wrist, carpal or metacarpal bones and a pre-existing impairment of wrist function.

The diagnosis of a scaphoid fracture was made by a combination of clinical and radiological examinations, which included scaphoid radiographs and CT scans. All fractures were classified according to a CT-based modified Herbert classification. ${ }^{28}$

A total of 117 patients were eligible for inclusion in the study: 12 patients withdrew, two patients had a primary indication for surgery because of the distraction in the fracture, and one patient did not comply to participate in the study due to a mental condition. This left 102 patients (78 male, 24 female; mean age 35 years (18 to 77)) who were included in the study. All fractures were treated with immobilization in a forearm cast with the first metacarpal and proximal phalanx immobilised. Electromagnetic stimulation was administered continuously for 24 hours a day using a PEMF bone growth stimulator (Ossatec ${ }^{\circledR}$, Uden, the Netherlands), which consists of a flexible coil incorporated into the plaster at the site of the fracture in order to ensure the coil could not be easily removed. The coil was attached to a battery-powered signal processor placed on the cast. The signal characteristics of the PEMF device were: pulse amplitude $50 \mathrm{mV}$, pulse width $5 \mu \mathrm{s}$, burst width $5 \mathrm{~ms}$, burst refractory period $62 \mathrm{~ms}$, repetition rate $15 \mathrm{~Hz}$. The attenuation of the PEMF signal through dense materials is limited, making it suitable for placement of coils over or in plaster casts. ${ }^{29}$ Half of the devices were disabled randomly in the factory so that no signal would be produced. Neither the investigators nor the patients were aware of the status of a given device. Treatment allocation was by block randomization, with a block size of four.

After randomization 51 patients (50\%) were placed in group A (active PEMF) and $51(50 \%)$ in group B (placebo) (Figure 1). Table 1 shows the baseline characteristics of both groups. A total of 11 patients were lost to follow-up, four in group A (active PEMF) and seven in group B (placebo). Of these 11, ten were men whose mean age was 28 years (18 to 65). The patients lost to follow-up were comparable to the group that had complete follow-up with regard to hand dominance, fracture type and comorbidities. 


\section{Chapter 5}

Table 1. BASELINE CHARACTERISTICS OF THE PATIENTS

\begin{tabular}{|c|c|c|c|}
\hline Variable & $\begin{array}{l}\text { Group A } \\
\text { (active PEMF) }\end{array}$ & $\begin{array}{l}\text { Group B } \\
\text { (placebo) }\end{array}$ & $p$-value \\
\hline Number & 51 & 51 & \\
\hline Age (years) ${ }^{*}$ & 35 (18 to 70$)$ & 34 (18 to 77$)$ & NS \\
\hline Days between fracture and start of treatment ${ }^{*}$ & 4.25 (0 to 5$)$ & 3.69 (0 to 5) & NS \\
\hline Male $(n, \%)$ & $40(78)$ & $38(75)$ & NS \\
\hline Fracture in dominant hand $(n, \%)$ & $28(55)$ & $29(57)$ & NS \\
\hline Anatomical snuff box tenderness ( $\mathrm{n}, \%$ ) & $46(90)$ & $49(96)$ & NS \\
\hline Pain with longitudinal compression ( $n, \%)$ & $39(77)$ & $45(88)$ & NS \\
\hline \multicolumn{4}{|l|}{ Fracture type ${ }^{28}(\mathrm{n}, \%)$} \\
\hline Tubercle (A1) & $9(18)$ & $9(18)$ & NS \\
\hline Transverse waist, undisplaced (A2) & $19(37)$ & $20(39)$ & NS \\
\hline Oblique (B1) & $15(29)$ & $18(35)$ & NS \\
\hline Transverse waist with distraction (B2) & $8(16)$ & $4(8)$ & NS \\
\hline \multicolumn{4}{|l|}{ Comorbidities (n, \%) } \\
\hline None & $34(67)$ & $38(75)$ & NS \\
\hline Smoking & $16(31)$ & $11(22)$ & NS \\
\hline Osteoporosis & $0(0)$ & $0(0)$ & NS \\
\hline Corticosteroids & $0(0)$ & $1(2)$ & NS \\
\hline Multiple & $1(2)$ & $1(2)$ & NS \\
\hline
\end{tabular}

The patients underwent clinical and radiological examination (including CT scans) at six, nine, 12, 24 and 52 weeks after diagnosis of the fracture. The PEMF device was removed six weeks after the start of treatment.

Clinical examination, which was blinded to the treatment allocation, included assessment of tenderness in the anatomical snuff box (ASB) and pain with longitudinal compression of the scaphoid bone (LC); both these signs needed to be absent for a clinical diagnosis of fracture union. The range of active extension, flexion, radial and ulnar deviation was determined using a handheld goniometer, and the sum was expressed as a proportion of that of the opposite, unaffected wrist. ${ }^{30} \mathrm{~A}$ decrease in range of movement $>25 \%$ was considered to be significant. ${ }^{31}$ Grip strength was measured using a JAMAR dynamometer (Sammons Preston Rolyan, Bolingbrook, Illinois, USA) and expressed as a proportion of the value on the unaffected side. ${ }^{32} \mathrm{~A}$ reduction in strength $>10 \%$ in the injured 
dominant hand or $>20 \%$ in the injured non-dominant hand in comparison with the unaffected side was considered significant. ${ }^{33}$

Radiological healing was assessed by multiplanar reconstructed CT (MRCT) scans using the technique described by Sanders. ${ }^{34} \mathrm{~A}$ set of scans consisted of the $1.0 \mathrm{~mm}$ source transverse images and sagittal and coronal multiplanar reconstructions (MPR) in the central longitudinal axis of the scaphoid, with contiguous slice thickness.

The extent of union was quantified as described by Singh et al. ${ }^{35}$ and judged independently by a musculoskeletal radiologist and an orthopedic trauma surgeon, who were blinded to the treatment allocation. Appearances on all scans were categorized as no union $(0 \%$ to $24 \%$ of the continuity of the trabecular pattern (trabecular bridging) across the whole width of the scaphoid), partial union ( $25 \%$ to $74 \%$ trabecular bridging) or union ( $75 \%$ to $100 \%$ trabecular bridging). ${ }^{35}$

The primary endpoint for this study was clinical and radiological evidence of fracture union. Secondary outcome parameters related to functional outcomes. The minimum, median, maximum and interquartile range (IQR) were calculated for the time to both clinical and radiological union. Nonunion was defined as the absence of fracture healing at 24 weeks' follow-up. ${ }^{22}$

\section{Statistical Analysis}

Power analysis for this study was based on previous research by Mayr et al. ${ }^{19}$ and was conducted with a two-sided significance level (a, type I error) of 0.05 and an assumed power (1-b) of 0.8. This resulted in a sample size of 50 patients per group. Statistical analysis was performed using proprietary statistical software (SPSS version 20.0; SPSS Inc., Chicago, Illinois, USA) with advanced statistics add-on modules. An independent Student's $t$-test was used in the case of normality and the non-parametric Mann-Whitney $U$ test in cases where normality could not be assumed. Categorical data were analyzed using the chi-squared test, or Fisher's exact test if the assumptions for the former test were not met. The cumulative incidence of clinical and radiological evidence of union was estimated using the Kaplan-Meier method with 95\% confidence intervals (Cl) and compared using log-rank analysis. All variables were evaluated for prognostic significance in an extensive regression analysis using Cox's proportional hazards model, with clinical and radiological union as dependent factors. The hazard ratio (HR) and $95 \% \mathrm{Cl}$ were calculated from the regression analysis. 


\section{Chapter 5}

For radiological union, the weighted mean of the interobserver agreement for the two blinded observers (Fleiss' kappa) was calculated for all CT scans. We interpreted the multi-rater kappa statistics as follows: values of 0.01-0.20 indicated slight agreement, 0.21-0.40 fair agreement, 0.41-0.60 moderate agreement, 0.61-0.80 substantial agreement, and more than 0.80 almost perfect agreement.

All patients were analyzed according to the intention-to-treat principle. Posthoc analyses (with Bonferroni correction for multiple imputations) pre-defined to be performed were aimed at finding differences in treatment outcomes for the factors fracture type and hand dominance. Statistical significance was assumed with $p$-values $<0.05$.

\section{Results}

The time to clinical union, based on the proportion of patients from each group reaching the criteria for clinical union, was a median of six weeks (6 to 24, IQR 6 to 9 ) in group A (active PEMF), compared to a median of six weeks (6 to 52, IQR 6 to 9) in group B (placebo). No significant difference in clinical evidence of union was observed during follow-up using log-rank analysis (chi-squared test $=0.03, p=0.69)($ Table 2$)$. The range of movement of the wrist returned to normal at 12 weeks in both groups. No significant differences regarding wrist movement were seen, except at 24 weeks, when wrist movement in group B was

Table 2. CLINICAL ASSESSMENT OF FRACTURE CONSOLIDATION

\begin{tabular}{llll}
\hline Variable & Group A (active) & Group B (placebo) & p-value* \\
\hline Number & 51 & 51 & \\
Anatomical snuff box tenderness ( $\mathrm{n}, \%)$ & & & \\
6 weeks & $14(28)$ & $15(29)$ & 0.82 \\
9 weeks & $9(18)$ & $4(8)$ & 0.28 \\
12 weeks & $6(12)$ & $4(8)$ & 0.74 \\
24 weeks & $6(12)$ & $1(2)$ & 0.11 \\
52 weeks & $2(4)$ & $1(2)$ & 1.00 \\
Pain with longitudinal compression (n, \%) & & & \\
6 weeks & $10(20)$ & $11(22)$ & 0.80 \\
9 weeks & $3(6)$ & $2(4)$ & 1.00 \\
12 weeks & $2(4)$ & $3(6)$ & 0.67 \\
24 weeks & 0 & $1(2)$ & 0.47 \\
52 weeks & $1(2)$ & 0 & 1.00 \\
* $p$-values were calculated using chi-squared tests if possible. Otherwise, Fisher's exact test was used
\end{tabular}


a median of $95 \%(92 \%$ to $98 \%, \mathrm{IQR}=6)$ of that on the non-fractured side compared with $91 \%(87 \%$ to $94 \%, \mathrm{IQR}=7)$ in group A (Table 3$)$. With respect to fractures in the dominant hand (28 (55\%) in group A and 29 (57\%) in group B), grip strength returned to normal levels earlier in group $A$ than in group B. Furthermore, at 12 weeks grip strength was significantly better in group A than in group B (Table 4). There were no significant differences in grip strength between the groups at any time interval for the non-dominant hand (Table 4). For radiological union, the weighted mean interobserver agreement for union $(\kappa=0.683$, $95 \% \mathrm{Cl} 0.473$ to 0.893 ) and nonunion ( $\kappa=0.791,95 \% \mathrm{Cl} 0.599$ to 0.984$)$ for all CT scans was substantial $(\mathrm{p}<0.001) .{ }^{27}$ Using $75 \%$ to $100 \%$ of the continuity of the trabecular pattern across the whole width of the scaphoid as union, there were no significant differences in the amount of radiologically confirmed united scaphoid fractures at any time point (Table 5).

Throughout the follow-up period, log-rank analysis revealed no significant difference in radiological union between the groups (chi-squared test $=0.001$, $\mathrm{p}=0.975)$. The median time to radiologically confirmed union in group $A$ was six weeks (6 to 52, IQR 6 to 12) compared with a median of 12 weeks (6 to 52, IQR 6 to 12$)$ in group $B$, a difference that was not significant $(p=0.30)$. There were four ( $8 \%$ ) radiologically confirmed nonunions in group $A$ and two $(4 \%)$ radiologically confirmed nonunions in group $B(p=0.68)$. However, radiological consolidation was assessed into the three different stages previously outlined, revealing there were no significant differences between the intervention and the placebo group at any of the chosen time points (Table 6).

Table 3. ASSESSMENT OF FUNCTIONAL OUTCOME IN TERMS OF WRIST MOVEMENT.
WRIST MOVEMENT IS DENOTED AS A PERCENTAGE OF WRIST MOVEMENT ON THE
FRACTURED SIDE, COMPARED WITH THE NON-FRACTURED SIDE

\begin{tabular}{|c|c|c|c|}
\hline Variable & Group A (active) & Group B (placebo) & $p$-value* \\
\hline \multicolumn{4}{|c|}{ Wrist movement, fractured side $\left(\%, 95 \% \mathrm{Cl}^{\dagger}\right)$} \\
\hline 6 weeks & 55 (51 to 60$)$ & 59 (53 to 66$)$ & 0.30 \\
\hline 9 weeks & 67 (58 to 76) & 74 (65 to 83) & 0.34 \\
\hline 12 weeks" & 78 (72 to 84$)$ & 81 (73 to 87$)$ & 0.54 \\
\hline 24 weeks & 91 (87 to 94) & 95 (92 to 98$)$ & 0.04 \\
\hline 52 weeks & $97(94$ to 100$)$ & 98 (96 to 101) & 0.44 \\
\hline
\end{tabular}




\section{Chapter 5}

Table 4. ASSESSMENT OF FUNCTIONAL OUTCOME IN TERMS OF GRIP STRENGTH. GRIP STRENGTH IS DENOTED AS A PERCENTAGE OF GRIP STRENGTH ON THE FRACTURED SIDE, COMPARED WITH THE NON-FRACTURED SIDE. A DISTINCTION IS MADE BETWEEN FRACTURES ON THE DOMINANT AND THE NON-DOMINANT SIDE

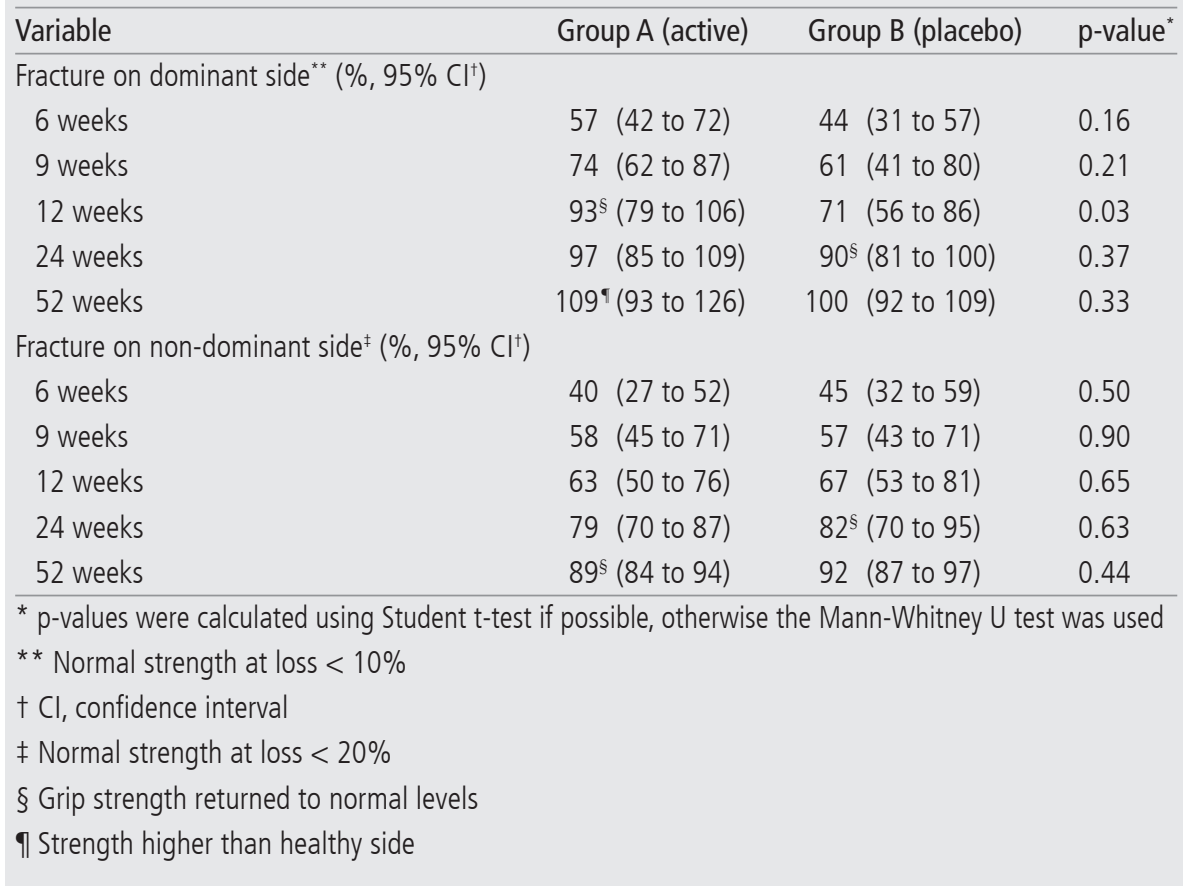

Table 5. ASSESSMENT OF TIME TO RADIOLOGICALLY CONFIRMED FRACTURE UNION

\begin{tabular}{|c|c|c|c|}
\hline Variable & Group A (active) & Group B (placebo) & $p$-value ${ }^{*}$ \\
\hline \multicolumn{4}{|l|}{ Fracture union $(n, \%)^{\dagger}$} \\
\hline 6 weeks & $24(47)$ & $19(37)$ & 0.23 \\
\hline 12 weeks & $14(27)$ & $15(29)$ & 0.51 \\
\hline 24 weeks & $4(8)$ & $6(12)$ & 0.74 \\
\hline 52 weeks & $1(2)$ & $2(4)$ & 1.00 \\
\hline Nonunion & $4(8)$ & $2(4)$ & 0.68 \\
\hline Lost to follow-up (no union observed) & $4(8)$ & $7(14)$ & 0.53 \\
\hline
\end{tabular}




\begin{tabular}{|c|c|c|c|c|}
\hline Variable & No union $(n, \%)$ & Partial union $(n, \%)$ & Union $(n, \%)$ & p-value \\
\hline \multicolumn{5}{|l|}{6 weeks } \\
\hline A (Active) & $10(20)$ & $14(28)$ & $24(47)$ & \multirow[t]{2}{*}{0.73} \\
\hline B (Placebo) & $10(20)$ & $16(31)$ & $19(37)$ & \\
\hline \multicolumn{5}{|l|}{12 weeks } \\
\hline A (Active) & $4(8)$ & $6(12)$ & $38(75)$ & \multirow[t]{2}{*}{0.98} \\
\hline B (Placebo) & $4(8)$ & $5(10)$ & $34(67)$ & \\
\hline \multicolumn{5}{|l|}{24 weeks } \\
\hline A (Active) & $4(8)$ & $2(4)$ & $42(82)$ & \multirow[t]{2}{*}{0.76} \\
\hline B (Placebo) & $2(4)$ & $2(4)$ & $40(78)$ & \\
\hline \multicolumn{5}{|l|}{52 weeks } \\
\hline A (Active) & $4(8)$ & 0 & $43(84)$ & \multirow[t]{2}{*}{0.68} \\
\hline B (Placebo) & $2(4)$ & 0 & $42(82)$ & \\
\hline
\end{tabular}

Of the confounding factors gender, age, hand dominance, comorbidities (smoking, diabetes and use of corticosteroids), fracture type (tubercle, transverse waist, oblique $)^{28}$ and time between fracture and treatment, type of fracture was found to be a significant predictor of union ( $p=0.001$, Cox's proportional hazards model). Specifically, undisplaced transverse waist fractures (type A2) ${ }^{28}$ were found to be a significant confounding factor (odds ratio (OR) $6.2,95 \% \mathrm{Cl} 1.3$ to $8.6 ; \mathrm{p}=0.02)$. Post-hoc log-rank analysis revealed that undisplaced transverse waist fractures proceeded to union significantly earlier in group $A$ than in group B (median 12 weeks ( 6 to 12) versus 52 weeks ( 6 to 52 ), chi-squared test $=4.156, p=0.04)$. However, regarding the minimum required group sample size based on our power analysis, these results should be interpreted with caution, as this analysis is underpowered.

\section{Discussion}

This is the first CT scan-evaluated, randomized prospective double-blind placebocontrolled multicenter trial to investigate the effect of PEMF on time to union and the functional outcomes of acute fractures of the scaphoid. Adams, Frykman and Taleisnik ${ }^{36}$ and Frykman et al. ${ }^{37}$ showed that, more than six months after injury, $69 \%$ to $80 \%$ of ununited scaphoid fractures were healed using PEMF 


\section{Chapter 5}

stimulation and a thumb spica cast. In these studies, even nonunions with evidence of osteonecrosis healed, with success rates of $73 \%$ to $89 \%{ }^{36,37}$ In our study, however, we found no positive effect of adding PEMF to the conservative treatment of acute scaphoid fractures overall.

There are several reasons to consider bone growth stimulation by PEMF. Conservative treatment often leads to a long period of immobilization and absenteeism from work. ${ }^{38}$ Operative treatment for delayed union or nonunion of scaphoid fractures is often initiated months after the injury, with inevitable socioeconomic consequences. ${ }^{38}$ Assiotis, Sachinis and Chalidis ${ }^{39}$ investigated the effectiveness of PEMF in treating delayed unions and nonunions of the tibia and concluded that a rate of union up to $87 \%$ could be achieved.

In a previous study using conventional radiological imaging, we found that there were no significant differences in either clinical or radiological union between PEMF treatment and conservative treatment for scaphoid fractures. ${ }^{21}$ Bony union is a continuous process of bone reconstruction, and there is no commonly accepted cut-off point for union of scaphoid fractures. Dias ${ }^{22}$ suggested that, at some stage during the process of bone reconstruction, bony bridging progresses so that most of the previous functions can be performed within the limits of the newly formed bone, which is why we included partial union in our analysis. However, this category yielded no significant differences between treatment arms.

Post-hoc log-rank analysis revealed a significantly shorter time to union in the active PEMF group for undisplaced transverse fractures of the scaphoid waist. PEMF bone growth stimulation seems to have an accelerating effect on union in stable scaphoid waist fractures. Because unstable fractures are more likely to progress to nonunion ${ }^{40}$, the stability of the fracture pattern may play a crucial role in predicting the effect of PEMF bone growth stimulation in fractures of the scaphoid waist. Since these subgroup analyses were not the primary focus of this study and they are underpowered in relation to the minimum required sample size based on our power analysis, the results of this analysis should be interpreted with caution. We therefore conclude that the addition of PEMF bone growth stimulation to the conservative treatment of acute scaphoid fractures does not accelerate bone healing. 


\section{CT scan-evaluated outcome of PEMF}

\section{RefERENCES}

1. Tiel-van Buul MM, van Beek EJ, Broekhuizen AH, Bakker AJ, Bos KE, van Royen EA. Radiography and scintigraphy of suspected scaphoid fracture. A long-term study in 160 patients. The Journal of bone and joint surgery British volume 1993;75:61-5.

2. Beeres FJ, Rhemrev SJ, Hogervorst M, den Hollander P, Jukema GN. [Scaphoid fractures: diagnosis and therapy]. Ned Tijdschr Geneeskd 2007;151:742-7.

3. Bergh TH, Lindau T, Bernardshaw SV, et al. A new definition of wrist sprain necessary after findings in a prospective MRI study. Injury 2012;43:1732-42.

4. Brydie A, Raby N. Early MRI in the management of clinical scaphoid fracture. The British journal of radiology 2003;76:296-300.

5. Tiel-van Buul MM, Roolker W, Broekhuizen AH, Van Beek EJ. The diagnostic management of suspected scaphoid fracture. Injury 1997;28:1-8.

6. Divelbiss BJ, Adams BD. Electrical and ultrasound stimulation for scaphoid fractures. Hand clinics 2001;17:697-701, x-xi.

7. Rajagopalan BM, Squire DS, Samuels LO. Results of Herbert-screw fixation with bone-grafting for the treatment of nonunion of the scaphoid. The Journal of bone and joint surgery American volume 1999;81:48-52.

8. Raudasoja L, Rawlins M, Kallio P, Vasenius J. Conservative treatment of scaphoid fractures: a follow up study. Ann Chir Gynaecol 1999;88:289-93.

9. Herbert TJ, Fisher WE. Management of the fractured scaphoid using a new bone screw. The Journal of bone and joint surgery British volume 1984;66:114-23.

10. McQueen MM, Gelbke MK, Wakefield A, Will EM, Gaebler C. Percutaneous screw fixation versus conservative treatment for fractures of the waist of the scaphoid: a prospective randomised study. The Journal of bone and joint surgery British volume 2008; 90:66-71.

11. Bond CD, Shin AY, McBride MT, Dao KD. Percutaneous screw fixation or cast immobilization for nondisplaced scaphoid fractures. The Journal of bone and joint surgery American volume 2001;83-A:483-8.

12. Vinnars B, Pietreanu M, Bodestedt A, Ekenstam F, Gerdin B. Nonoperative compared with operative treatment of acute scaphoid fractures. A randomized clinical trial. The Journal of bone and joint surgery American volume 2008;90:1176-85.

13. Ibrahim T, Qureshi A, Sutton AJ, Dias JJ. Surgical versus nonsurgical treatment of acute minimally displaced and undisplaced scaphoid waist fractures: pairwise and network meta-analyses of randomized controlled trials. The Journal of hand surgery 2011;36:175968 e1.

14. Buijze GA, Doornberg JN, Ham JS, Ring D, Bhandari M, Poolman RW. Surgical compared with conservative treatment for acute nondisplaced or minimally displaced scaphoid fractures: a systematic review and meta-analysis of randomized controlled trials. The Journal of bone and joint surgery American volume 2010;92:1534-44. 


\section{Chapter 5}

15. Mollon B, da Silva V, Busse JW, Einhorn TA, Bhandari M. Electrical stimulation for longbone fracture-healing: a meta-analysis of randomized controlled trials. The Journal of bone and joint surgery American volume 2008;90:2322-30.

16. Jansen $\mathrm{JH}$, van der Jagt OP, Punt BJ, et al. Stimulation of osteogenic differentiation in human osteoprogenitor cells by pulsed electromagnetic fields: an in vitro study. BMC musculoskeletal disorders 2010;11:188.

17. Sharrard WJ. A double-blind trial of pulsed electromagnetic fields for delayed union of tibial fractures. The Journal of bone and joint surgery British volume 1990;72:347-55.

18. Ito $\mathrm{H}$, Shirai $\mathrm{Y}$. The efficacy of ununited tibial fracture treatment using pulsing electromagnetic fields: relation to biological activity on nonunion bone ends. J Nippon Med Sch 2001;68:149-53.

19. Mayr E, Rudzki MM, Rudzki M, Borchardt B, Hausser H, Ruter A. [Does low intensity, pulsed ultrasound speed healing of scaphoid fractures?]. Handchir Mikrochir Plast Chir 2000;32:115-22.

20. Heckman JD, Ryaby JP, McCabe J, Frey JJ, Kilcoyne RF. Acceleration of tibial fracturehealing by non-invasive, low-intensity pulsed ultrasound. The Journal of bone and joint surgery American volume 1994;76:26-34.

21. Hannemann PF, Gottgens KW, van Wely BJ, et al. The clinical and radiological outcome of pulsed electromagnetic field treatment for acute scaphoid fractures: A randomised double-blind placebo-controlled multicentre trial. The Journal of bone and joint surgery British volume 2012;94:1403-8.

22. Dias JJ. Definition of union after acute fracture and surgery for fracture nonunion of the scaphoid. J Hand Surg Br 2001;26:321-5.

23. Barton NJ. The late consequences of scaphoid fractures. The Journal of bone and joint surgery British volume 2004;86:626-30.

24. Dias JJ, Taylor M, Thompson J, Brenkel IJ, Gregg PJ. Radiographic signs of union of scaphoid fractures. An analysis of inter-observer agreement and reproducibility. The Journal of bone and joint surgery British volume 1988;70:299-301.

25. Hackney LA, Dodds SD. Assessment of scaphoid fracture healing. Current reviews in musculoskeletal medicine 2011;4:16-22.

26. Buijze GA, Wijffels MM, Guitton TG, Grewal R, van Dijk CN, Ring D. Interobserver reliability of computed tomography to diagnose scaphoid waist fracture union. The Journal of hand surgery 2012;37:250-4.

27. Hannemann PF, Brouwers L, van der Zee D, et al. Multiplanar reconstruction computed tomography for diagnosis of scaphoid waist fracture union: a prospective cohort analysis of accuracy and precision. Skeletal Radiol 2013.

28. Karle B, Mayer B, Kitzinger HB, Frohner S, Schmitt R, Krimmer H. [Scaphoid fracturesoperative or conservative treatment? A CT-based classification]. Handchir Mikrochir Plast Chir 2005;37:260-6. 
29. Zborowski M, Kligman B, Midura RJ, et al. Decibel attenuation of pulsed electromagnetic field (PEMF) in blood and cortical bone determined experimentally and from the theory of ohmic losses. Ann Biomed Eng 2006;34:1030-41.

30. Dias JJ, Wray CC, Jones JM, Gregg PJ. The value of early mobilisation in the treatment of Colles' fractures. The Journal of bone and joint surgery British volume 1987;69:463-7.

31. Roolker W, Maas M, Broekhuizen AH. Diagnosis and treatment of scaphoid fractures, can non-union be prevented? Archives of orthopaedic and trauma surgery 1999;119: 428-31.

32. Hamilton GF, McDonald C, Chenier TC. Measurement of grip strength: validity and reliability of the sphygmomanometer and jamar grip dynamometer. J Orthop Sports Phys Ther 1992;16:215-9.

33. Crosby CA, Wehbe MA, Mawr B. Hand strength: normative values. The Journal of hand surgery 1994; 19:665-70.

34. Sanders WE. Evaluation of the humpback scaphoid by computed tomography in the longitudinal axial plane of the scaphoid. The Journal of hand surgery 1988;13:182-7.

35. Singh HP, Forward D, Davis TR, Dawson JS, Oni JA, Downing ND. Partial union of acute scaphoid fractures. J Hand Surg Br 2005;30:440-5.

36. Adams BD, Frykman GK, Taleisnik J. Treatment of scaphoid nonunion with casting and pulsed electromagnetic fields: a study continuation. The Journal of hand surgery 1992; 17:910-4.

37. Frykman GK, Taleisnik J, Peters G, et al. Treatment of nonunited scaphoid fractures by pulsed electromagnetic field and cast. The Journal of hand surgery 1986;11:344-9.

38. van der Molen AB, Groothoff JW, Visser GJ, Robinson PH, Eisma WH. Time off work due to scaphoid fractures and other carpal injuries in The Netherlands in the period 1990 to 1993. J Hand Surg Br 1999;24:193-8.

39. Assiotis A, Sachinis NP, Chalidis BE. Pulsed electromagnetic fields for the treatment of tibial delayed unions and nonunions. A prospective clinical study and review of the literature. Journal of orthopaedic surgery and research 2012;7:24.

40. Buijze GA, Ochtman L, Ring D. Management of scaphoid nonunion. The Journal of hand surgery 2012;37:1095-100; quiz 101. 


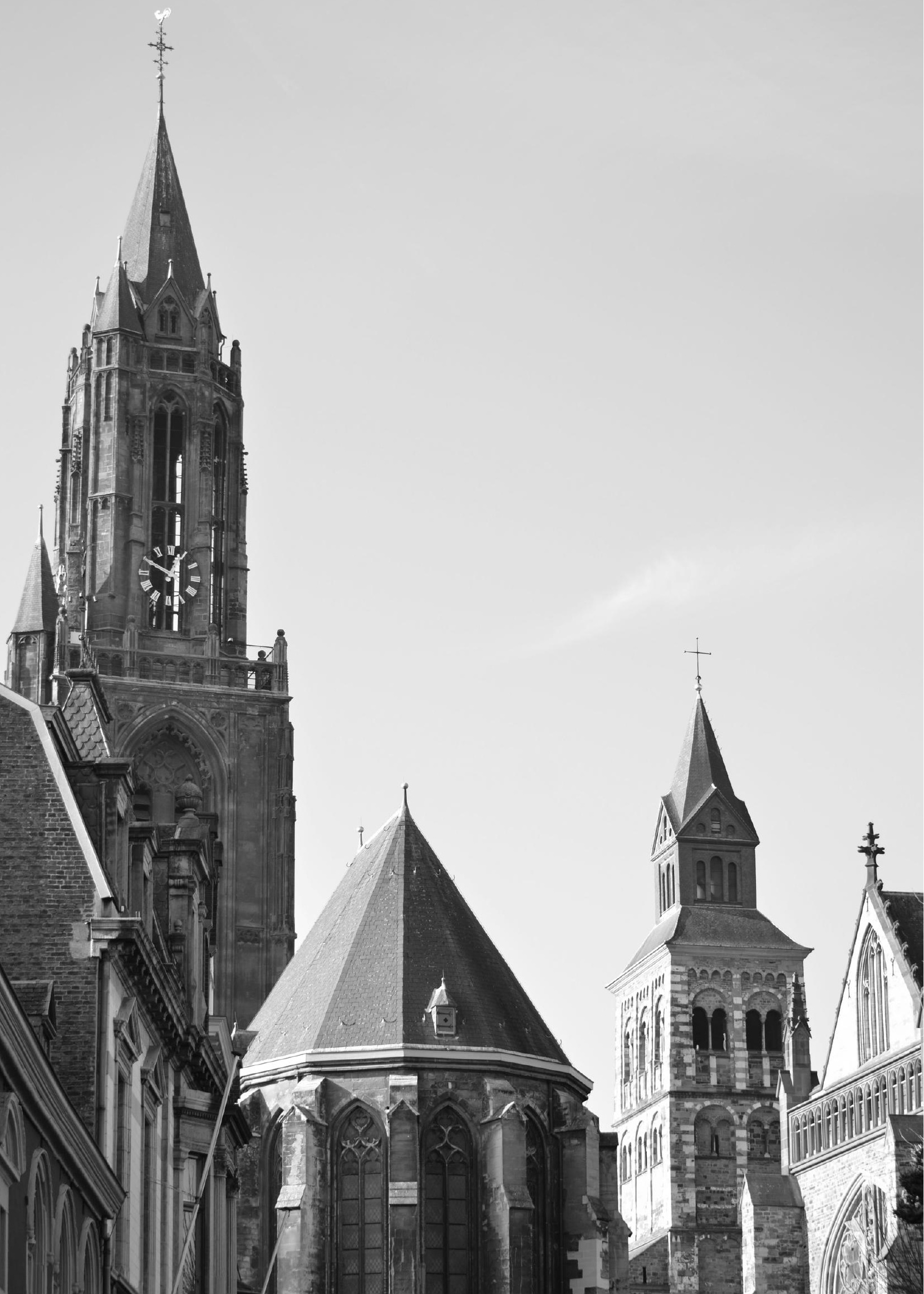




\section{Chapter 6}

\section{FUNCTIONAL OUTCOME AND COST-EFFECTIVENESS OF PULSED ELECTROMAGNETIC FIELDS IN THE TREATMENT OF ACUTE SCAPHOID FRACTURES}

Hannemann PFW

Essers BAB

Schots JPM

Dullaert K

Poeze M

Brink PRG

Submitted 


\section{Chapter 6}

\section{Abstract}

Physical forces have been used widely to stimulate bone growth in fracture repair. Addition of bone growth stimulation to the conservative treatment regime is more costly than standard health care. However, it might lead to cost-savings due to a reduction of the total amount of working days lost. This economic evaluation was performed to assess the cost-effectiveness of Pulsed Electromagnetic Fields (PEMF) compared to standard health care in the treatment of acute scaphoid fractures.

An economic evaluation was carried out from a societal perspective, alongside a double-blind, randomized, placebo-controlled, multicenter trial involving five centers in the Netherlands. One hundred and two patients with a clinically and radiographically proven fracture of the scaphoid were included in the study and randomly allocated to either active bone growth stimulation or standard health care, using a placebo. All costs (medical costs and costs due to productivity loss) were measured during one-year follow up. Functional outcome and general health related quality of life were assessed by the EuroQol-5D and PRWHE (patient rated wrist and hand evaluation) questionnaires. Utility scores were derived from the EuroQol-5D.

The average total number of working days lost was lower in the active PEMF group (9.82 days) compared to the placebo group (12.91 days), although not statistically significant $(p=0.651)$. Total medical costs of the intervention group $(€ 1594)$ were significantly higher compared to the standard health care (€875). The total amount of mean QALY's (quality-adjusted life year) for the active PEMF group was 0.84 and 0.85 for the control group. The cost-effectiveness plane shows that the majority of all cost-effectiveness ratios fall into the quadrant where PEMF is not only less effective in terms of QALY's but also more costly.

This study demonstrates that the desired effects in terms of cost-effectiveness are not met. When comparing the effects of PEMF to standard health care in terms of QALY's, PEMF cannot be considered a cost-effective treatment for acute fractures of the scaphoid bone. 


\section{INTRODUCTION}

The scaphoid has an essential role in proper functionality of the wrist. Fractures of the scaphoid bone are the most common fracture of the carpus, counting for up to $90 \%$ of all carpal fractures and $2 \%-6 \%$ of all fractures in the Netherlands. ${ }^{1,2}$ In Western countries the annual incidence rate of scaphoid fractures is estimated between $2.9-5$ cases per 10.000 inhabitants. ${ }^{3-5}$ Usually, scaphoid fractures are initially diagnosed on conventional radiographs. However, diagnosis of a scaphoid fracture can be challenging, since non- and minimally displaced fractures are often not apparent in first instance on radiographs. Timely diagnosis and accurate follow-up with the use of other diagnostic modalities, like CT-scanning, and appropriate immobilization can decrease the likelihood of occurrence of adverse outcomes like nonunion and early osteoarthritis. ${ }^{1,-9}$ Furthermore, delayed union leads to longer immobilization and prolonged functional deficit. Since mainly the young and working population is affected, prolonged cast immobilization leads to more days of lost at work with socioeconomic consequences. A previous study showed that even uncomplicated healing leads to a mean total of 155 days of lost at work, increasing to 296 days in case of complicated healing, for instance because of nonunion. ${ }^{2}$

Physical forces (low intensity pulsed ultrasound (LIPUS) or pulsed electromagnetic field (PEMF)) have been widely used to accelerate fracture repair in delayed union..$^{10}$ It is thought to reduce osteoclast resorption, to induce osteoid formation and to stimulate angiogenesis. ${ }^{11}$ Evidence has accumulated over the past two decades that physical forces can also be used in the treatment of acute fractures, shortening time to union by $30 \%$ and reducing nonunion within 12 weeks of initiation of therapy by $71 \% .^{12-14}$

Implementation of PEMF to the conservative treatment protocol of scaphoid fractures is more costly compared to standard care. However, it might lead to cost-savings due to a reduction of the total amount of working days lost. Therefore it is necessary to assess whether PEMF stimulation is a cost-effective treatment for acute scaphoid fractures.

This paper reports the results of our economic evaluation, performed alongside a large double-blind, randomized, placebo-controlled, multicenter trial in which the costs and effectiveness of PEMF are compared with standard care in conservatively treated acute fractures of the scaphoid bone. 


\section{Chapter 6}

\section{Patients and Methods}

We performed an economic evaluation alongside a double-blind, randomized, placebo-controlled, multicenter trial involving five centers in the Netherlands, to establish the cost-effectiveness of pulsed electromagnetic fields (PEMF) in the treatment of acute scaphoid fractures. The clinical and radiological outcomes of the trial have been reported in detail elsewhere. ${ }^{15}$

For the economic evaluation we used data from our randomized controlled trial and focused on functional outcome, costs and cost-effectiveness. The time horizon was similar to the clinical study from the moment of inclusion until 12 months follow-up. Approval was obtained from each local ethics committee and written informed consent for participation was obtained from all patients.

\section{Patients}

All patients $\geq 18$ years of age diagnosed between January $1^{\text {st }} 2010$ and December $31^{\text {st }} 2011$ with an acute, unilateral undisplaced fracture of the scaphoid types A1, A2, B1 or B2 according to the Herbert classification ${ }^{16}$, were included in the trial. Exclusion criteria were: displaced scaphoid fractures, proximal pole scaphoid fractures (Herbert type B3), fracture dislocations of the carpus or comminuted scaphoid fractures (Herbert type B4 and B5 fractures), presentation > five days after injury, additional fractures of the wrist, carpal or metacarpal bones, a pre-existing impairment of wrist function, pregnancy and presence of a lifesupporting implanted electronic device. All scaphoid fractures were diagnosed by a combination of physical examination and radiographic imaging (conventional scaphoid series and CT scan) at the time of trauma. All included fractures were classified according to a CT-based modified Herbert classification. ${ }^{17}$ All fractures were treated conservatively with immobilization in a below elbow cast with the first metacarpal and proximal phalanx immobilized. Electromagnetic stimulation was administered continuously for 24 hours a day using a PEMF bone growth stimulator incorporated into the cast (Orthopulse III ${ }^{\circledR}$ PEMF bone growth stimulator, Ossatec ${ }^{\circledR}, U_{\text {den, The Netherlands). The signal characteristics }}$ of the PEMF device used in our study were: pulse amplitude $50 \mathrm{mV}$, pulse width $5 \mu \mathrm{s}$, burst width $5 \mathrm{~ms}$, burst refractory period $62 \mathrm{~ms}$, repetition rate $15 \mathrm{~Hz}$. Half of the PEMF-devices were randomly disabled in the factory. Identical devices and the same follow-up protocol were used for both control and PEMF cases. Neither the investigators nor the patients were aware of the device's functionality. The PEMF device was removed six weeks after the start of treatment. The patients underwent clinical and radiological examination (including multiplanar recon- 
structed CT scans) at 6, 9, 12, 24 and 52 weeks after the start of treatment. In patients with complete clinical and radiological union, the cast was removed at six, 9 or 12 weeks, depending on the time of union.

We hypothesized that PEMF would reduce the time to union by up to $30 \%$ with subsequent shortening of time off work. ${ }^{13}$ Based on this information we conducted a power analysis with a two-sided significance level (alpha, type I error) of 0.05 and an assumed power (1-beta) of 0.8 . This resulted in a total study group of 100 patients, with a sample size of 50 patients per group. ${ }^{18}$

\section{Functional and quality of life outcomes}

All patients were required to fill in three questionnaires at baseline, 6, 9, 12, 24 and 52 weeks after the scaphoid fracture was diagnosed. The Patient Rated Wrist/ Hand Evaluation (PRWHE) was used to assess the level of fracture related functional deficit and pain level from the patient's perspective. The PRWHE is a 15 -item questionnaire that allows patients to rate the level of wrist pain and disability in activities of daily living via a 10-point categorical scale from 0 (no pain/difficulty) to 10 (worst pain ever/unable to do). ${ }^{19}$ The EuroQol-5-D questionnaire was used for quality of life assessment through measurement of the following six dimensions: mobility, self-care, usual activities, pain/discomfort, anxiety/depression and the visual analogue scale (VAS). ${ }^{20}$

\section{Costs}

Costs were collected from the first outpatient visit until 12 months follow up and included all costs in- and outside health care. Cost analysis within health care included costs of the intervention (i.e. device, application and removal of a plaster cast), wrist/scaphoid X-rays, wrist/scaphoid CT-scans, emergency visits and outpatient clinic visits. Real resource use was collected from hospital information systems of the different hospitals. The costs per unit were derived from the financial department of our hospital and the Dutch guidelines for costcalculations in health care. ${ }^{21}$ Diagnostic tests (conventional radiographs and CT-scans) and outpatient clinic visits are more costly in university hospitals; therefore university and general hospital prices were used separately.

Costs concerning outside health care included productivity costs, as measured by the number of working days lost determined at baseline and 12, 24 and 52 weeks after inclusion, by the PRODISQ-questionnaire (PROductivity and DISease Questionnaire). ${ }^{22}$ The costs of productivity loss were calculated by means of the friction cost method, based on the average standardized wages 


\section{Chapter 6}

per hour. ${ }^{21}$ The basic idea of the friction cost method is that the amount of production lost due to disease depends on the time-span organizations need to restore the production at the initial production level. ${ }^{23}$

No discounting was applied, since all data with regard to the costs and effectiveness were collected within one year. All costs are indexed to 2011. Table 1 provides an overview of the costs per unit.

\begin{tabular}{lll} 
Table 1. COSTS PER UNIT & \\
& & \\
\hline Unit & $\begin{array}{l}\text { Cost price in } \\
\text { academic hospital }\end{array}$ & $\begin{array}{l}\text { Cost price in } \\
\text { general hospital }\end{array}$ \\
\hline PEMF device & 665.90 & 665.90 \\
Application of a cast & 31.25 & 31.25 \\
Removal of a cast & 8.71 & 8.71 \\
Wrist / scaphoid conventional radiographs & 39.97 & 24.46 \\
Wrist / scaphoid CT scan & 126.29 & 80.59 \\
Emergency department visit & 154.45 & 154.45 \\
Outpatient clinic visit & 70.06 & 65.46 \\
\hline
\end{tabular}

* Costs are indexed to 2011 and given in Euro

\section{Economic evaluation}

The economic evaluation was performed from a societal perspective and includes a cost-utility analysis. The incremental costs per QALY (quality-adjusted life year), usually interpreted as the additional costs of PEMF to gain one additional QALY compared to standard care, were calculated. A QALY is calculated by multiplying the utility of being in a certain health state by the time a patient experiences that health state. Utility scores were derived from the EuroQol-5D and converted to utility scores by the UK Dolan algorithm. ${ }^{24}$

\section{Statistical methods}

Statistical analysis was performed using proprietary statistical software with advanced statistics add-on modules (SPSS statistical package version 20.0; SPSS inc, 233 S Wacker Drive, Chicago, 60606 Illinois, United States). A statistician blinded from treatment allocation was recruited for analysis of the clinical data. P-values $<0.05$ were considered to indicate statistical significance. In case of normal distribution an independent student's t-test was performed, to compare means between the intervention and control group. The non-parametric Mann- 
Whitney U-test was used in case of ordinal variables and in cases where normality could not be assumed.

In case of missing values, a multiple imputation model was used to analyze and complete the dataset. Missing values were below $30 \%$ for all variables. Multiple imputations for missing values concerning the questionnaires were performed using all baseline characteristics (age, sex, type of fracture, hand dominance and comorbidity) and existing variables of the EuroQol-5D and PRWHE. For each missing value, 5 imputations according to the Bayesian probability rules were performed. In addition, multiple imputations were performed for missing data on the productivity loss, again using all baseline characteristics as stated above. Since cost data generally have a highly skewed distribution, we performed a non-parametric bootstrap analysis (1000 replications) to estimate uncertainty intervals around the difference in mean costs and to quantify the uncertainty surrounding the incremental cost-effectiveness ratio (ICER). ${ }^{25,26}$ The bootstrap analysis was performed in Microsoft Excel. Results of the bootstrap analysis regarding the effectiveness and costs were presented in a cost-effectiveness plane and an acceptability curve. The cost-effectiveness plane is a graphical presentation of four quadrants in which the additional costs and QALY's of a new therapy (active PEMF) are compared to standard care. The cost-effectiveness acceptability curve shows the probability of PEMF being more cost-effective compared to standard care. All patients were analyzed according to the intention-to-treat principle.

\section{RESULTS}

\section{Patients}

A total of 117 patients were eligible for inclusion; 12 patients withdrew, for two patients a primary indication for operation was set and one patient was not mentally fit enough to participate in the study. Therefore, 102 patients with clinical and radiographic diagnosis of a scaphoid fracture were included in the study and randomly allocated to either active PEMF treatment $(n=51)$ or placebo treatment $(n=51)$ (Figure 1). The two groups were similar concerning baseline characteristics (Table 2).

\section{Clinical effect}

Results from our recently published clinical study showed no overall positive effect of adding PEMF to the conservative treatment of acute scaphoid fractures. ${ }^{15}$ However, the use of PEMF in A2 type scaphoid fractures revealed a signi- 


\section{Chapter 6}

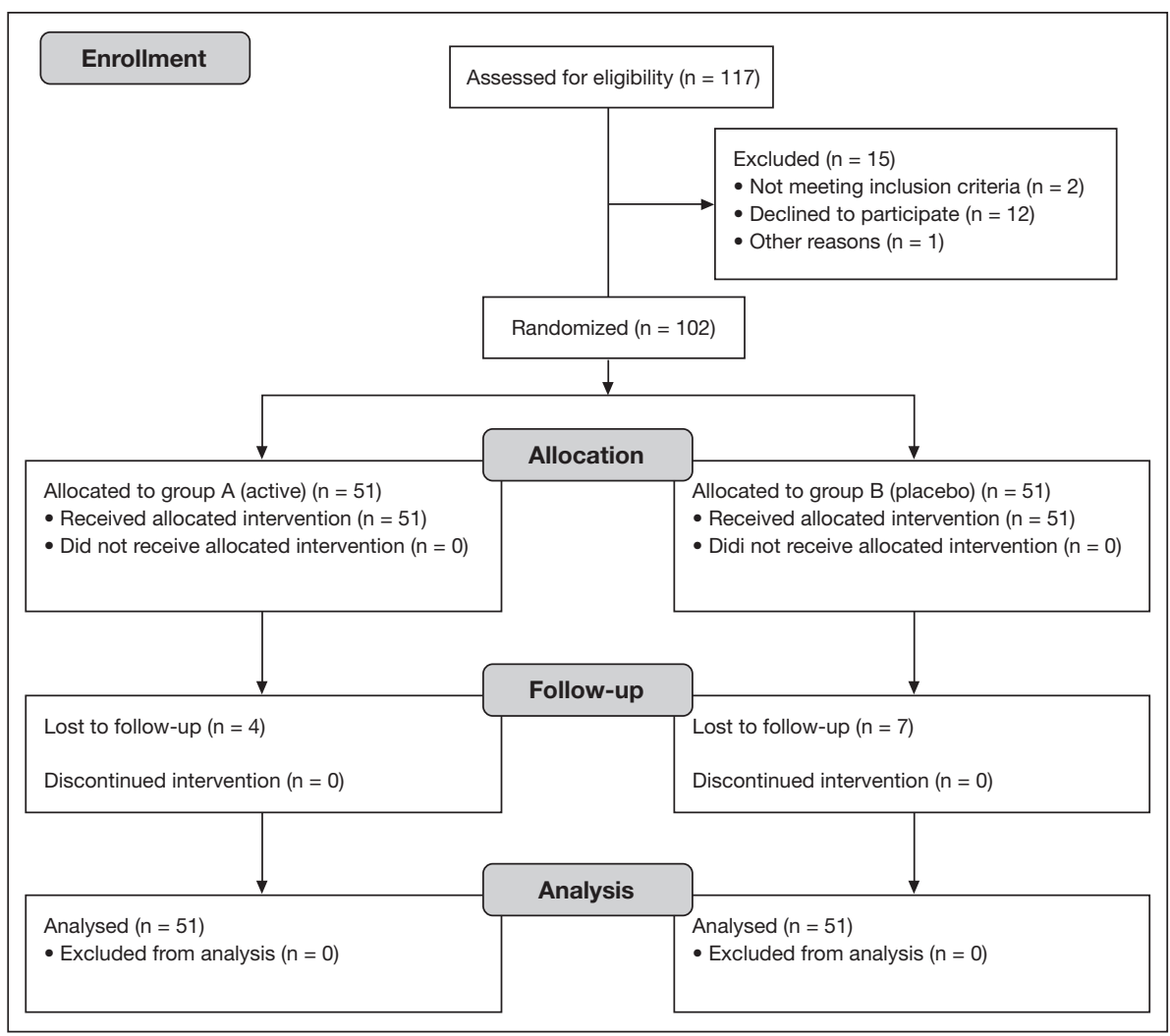

Figure 1. CONSORT flow diagram.

ficantly shorter time to union. ${ }^{15}$ Therefore, PEMF might accelerate union in a well-defined subgroup of stable, undisplaced scaphoid waist fractures.

For the PRWHE no significant differences were found between the active PEMF group and the control group at any of the time points (Table 3). Concerning Self-Care and Anxiety/Depression, both variables of the EuroQol-5D, we found a significant difference at respectively baseline and 24 weeks. For the other variables of the EuroQol-5D there were no significant differences at any of the time points (Table 4).

\section{Costs}

The mean total health care costs per patient were $€ 875$ in the placebo group and $€ 1594$ in the active PEMF group (Table 5). This difference in costs was statistically significant (€719, 95\% Cl €652 to €772) (Table 6) and could be attributed entirely to the use of the PEMF device. 


\begin{tabular}{lll}
\multicolumn{4}{l}{ Table 2. BASELINE CHARACTERISTICS OF THE PATIENTS } \\
\hline Variable & $\begin{array}{l}\text { Group A } \\
\text { (active PEMF) }\end{array}$ & $\begin{array}{l}\text { Group B } \\
\text { (placebo) }\end{array}$ \\
\hline Number & 51 & 51 \\
Age - year* & $35(18-70)$ & $34(18-77)$ \\
Days between fracture and start of treatment* & $4.25(0-5)$ & $3.69(0-5)$ \\
Male (n, \%) & $40(78)$ & $38(75)$ \\
Fracture in dominant hand (n,\%) & $28(55)$ & $29(57)$ \\
Anatomical snuff box tenderness (n, \%) & $46(90)$ & $49(96)$ \\
Pain with longitudinal compression (n, \%) & $39(77)$ & $45(88)$ \\
Fracture type ${ }^{17}$ (n, \%) & & $9(18)$ \\
Tubercle (A1) & $9(18)$ & $20(39)$ \\
Transverse waist, undisplaced (A2) & $19(37)$ & $18(35)$ \\
Oblique (B1) & $15(29)$ & $4(8)$ \\
Transverse waist with distraction (B2) & $8(16)$ & $38(75)$ \\
Comorbidities (n, \%) & & $0(0)$ \\
None & $34(67)$ & $1(2)$ \\
Osteoporosis & $0(0)$ & $1(2)$ \\
Corticosteroids & $0(0)$ & $11(22)$ \\
Multiple & $1(2)$ & \\
Smoking (n, \%) & $16(31)$ & \\
* Variables are denoted as mean (range) & & \\
No significant differences were seen between groups & & \\
& &
\end{tabular}

Concerning productivity loss the average total number of working days lost was lower in the active PEMF group (9.82 days) compared to the placebo group (12.91 days). However, this difference was not statistically significant $(p=0.651)$. When including costs due to productivity loss in the cost-analysis, mean total costs for the active PEMF group are higher ( $€ 2827)$ compared to mean total costs for the standard treatment $(€ 2253)$, although this difference is not statistically significant (difference $=€ 574,95 \% \mathrm{Cl}=€-423$ to $€ 1438$ ) (Table 6).

When excluding patients from the analysis that were student or unemployed (17 in the active PEMF group and 12 in the placebo group, $p=0.27$ ), mean total costs for the active PEMF group are still higher $(€ 3305)$ compared to mean total costs for the standard treatment $(€ 2634)$ (difference $=€ 670,95 \% \mathrm{Cl}=€-405$ to $€ 1732$ ) (Table 7). 


\section{Chapter 6}

Table 3. ASSESSMENT OF FUNCTIONAL OUTCOME ACCORDING TO THE PATIENT-RATED HAND/WRIST EVALUATION (PRWHE)

\begin{tabular}{|c|c|c|c|}
\hline Variable & Group A (active) & Group B (placebo) & $\mathrm{p}$-value \\
\hline \multicolumn{4}{|c|}{ Pain Subscale* (mean, $\left[95 \% \mathrm{Cl}^{* *}\right]$ ) } \\
\hline Baseline & $25.7[21.4 ; 30.0]$ & $26.8[22.7 ; 31.0]$ & 0.708 \\
\hline 6 weeks & $16.0[12.4 ; 19.5]$ & $15.4[11.3 ; 19.4]$ & 0.824 \\
\hline 9 weeks & $14.6[11.1 ; 18.0]$ & $15.4[11.1 ; 19.6]$ & 0.770 \\
\hline 12 weeks & $10.7[7.4 ; 14.0]$ & $10.2[6.6 ; 13.9]$ & 0.851 \\
\hline 24 weeks & $8.3[4.9 ; 11.7]$ & $7.2[4.3 ; 10.1]$ & 0.631 \\
\hline 52 weeks & $4.6[2.1 ; 7.1]$ & $3.7[1.1 ; 6.3]$ & 0.626 \\
\hline \multicolumn{4}{|c|}{ Function Subscale ${ }^{\dagger}$ (mean, $\left.\left[95 \% \mathrm{Cl}^{* *}\right]\right)$} \\
\hline Baseline & $74.3[67.9 ; 81.0]$ & $68.1[59.8 ; 76.3]$ & 0.235 \\
\hline 6 weeks & $52.2[44.3 ; 60.1]$ & $47.5[38.4 ; 56.5]$ & 0.426 \\
\hline 9 weeks & $29.3[21.0 ; 37.6]$ & $34.9[23.5 ; 46.3]$ & 0.411 \\
\hline 12 weeks & $16.6[9.3 ; 23.9]$ & $20.8[12.2 ; 29.3]$ & 0.456 \\
\hline 24 weeks & $8.1[4.0 ; 12.1]$ & $6.42 .1 ; 10.7]$ & 0.569 \\
\hline 52 weeks & $2.8[0.8 ; 4.7]$ & $3.4[0.5 ; 6.2]$ & 0.724 \\
\hline \multicolumn{4}{|c|}{ Total Score ${ }^{\ddagger}$ (mean, $\left[95 \% \mathrm{Cl}^{* *}\right]$ ) } \\
\hline Baseline & $62.9[56.5 ; 69.3]$ & $60.9[53.1 ; 68.7]$ & 0.687 \\
\hline 6 weeks & $42.1[35.5 ; 48.7]$ & $39.1[31.0 ; 47.2]$ & 0.565 \\
\hline 9 weeks & $29.2[22.1 ; 36.4]$ & $32.8[23.4 ; 42.2]$ & 0.531 \\
\hline 12 weeks & $19.0[12.6 ; 25.4]$ & $20.6[13.2 ; 28.0]$ & 0.738 \\
\hline 24 weeks & $12.3[7.1 ; 17.6]$ & $10.4[5.7 ; 15.1]$ & 0.586 \\
\hline 52 weeks & $5.9[2.7 ; 9.2]$ & $5.4[1.5 ; 9.3]$ & 0.832 \\
\hline \multicolumn{4}{|c|}{${ }^{*}$ Best possible outcome (no pain) $=0$, worst possible outcome $=50$} \\
\hline \multicolumn{4}{|c|}{ ** $\mathrm{Cl}$, confidence interval } \\
\hline \multicolumn{4}{|c|}{ † Best possible outcome (no functional disability) $=0$, worst possible outcome $=100$} \\
\hline \multicolumn{4}{|c|}{$\ddagger$ Best possible outcome (no pain \& no functional disability) $=0$, worst possible outcome $=100$} \\
\hline
\end{tabular}

\section{Cost-effectiveness}

The mean QALY was 0.84 for the active PEMF group and 0.85 for the control group, resulting in a non-significant difference of $0.01(95 \% \mathrm{Cl}=-0.01 ; 0.04)$ (Table 8). The cost-effectiveness plane (Figure 2) shows that the majority of all cost-effectiveness ratios ( $85 \%$ ) fall into the north-western quadrant where PEMF is less effective in terms of QALY's and more costly. 
Functional outcome and cost-effectiveness of PEMF

Table 4. ASSESSMENT OF FUNCTIONAL OUTCOME ACCORDING TO THE EUROQOL-5D

\begin{tabular}{|c|c|c|c|}
\hline Variable & Group A (active) & Group B (placebo) & $\mathrm{p}$-value \\
\hline \multicolumn{4}{|c|}{ Mobility* (mean rank**) } \\
\hline Baseline & 49.35 & 43.52 & 0.052 \\
\hline 6 weeks & 43.28 & 39.54 & 0.115 \\
\hline 9 weeks & 39.19 & 38.76 & 0.848 \\
\hline 12 weeks & 38.00 & 37.00 & 0.646 \\
\hline 24 weeks & 37.54 & 36.54 & 0.597 \\
\hline 52 weeks & 36.34 & 34.50 & 0.191 \\
\hline \multicolumn{4}{|c|}{ Self-Care* ${ }^{*}$ mean rank**) } \\
\hline Baseline & 51.34 & 41.44 & 0.039 \\
\hline 6 weeks & 44.51 & 37.22 & 0.111 \\
\hline 9 weeks & 37.24 & 41.22 & 0.340 \\
\hline 12 weeks & 37.42 & 37.58 & 0.960 \\
\hline 24 weeks & 37.00 & 37.00 & 1.00 \\
\hline 52 weeks & 35.29 & 35.00 & 0.359 \\
\hline \multicolumn{4}{|c|}{ Usual activities* (mean rank**) } \\
\hline Baseline & 48.6 & 44.3 & 0.373 \\
\hline 6 weeks & 42.3 & 40.6 & 0.704 \\
\hline 9 weeks & 38.9 & 39.2 & 0.945 \\
\hline 12 weeks & 35.9 & 39.1 & 0.441 \\
\hline 24 weeks & 38.4 & 35.5 & 0.309 \\
\hline 52 weeks & 37.0 & 33.7 & 0.215 \\
\hline \multicolumn{4}{|c|}{ Pain/discomfort* (mean rank**) } \\
\hline Baseline & 49.3 & 43.6 & 0.250 \\
\hline 6 weeks & 44.3 & 38.4 & 0.195 \\
\hline 9 weeks & 39.1 & 37.8 & 0.769 \\
\hline 12 weeks & 39.4 & 35.7 & 0.379 \\
\hline 24 weeks & 40.7 & 33.2 & 0.051 \\
\hline 52 weeks & 37.3 & 33.4 & 0.234 \\
\hline \multicolumn{4}{|c|}{ Anxiety/depression* (mean rank**) } \\
\hline Baseline & 47.8 & 45.1 & 0.339 \\
\hline 6 weeks & 40.9 & 42.2 & 0.625 \\
\hline 9 weeks & 37.8 & 40.5 & 0.251 \\
\hline 12 weeks & 35.5 & 39.5 & 0.091 \\
\hline 24 weeks & 35.0 & 39.1 & 0.038 \\
\hline 52 weeks & 34.4 & 36.8 & 0.229 \\
\hline
\end{tabular}




\section{Chapter 6}

Table 4 continued. ASSESSMENT OF FUNCTIONAL OUTCOME ACCORDING TO THE EUROQOL-5D

\begin{tabular}{|c|c|c|c|}
\hline Variable & Group A (active) & Group B (placebo) & $\mathrm{p}$-value \\
\hline \multicolumn{4}{|c|}{ VAS-score ${ }^{\dagger}$ (mean, $\left.\left[95 \% \mathrm{Cl}^{\ddagger}\right]\right)$} \\
\hline Baseline & $72.5[65.9 ; 79.0]$ & $78.7[73.9 ; 83.4]$ & 0.126 \\
\hline 6 weeks & $78.0[73.8 ; 82.3]$ & $82.6[78.4 ; 86.8]$ & 0.127 \\
\hline 9 weeks & $82.2[78.3 ; 86.1]$ & $82.2[77.2 ; 87.3]$ & 0.987 \\
\hline 12 weeks & $84.8[80.7 ; 89.0]$ & $82.9[77.6 ; 88.3]$ & 0.576 \\
\hline 24 weeks & $88.1[83.9 ; 92.2]$ & $88.7[85.0 ; 92.4]$ & 0.818 \\
\hline 52 weeks & $87.9[84.1 ; 91.8]$ & $90.8[87.0 ; 94.7]$ & 0.282 \\
\hline \multicolumn{4}{|c|}{ * Mann Whitney U test; $p<0.05$} \\
\hline \multicolumn{4}{|c|}{$\begin{array}{l}\text { * Scores are presented as mean rank. The higher the score, the more problems experienced with } \\
\text { activities of daily living } \\
{ }^{\dagger} \text { All variables are denoted as a score between } 0-100 \text {, with } 100 \text { being the best possible outcome } \\
{ }^{\ddagger} \mathrm{Cl} \text {, confidence interval }\end{array}$} \\
\hline
\end{tabular}

Table 5. RESOURCE USE AND COSTS PER TREATMENT ARM

\begin{tabular}{|c|c|c|c|c|}
\hline \multirow[t]{2}{*}{ Variable } & \multicolumn{2}{|c|}{ Group A (active PEMF) } & \multicolumn{2}{|c|}{ Group B (Placebo) } \\
\hline & $\begin{array}{l}\text { Mean } \\
\text { total use (n) }\end{array}$ & $\begin{array}{l}\text { Mean } \\
\text { total costs* }\end{array}$ & $\begin{array}{l}\text { Mean } \\
\text { total use (n) }\end{array}$ & $\begin{array}{l}\text { Mean } \\
\text { total costs* }\end{array}$ \\
\hline PEMF device & 1.0 & 665.90 & 0 & 0 \\
\hline Application of a cast & 2.61 & 81.50 & 2.53 & 79.04 \\
\hline Removal of a cast & 2.61 & 22.71 & 2.53 & 22.03 \\
\hline $\begin{array}{l}\text { Wrist / scaphoid } \\
\text { conventional } \\
\text { radiographs }\end{array}$ & 1.0 & 30.85 & 1.0 & 31.15 \\
\hline Wrist / scaphoid & 2.95 & 276.78 & 2.65 & 255.35 \\
\hline CT scan & 2.95 & 276.78 & 2.65 & 255.35 \\
\hline $\begin{array}{l}\text { Emergency } \\
\text { department visit }\end{array}$ & 1.0 & 154.45 & 1.0 & 154.45 \\
\hline Outpatient clinic visit & 5.12 & 345.46 & 4.69 & 317.23 \\
\hline $\begin{array}{l}\text { Total health care } \\
\text { costs** }\end{array}$ & & $€ 1594$ & & $€ 875$ \\
\hline
\end{tabular}


Table 6. TOTAL COSTS PER TREATMENT ARM

\begin{tabular}{llll}
\hline Variable & $\begin{array}{l}\text { Group A (active PEMF) } \\
\text { mean }\end{array}$ & $\begin{array}{l}\text { Group B (Placebo) } \\
\text { mean total }\end{array}$ & $\begin{array}{l}\text { Difference in costs } \\
{[95 \% \mathrm{Cl}]}\end{array}$ \\
\hline Total health care costs* & $€ 1594$ & $€ 875$ & $€ 719[652 ; 772]$ \\
Costs of productivity los & $€ 1226$ & $€ 1423$ & $€-197[-1158 ; 657]$ \\
Total societal costs*** & $€ 2827$ & $€ 2253$ & $€ 574[-423 ; 1438]$ \\
${ }^{*}$ Costs are denoted in Euro & & \\
${ }^{* *} \mathrm{Cl}$, confidence interval & & \\
${ }^{* * *}$ Numbers do not exactly add up due to the bootstrap analysis &
\end{tabular}

Table 7. TOTAL COSTS PER TREATMENT ARM FOR WORKING PATIENTS ONLY

\begin{tabular}{llll}
\hline Variable & $\begin{array}{l}\text { Group A (active PEMF) } \\
\text { mean }\end{array}$ & $\begin{array}{l}\text { Group B (Placebo) } \\
\text { mean total }\end{array}$ & $\begin{array}{l}\text { Difference in costs } \\
{[95 \% \mathrm{Cl}]}\end{array}$ \\
\hline Total health care costs* & $€ 1543$ & $€ 840$ & $€ 703[637 ; 755]$ \\
Costs of productivity los & $€ 1747$ & $€ 1798$ & $€-51[-1119 ; 975]$ \\
Total societal costs*** & $€ 3305$ & $€ 2634$ & $€ 670[-405 ; 1732]$ \\
\hline${ }^{*}$ Costs are denoted in Euro & & \\
${ }^{* *} \mathrm{Cl}$, confidence interval & & \\
${ }^{* * *}$ Numbers do not exactly add up due to the bootstrap analysis &
\end{tabular}

Table 8. INCREMENTAL COST-EFFECTIVENESS RATIO OF PEMF VS. STANDARD TREATMENT FOR ACUTE SCAPHOID FRACTURES

\begin{tabular}{llll}
\hline & Costs* $^{*}$ & QALY & ICER \\
\hline Group A (Active) & $€ 2827$ & 0.84 & \\
Group B (Placebo) & $€ 2253$ & 0.8545 & \\
Increment & $€ 574$ & -0.0145 & inferior \\
\hline${ }^{*}$ Costs are denoted in Euro & & \\
QALY , quality adjusted life year; ICER, incremental cost-effectiveness ratio &
\end{tabular}




\section{Chapter 6}

When only considering patients with a paid job, the difference in QALY's was in favor of the PEMF group (non-significant difference: 0.01 : $95 \% \mathrm{Cl}=-0.04 ; 0.02$ ) which results in an incremental cost-effectiveness ratio of $€ 113559$ per QALY gained which is unlikely to be considered cost-effective (Table 9). In addition, the cost-effectiveness plane shows that although $64 \%$ of the cost-effectiveness pairs are located in the north-eastern quadrant where active PEMF treatment leads to more effect against more costs, $29 \%$ is situated in the quadrant where PEMF is less effective and more costly (Figure 3 ) The acceptability curve (Figure 4) shows that even for a threshold up to $€ 70000$, there is only a $40 \%$ probability that PEMF is more cost-effective compared to standard care.

\section{DisCUSSION}

Data about the amount of working days lost due to scaphoid fractures is limited. The most detailed source is a previously published prospective study that assessed, among other things, time off work due to carpal injuries in the Netherlands in the period from 1990 to $1993 .{ }^{2}$ In this study the mean total time off work for conservatively treated fractures of the scaphoid was 144 days with a range of 12 to 1353 days. In our trial the mean total number of working days lost was remarkably lower, 9.82 working days in the active PEMF group compared to 12.91 working days lost in the control group with a range of 0 to 190 days. In the study by van der Molen et al. ${ }^{2}$ the majority of the included patients (94\%) performed manual work whereby they needed both hands for their job. Only $2 \%$ of the study population was able to resume their previous job with an immobilized wrist. All 533 patients were off work for at least one day. In contrast, in our study $55 \%$ of the included patients performed manual work and $49 \%$ of the responders with a paid job resumed their jobs immediately with an immobilized wrist and therefore had no working days lost. This suggests that the most important factor influencing time off work among patients with immobilized wrists due to carpal injuries is the patient's occupation. In accordance with other authors, we concluded that non-manual workers had less time off work than manual workers. ${ }^{27}$

The average total number of working days lost was lower in the active PEMF group compared to the placebo group, although not statistically significant. However, we could only retrieve information concerning the number of working days lost in $73 \%$ of the study population. In total, 49 out of 74 patients had no working days lost; 26 out of 39 patients in the active group compared to 23 out of 35 patients in the control group. Since $49 \%$ of the responders with a paid job was able to return to their previous job immediately, and only $11 \%$ was off work 
Table 9. INCREMENTAL COST-EFFECTIVENESS RATIO OF PEMF VS. STANDARD TREATMENT FOR ACUTE SCAPHOID FRACTURES FOR WORKING PATIENTS ONLY

\begin{tabular}{llll}
\hline & Costs* $^{*}$ & QALY & ICER \\
\hline Group A (Active) & $€ 3305$ & 0.8474 & \\
Group B (Placebo) & $€ 2634$ & 0.8415 & \\
Increment & $€ 670$ & 0.0059 & 113559
\end{tabular}

* Costs are denoted in Euro

QALY , quality adjusted life year; ICER, incremental cost-effectiveness ratio

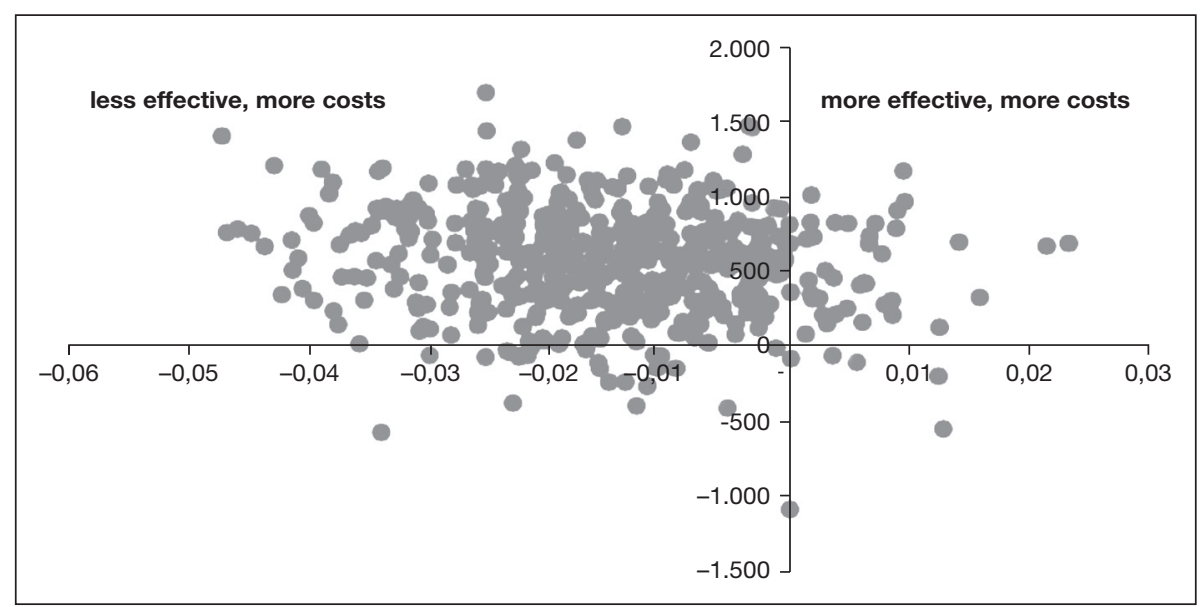

Figure 2. Cost-effectiveness plane for the incremental costs per QALY (based on EuroQol-5D).

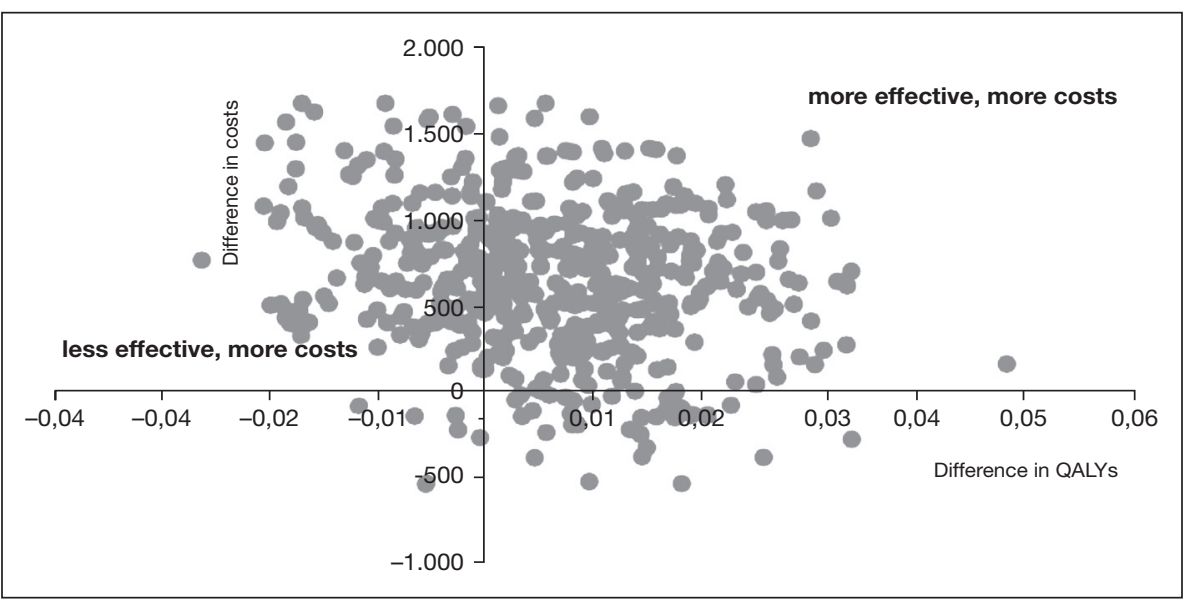

Figure 3. Cost-effectiveness plane for the incremental costs per QALY (based on EuroQol-5D) for working patients only. 


\section{Chapter 6}

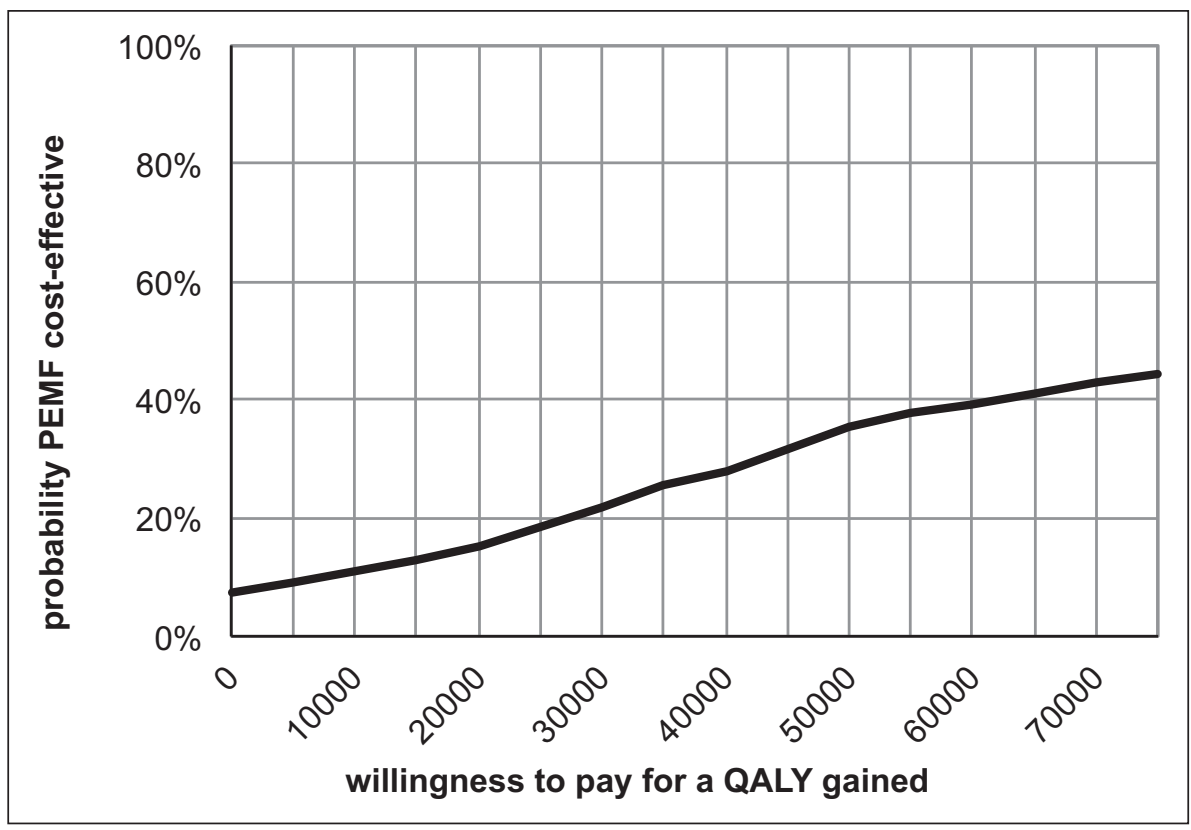

Figure 4. Cost-effectiveness acceptability curve (based on EuroQol-5D) for working patients only.

for more than one month, the costs due to productivity loss were less than we originally expected on basis of previously best available evidence from van der Molen et al. ${ }^{2}$ Moreover, this study was based on data from 1991 to 1993. Properties and demands regarding manual work have changed over this period of almost 20 years.

A number of patients were student or unemployed and therefore not generating a loss in working days in the context of a paid job. Although the difference in unemployed patients between groups was not statistically different $(p=0.27)$, we also calculated costs due to productivity loss and total costs among working patients only. Obviously, the number of working days lost was higher amongst working patients (15.32 days in the PEMF group vs. 18.83 days in the placebo group, $p=0.73$ ) resulting in higher costs due to loss of productivity. However, mean total costs were still higher in the PEMF group. Combining the costs and effects for the subgroup of working patients resulted in an incremental cost-effectiveness ratio of $€ 113559$ per QALY gained which is unlikely to be considered cost-effective given the commonly applied Dutch threshold value of $€ 40000 .{ }^{28}$

Our research group performed the first CT-scan evaluated, double-blind, randomized, placebo-controlled trial to investigate the effect of PEMF bone growth 
stimulation on the time to union, functional outcome and cost-effectiveness of acute fractures of the scaphoid. We found no conclusive evidence supporting the implementation of PEMF stimulation to the conservative treatment regime. ${ }^{15,29}$ As reported in our recently published study concerning the clinical section of the study, the addition of PEMF stimulation to the conservative treatment of acute scaphoid fractures might accelerate union in a well-defined subgroup of stable undisplaced scaphoid waist fractures..$^{15}$ However, it does not improve overall functional and radiological outcomes of conservatively treated scaphoid fractures.

These results are not consistent with the results of former acute fracture studies on the use of electrical bone growth stimulation. Heckman et al. reported in a randomized controlled trial concerning addition of LIPUS to the treatment protocol of acute diaphyseal tibia fractures, a significant decrease in time to union ( $p=0.0001)$ and substantial cost-savings. ${ }^{12}$ Kristiansen et al. compared LIPUS with standard care in non-operatively treated extra-articular distal radius fractures. The time to union was accelerated by 37 days $(p<0.0001)$ and LIPUS treatment was associated with a significantly smaller loss of reduction $(p<0.01) .{ }^{14}$ Mayr et al. reported on acute nondisplaced scaphoid fractures (Herbert B1 and B2) treated with LIPUS. Results showed a significant acceleration of the fracture-healing process by 17 days $(p<0.01)$. Furthermore, there was significantly more trabecular bridging after six weeks in the LIPUS group $(81,2 \%)$ compared to the placebo group $(54,6 \%) .^{13}$

A possible explanation for the difference in clinical outcome compared to previous literature and a limitation of our study may be the large heterogeneity of our study group, since we included different types of scaphoid fractures (Herbert types A1, A2, B1 and B2). Post-hoc log-rank analysis of all data from our recently published clinical study revealed a significantly shorter time to union in the active PEMF group for undisplaced transverse scaphoid waist fractures (Herbert type A2 fractures). ${ }^{15,16}$ PEMF bone growth stimulation seems to have an accelerating effect on union in stable scaphoid waist fractures. Since unstable fractures are more likely to progress to nonunion, we think that stability of the fracture pattern may play a crucial role in predicting the effect of PEMF bone growth stimulation in scaphoid waist fractures. Therefore, electrical bone growth stimulation might be only effective in a well-defined subgroup of stable scaphoid fractures. Future studies should focus on this subgroup of scaphoid fractures to evaluate whether the use of PEMF is clinically effective and therefore justified among patients with this type of fracture. This seems particularly relevant since recent research has shown that the majority of scaphoid waist fractures are undisplaced. ${ }^{30}$ 


\section{Chapter 6}

Concerning the functional outcome as measured by the PRWHE questionnaire and general health related quality of life, as measured by the EuroQol-5D, we found no significant differences between the active PEMF group and the control group. Our cost-effectiveness analysis shows that PEMF stimulation significantly increases treatment costs against no significant improvement of general health related quality of life.

In conclusion, evidence from our clinical trial has not demonstrated sufficient advantage to warrant routine use of PEMF, although PEMF might accelerate union in a well-defined subgroup of stable, undisplaced scaphoid waist fractures. From a societal perspective, we conclude that the desired effects in terms of cost-effectiveness are not met. When comparing the effects of PEMF to placebo expressed in QALY's, PEMF cannot be considered a cost-effective treatment for acute fractures of the scaphoid bone in general. 


\section{Functional outcome and cost-effectiveness of PEMF}

\section{REFERENCES}

1. Tiel-van Buul MM, van Beek EJ, Broekhuizen AH, Bakker AJ, Bos KE, van Royen EA. Radiography and scintigraphy of suspected scaphoid fracture. A long-term study in 160 patients. The Journal of bone and joint surgery British volume 1993;75:61-5.

2. van der Molen AB, Groothoff JW, Visser GJ, Robinson PH, Eisma WH. Time off work due to scaphoid fractures and other carpal injuries in The Netherlands in the period 1990 to 1993. J Hand Surg Br 1999;24:193-8.

3. Hove LM. Epidemiology of scaphoid fractures in Bergen, Norway. Scandinavian journal of plastic and reconstructive surgery and hand surgery / Nordisk plastikkirurgisk forening [and] Nordisk klubb for handkirurgi 1999;33:423-6.

4. Schaefer M, Siebert HR. [Fracture of the semilunar bone]. Der Unfallchirurg 2002;105: 540-52; quiz 52-3.

5. Duckworth AD, Buijze GA, Moran M, et al. Predictors of fracture following suspected injury to the scaphoid. The Journal of bone and joint surgery British volume 2012;94: 961-8.

6. Divelbiss BJ, Adams BD. Electrical and ultrasound stimulation for scaphoid fractures. Hand clinics 2001;17:697-701, x-xi.

7. Raudasoja L, Rawlins M, Kallio P, Vasenius J. Conservative treatment of scaphoid fractures: a follow up study. Ann Chir Gynaecol 1999;88:289-93.

8. Hannemann PF, Brouwers L, van der Zee D, et al. Multiplanar reconstruction computed tomography for diagnosis of scaphoid waist fracture union: a prospective cohort analysis of accuracy and precision. Skeletal radiology 2013;42:1377-82.

9. Rajagopalan BM, Squire DS, Samuels LO. Results of Herbert-screw fixation with bonegrafting for the treatment of nonunion of the scaphoid. The Journal of bone and joint surgery American volume 1999;81:48-52.

10. Mollon B, da Silva V, Busse JW, Einhorn TA, Bhandari M. Electrical Stimulation for Long-Bone Fracture-Healing: A Meta-Analysis of Randomized Controlled Trials. Journal of Bone and Joint Surgery-American Volume 2008;90A:2322-30.

11. Otter MW, McLeod KJ, Rubin CT. Effects of electromagnetic fields in experimental fracture repair. Clinical orthopaedics and related research 1998:S90-S104.

12. Heckman JD, Ryaby JP, McCabe J, Frey JJ, Kilcoyne RF. Acceleration of tibial fracturehealing by non-invasive, low-intensity pulsed ultrasound. The Journal of bone and joint surgery American volume 1994;76:26-34.

13. Mayr E, Rudzki MM, Rudzki M, Borchardt B, Hausser H, Ruter A. [Does low intensity, pulsed ultrasound speed healing of scaphoid fractures?]. Handchirurgie, Mikrochirurgie, plastische Chirurgie: Organ der Deutschsprachigen Arbeitsgemeinschaft fur Handchirurgie: Organ der Deutschsprachigen Arbeitsgemeinschaft fur Mikrochirurgie der Peripheren Nerven und Gefasse 2000;32:115-22. 


\section{Chapter 6}

14. Kristiansen TK, Ryaby JP, McCabe J, Frey JJ, Roe LR. Accelerated healing of distal radial fractures with the use of specific, low-intensity ultrasound. A multicenter, prospective, randomized, double-blind, placebo-controlled study. The Journal of bone and joint surgery American volume 1997;79:961-73.

15. Hannemann PF, van Wezenbeek MR, Kolkman KA, et al. CT scan-evaluated outcome of pulsed electromagnetic fields in the treatment of acute scaphoid fractures: a randomised, multicentre, double-blind, placebo-controlled trial. The bone \& joint journal 2014; 96-B:1070-6.

16. Herbert TJ, Fisher WE. Management of the fractured scaphoid using a new bone screw. The Journal of bone and joint surgery British volume 1984;66:114-23.

17. Karle B, Mayer B, Kitzinger HB, Frohner S, Schmitt R, Krimmer H. [Scaphoid fracturesoperative or conservative treatment? A CT-based classification]. Handchirurgie, Mikrochirurgie, plastische Chirurgie: Organ der Deutschsprachigen Arbeitsgemeinschaft fur Handchirurgie: Organ der Deutschsprachigen Arbeitsgemeinschaft fur Mikrochirurgie der Peripheren Nerven und Gefasse 2005;37:260-6.

18. Hannemann P, Gottgens KW, van Wely BJ, et al. Pulsed Electromagnetic Fields in the treatment of fresh scaphoid fractures. A multicenter, prospective, double blind, placebo controlled, randomized trial. BMC musculoskeletal disorders 2011;12:90.

19. MacDermid JC, Turgeon T, Richards RS, Beadle M, Roth JH. Patient rating of wrist pain and disability: a reliable and valid measurement tool. Journal of orthopaedic trauma 1998;12:577-86.

20. Brooks RG, Jendteg S, Lindgren B, Persson U, Bjork S. EuroQol: health-related quality of life measurement. Results of the Swedish questionnaire exercise. Health Policy 1991;18: 37-48.

21. Hakkaart-van Roijen L, Tan S, Bouwmans C. Handleiding voor kostenonderzoek. Methoden en standaard kostprijzen voor economische evaluaties in de gezondheidszorg Geactualiseerde versie 2010.

22. Koopmanschap MA. PRODISQ: a modular questionnaire on productivity and disease for economic evaluation studies. Expert Rev Pharmacoecon Outcomes Res 2005;5:23-8.

23. Oostenbrink JB, Koopmanschap MA, Rutten FF. Standardisation of costs: the Dutch Manual for Costing in economic evaluations. PharmacoEconomics 2002;20:443-54.

24. Dolan P, Roberts J. Modelling valuations for EQ-5D health states - An alternative model using differences in valuations. Med Care 2002;40:442-6.

25. Briggs AH, Wonderling DE, Mooney CZ. Pulling cost-effectiveness analysis up by its bootstraps: A non-parametric approach to confidence interval estimation. Health economics 1997;6:327-40.

26. Efron B, Tibshirani RJ. An introduction to the bootstrap: CRC press; 1994.

27. Vinnars B, Ekenstam FA, Gerdin B. Comparison of direct and indirect costs of internal fixation and cast treatment in acute scaphoid fractures: a randomized trial involving 52 patients. Acta orthopaedica 2007;78:672-9. 


\section{Functional outcome and cost-effectiveness of PEMF}

28. RVZ. Fair and sustainable care (Zicht op duurzame zorg). Council for Public Health and Health Care (The Hague) 2006.

29. Hannemann PF, Gottgens KW, van Wely BJ, et al. The clinical and radiological outcome of pulsed electromagnetic field treatment for acute scaphoid fractures: A randomised double-blind placebo-controlled multicentre trial. The Journal of bone and joint surgery British volume 2012;94:1403-8.

30. Grewal R, Suh N, Macdermid JC. Use of computed tomography to predict union and time to union in acute scaphoid fractures treated nonoperatively. The Journal of hand surgery 2013;38:872-7. 


\section{Chapter 7}

\section{THE EFFECTS OF LOW INTENSITY PULSED ULTRASOUND AND PULSED ELECTROMAGNETIC}

FIELDS BONE GROWTH STIMULATION IN ACUTE FRACTURES: A SYSTEMATIC REVIEW AND META-ANALYSIS OF RANDOMIZED CONTROLLED TRIALS

Hannemann PFW

Mommers $\mathrm{EHH}$

Schots JPM

Brink PRG

Poeze M

Arch Orthop Trauma Surg. 2014 Aug;134(8):1093-106 


\section{Chapter 7}

\section{Abstract}

The aim of this systematic review and meta-analysis was to evaluate the best currently available evidence from randomized controlled trials comparing pulsed electromagnetic fields (PEMF) or low intensity pulsed ultrasound (LIPUS) bone growth stimulation with placebo for acute fractures.

We performed a systematic literature search of the medical literature from 1980 to 2013 for randomized clinical trials concerning acute fractures in adults treated with PEMF or LIPUS. Two reviewers independently determined the strength of the included studies by assessing the risk of bias according to the criteria in the Cochrane Handbook for Systematic Reviews of Interventions.

Seven hundred and thirty-seven patients from 13 trials were included. Pooled results from 13 trials reporting proportion of nonunion showed no significant difference between PEMF or LIPUS and control. With regard to time to radiological union, we found heterogeneous results that significantly favored PEMF or LIPUS bone growth stimulation only in non-operatively treated fractures or fractures of the upper limb. Furthermore, we found significant results that suggest that the use of PEMF or LIPUS in acute diaphyseal fractures may accelerate the time to clinical union.

Current evidence from randomized trials is insufficient to conclude a benefit of PEMF or LIPUS bone growth stimulation in reducing the incidence of nonunions when used for treatment in acute fractures. However, our systematic review and meta-analysis suggest that PEMF or LIPUS can be beneficial in the treatment of acute fractures regarding time to radiological and clinical union. PEMF and LIPUS significantly shorten time to radiological union for acute fractures undergoing non-operative treatment and acute fractures of the upper limb. Furthermore, PEMF or LIPUS bone growth stimulation accelerates the time to clinical union for acute diaphyseal fractures. 


\section{INTRODUCTION}

Although many patient-related and surgeon-related factors can influence time to resumption of activities after an upper or lower extremity fracture, prolonged healing time may have severe socio-economic consequences, especially in the working age population ${ }^{1,2}$

The two most common forms of electrophysical bone growth stimulation, pulsed electromagnetic fields (PEMF) and low intensity pulsed ultrasound (LIPUS) bone growth stimulation, have been proposed to accelerate bone healing and reduce the incidence of disabling complications such as delayed union or nonunion and therefore lowering financial costs by minimizing time off work and reducing the time of immobility. ${ }^{3,4}$

Since 1990 several trials have been conducted to test whether LIPUS and PEMF can be used to promote healing in acute fractures. ${ }^{3,4}$ Clinical outcomes however were mixed. ${ }^{3,4}$ We therefore conducted this systematic review and performed meta-analyses when sufficient dichotomous or continuous data were available to evaluate the best currently available evidence from randomized controlled trials comparing PEMF or LIPUS bone growth stimulation with placebo for healing of acute fractures.

\section{Materials ANd Methods}

This systematic review and meta-analysis is reported following the guidelines of the PRISMA statement. ${ }^{5}$

\section{Study selection criteria}

Types of studies, participants and interventions included

All clinical trials with a random allocation of participants over at least one treatment group and one control group, concerning acute fractures in adult patients treated with PEMF or LIPUS bone growth stimulation were considered in the present review. Trials including children, patients with congenital deformities and degenerative conditions and trials that focused on the treatment of delayed union (four weeks to six months after a fracture) or nonunion (more than six months after a fracture) were excluded from the analysis.

\section{Types of outcome measures}

The primary outcome measure of this review was time to complete radiological fracture healing (union), which had to be clearly defined. The secondary out- 


\section{Chapter 7}

come measures of this review were time to full clinical healing, based on validated function scoring systems or derivates of this (e.g. time until full resumption of work or time until full weight bearing in lower extremity fractures) and number of nonunions. Nonunion was defined as failure of the fracture to unite at more than six months after injury.

\section{Search methods for identification of studies}

We performed a systematic search of three major databases; EMBASE (OvidSP 1980 through October 30 2013), MEDLINE (PubMed 1966 through October 30 2013) and the Cochrane Central Register of Controlled Trials (CENTRAL) (The Cochrane Library issue 9 of 12 September 2013). Search terms were "pulsed electromagnetic fields", "PEMF", "low-intensity pulsed ultrasound", "LIPUS" and "fracture". No language restrictions were applied. Additionally, we screened the reference lists of all selected articles from the database search and additional relevant reviews and meta-analyses in order to find suitable studies for this review. Researchers in the field were contacted to inquire about any additional unpublished trials or trials in progress.

\section{Data collection and analysis}

\section{Selection of studies}

Full-text analysis of all eligible articles was performed by two reviewers separately in order to independently assess whether all inclusion criteria were met. Disagreement between the reviewers was resolved by means of discussion. If necessary, a third reviewer with a degree in study methodology and clinical epidemiology was consulted for arbitration if no consensus could be reached.

\section{Strength of the evidence}

Two reviewers independently assessed the risk of bias in the included studies according to the methods in the Cochrane Handbook for Systematic Reviews of Interventions. ${ }^{6}$ The following components of the risk of bias tool were assessed: sequence generation (selection bias), allocation concealment (selection bias), blinding (performance bias), incomplete outcome data (attrition bias), selective outcome reporting (reporting bias) and other biases (including description of the study protocol with sample size calculation, source of funding and other problems not covered elsewhere in the table). All items were judged as having a low, unclear or high risk of bias. We used Cohen's Kappa to estimate agreement between the two reviewers concerning assessment of risk of bias. We interpreted kappa values using the Landis and Koch criteria: values of 0.01-0.20 indicate slight agreement, 0.21-0.40 fair agreement, 0.41-0.60 moderate agreement, $0.61-0.80$ substantial agreement and $>0.80$ indicates almost perfect agreement. ${ }^{7}$ 
Finally, any disagreement between the two reviewers was resolved through discussion.

\section{Data collection}

Two reviewers independently extracted data from all eligible studies. Disagreement was resolved as mentioned above. For dichotomous outcomes, events from totals were extracted. For continuous outcomes, means and standard deviations were calculated. If means and confidence intervals ( $\mathrm{Cl}^{\prime}$ s) were reported instead, standard deviations were calculated from these values. Incomplete data (e.g. means without standard deviations) were excluded from analysis, after contacting the authors for eventually previously unreported data.

\section{Data pooling and analysis}

A statistical meta-analysis was performed with Review Manager 5.2. (The Cochrane Collaboration, 2012, Copenhagen, Denmark).

For both treatment arms in all studies, mean differences and 95\% confidence intervals $(\mathrm{Cl})$ were calculated for comparable continuous outcomes using a random effects model. For our primary outcome measure, time to complete radiological fracture healing and our secondary outcome measure, time until full clinical healing, values from all studies were expressed in days. For our dichotomous outcome, number of nonunions, risk ratios (RR's) and 95\% $\mathrm{Cl}^{\prime} \mathrm{s}$ using a fixed effects model were calculated. Heterogeneity between studies was tested using both the $\chi^{2}$ test (significance defined as $p<0.10$ ) and the $I^{2}$ tests (substantial heterogeneity defined as values $>50 \%$ ). ${ }^{8}$

\section{Subgroup-analysis}

The included trials are characterized by extensive clinical diversity. Fractures of the upper limb or metaphyseal fractures may be expected to heal more quickly than lower limb fractures or diaphyseal fractures. To minimize this heterogeneity, the following post hoc subgroup-analyses were performed: type of treatment (operatively or non-operatively treated fractures); the site of fractures (upper or lower limb); the type of fractures (metaphyseal or diaphyseal fractures).

\section{RESULTS}

\section{Literature search}

The search resulted in 655 potentially eligible studies (LIPUS 508, PEMF 147). After screening the titles and abstracts to see whether the inclusion criteria were met, 37 studies remained (LIPUS 29, PEMF 8). Removal of all duplicate articles resulted in 16 studies (LIPUS 13, PEMF 3), which were identified for full text 


\section{Chapter 7}

assessment of eligibility. After excluding one trial that applied high intensity ultrasound, one study that used the dataset from an already included study and one retrospective cohort study, 737 patients from thirteen trials were included ${ }^{9-21}$ (Figure 1). 355 Participants were treated with LIPUS $(n=209)$ or PEMF $(n=146)$ bone growth stimulation, 382 participants were treated with a placebo device.

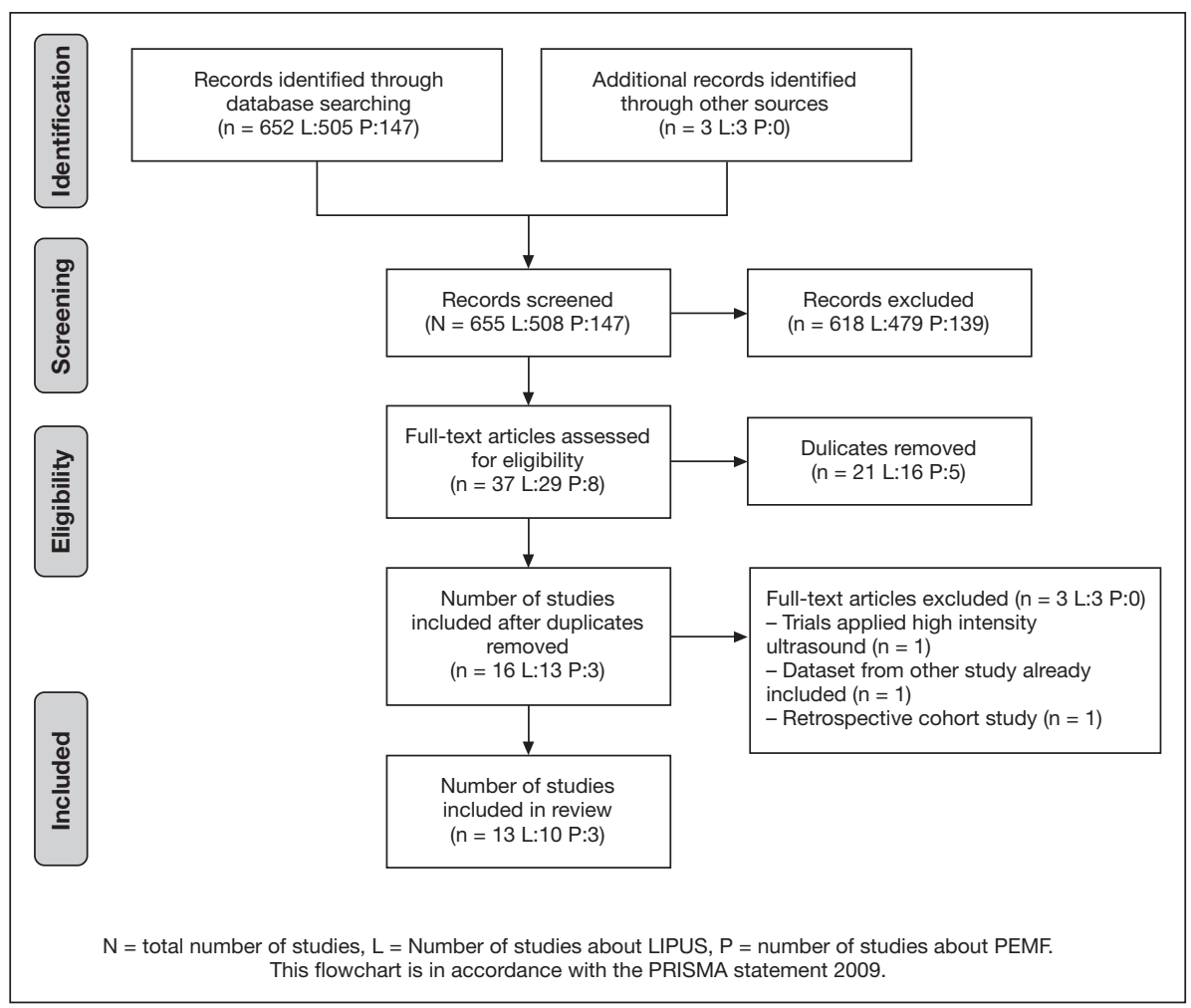

Figure 1. Flow of trials through review

\section{Description of included studies}

The study characteristics are summarized in Table 1.

\section{Outcome measure reporting}

Reported outcomes of included studies are summarized in Table 2. Eleven of the thirteen studies evaluated fracture healing, assessed by radiological examination. ${ }^{9-16,19-21}$ Ten studies assessed fracture healing on standard anterior posterior (AP) and lateral radiographs. ${ }^{9-11,13-16,19-21}$ One study used CT scans for assessment of fracture healing. ${ }^{12}$ In four studies, union was defined as trabecular bridging of 3 out of 4 cortices. ${ }^{9,11,13,20}$ In two studies, union was defined as bridging of 4 out 
Table 1. CHARACTERISTICS OF INCLUDED RANDOMIZED CONTROLLED TRIALS

\begin{tabular}{|c|c|c|c|c|c|c|c|c|c|}
\hline $\begin{array}{l}\text { Author } \\
\text { (references) }\end{array}$ & Year & $\begin{array}{l}\text { Inter- } \\
\text { vention }\end{array}$ & $\begin{array}{l}\text { Fracture } \\
\text { location }\end{array}$ & $\begin{array}{l}\text { Total } \\
\text { number of } \\
\text { patients } \\
\text { (n) }\end{array}$ & $\begin{array}{l}\text { Active } \\
\text { treat- } \\
\text { ment } \\
\text { (n) }\end{array}$ & $\begin{array}{l}\text { Placebo } \\
\text { treat- } \\
\text { ment } \\
\text { (n) }\end{array}$ & $\begin{array}{l}\text { Operatively } \\
\text { treated } \\
\text { fractures }\end{array}$ & $\begin{array}{l}\text { Follow up } \\
\text { (months) }\end{array}$ & $\begin{array}{l}\text { Follow up } \\
\text { completec } \\
(\%)\end{array}$ \\
\hline Adie $^{20}$ & 2011 & PEMF & tibia & 259 & 129 & 130 & yes & 12 & 84 \\
\hline Emami ${ }^{11}$ & 1999 & LIPUS & tibia & 32 & 15 & 17 & yes & 12 & 100 \\
\hline Faldini ${ }^{19}$ & 2010 & PEMF & femoral neck & 77 & 37 & 40 & yes & 24 & 84 \\
\hline Handolin ${ }^{16}$ & 2005 & LIPUS & lat malleolus & 30 & 15 & 15 & yes & 3 & 100 \\
\hline Handolin ${ }^{15}$ & 2005 & LIPUS & lat malleolus & 22 & 11 & 11 & yes & 3 & 100 \\
\hline Handolin ${ }^{14}$ & 2005 & LIPUS & lat malleolus & 16 & 8 & 8 & yes & 18 & 100 \\
\hline Hannemann ${ }^{21}$ & 2012 & PEMF & scaphoid & 53 & 24 & 29 & no & 12 & 77 \\
\hline Heckman ${ }^{9}$ & 1994 & LIPUS & tibia & 97 & 48 & 49 & no & 12 & 87 \\
\hline Kristiansen 10 & 1997 & LIPUS & radius & 85 & 40 & 45 & no & 4 & 72 \\
\hline Leung ${ }^{13}$ & 2004 & LIPUS & tibia & 30 & 16 & 14 & yes & 12 & 100 \\
\hline Lubbert ${ }^{17}$ & 2008 & LIPUS & clavicle & 120 & 61 & 59 & no & 2 & 84 \\
\hline Mayr ${ }^{12}$ & 2000 & LIPUS & scaphoid & 30 & 15 & 15 & no & 3 & 100 \\
\hline Rue ${ }^{18}$ & 2004 & LIPUS & tibia & 26 & 14 & 12 & yes & unclear & 100 \\
\hline
\end{tabular}

of 4 cortices. ${ }^{10,21}$ The study using CT for assessment of fracture healing defined union as trabecular bridging of more than $50 \%$ of the surface of the fracture and healing of 1 cortex. ${ }^{12}$ Three studies investigating lateral malleolar fractures defined union as fading of the fracture line on AP and lateral radiographs. ${ }^{14-16}$ In one study investigating femoral neck fractures, union was defined as trabecular bridging of $70 \%$ of the fracture surface..$^{19}$ Primary outcome parameter time to complete radiological union could be established in eight studies. ${ }^{9-13,15,16,21}$

Two studies evaluated the number of necessary surgical revisions to establish fracture union after initial non-operative ${ }^{17}$ or operative ${ }^{20}$ fracture treatment.

Six studies evaluated time to clinical fracture healing. ${ }^{9,11,13,17,18,21}$ Healing in these studies was defined as presence of a stable fracture with no pain on manual stress or full weight bearing. Three of the thirteen studies evaluated functional outcome. ${ }^{14,20,21}$ One study evaluated health status ${ }^{20}$ and two evaluated pain. ${ }^{17,19}$ Resumption of previous activities was outcome parameter of one study. ${ }^{17}$ Two studies evaluated related adverse events ${ }^{11,17}$ and three studies evaluated bone mineral density measured with dual-energy X-ray absorptiometry (DEXA) scan. ${ }^{13,14,16}$ One study evaluated plasma bone-specific alkaline phosphatase. ${ }^{13}$ 


\section{Chapter 7}

Table 2. REPORTED OUTCOMES OF SELECTED STUDIES

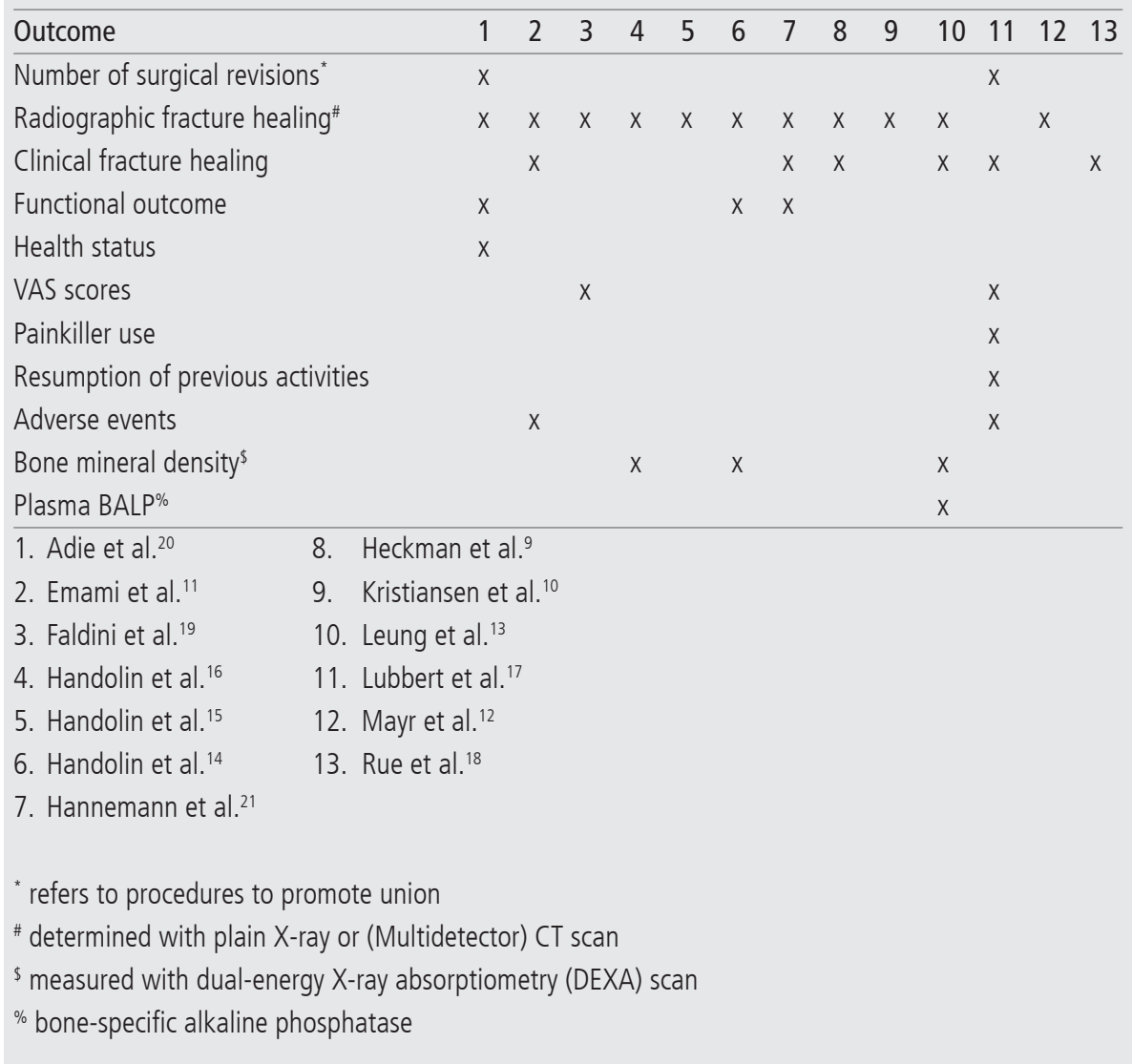

\section{Risk of bias and methodological quality in included studies}

The risk of bias assessment is summarized in Figure 2.

Inter-rater agreement for risk of bias assessments

The overall inter-rater agreement was high (0.803). The agreement was substantial for the domains allocation of concealment (0.713), blinding of outcome assessment (0.714) and incomplete outcome data (0.717). For the domains random sequence generation (0.855) and other bias (0.877), the agreement was almost perfect. There was no disagreement for selective reporting. Only the agreement for blinding of participants and personnel was moderate (0.469) (Table 3). 


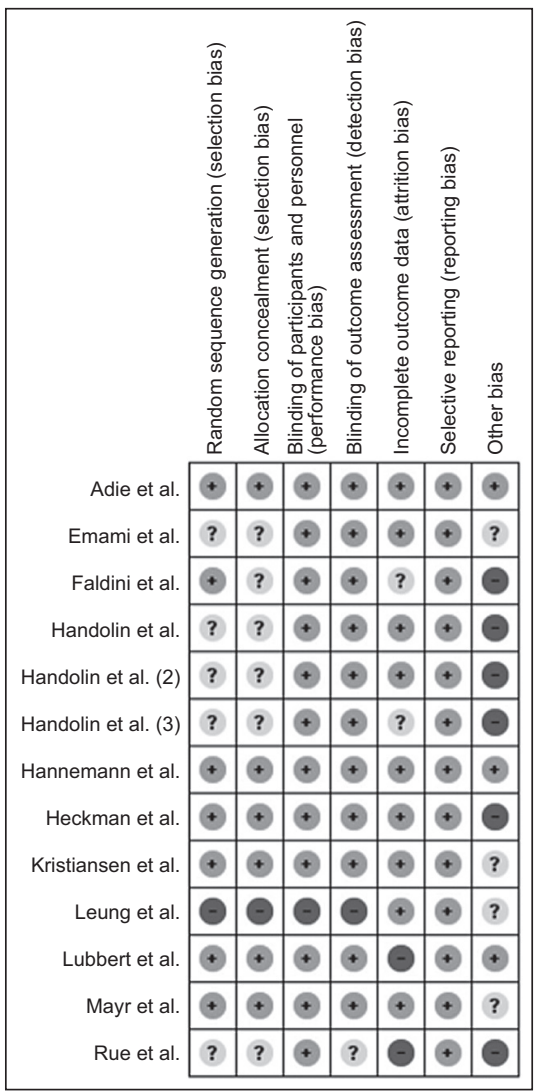

Low risk of bias

High risk of bias

? Unclear risk of bias

Figure 2. Risk of bias summary: review authors' judgments about each risk of bias item for each included study.

Table 3. INTER-RATER AGREEMENT FOR RISK OF BIAS ASSESSMENTS

\begin{tabular}{llll}
\hline Assessment & $\kappa$ & $p$ & Interpretation \\
\hline Overall risk of bias & 0.803 & $\mathrm{P}<0.001$ & Almost perfect agreement \\
Random sequence & 0.855 & $\mathrm{p}=0.001$ & Almost perfect agreement \\
Allocation of concealment & 0.713 & $\mathrm{p}=0,005$ & Substantial agreement \\
Blinding participants & 0.469 & $\mathrm{p}=0,485$ & Moderate agreement \\
Blinding outcome & 0.714 & $\mathrm{p}=0,118$ & Substantial agreement \\
Incomplete outcome data & 0.717 & $\mathrm{p}=0,004$ & Substantial agreement \\
Selective reporting & 0.99 & & Perfect agreement \\
Other bias & 0.877 & $\mathrm{p}<0,001$ & Almost perfect agreement
\end{tabular}




\section{Chapter 7}

\section{Primary outcome}

Time to radiological union

Eight studies compared PEMF or LIPUS with regard to time to radiological union. ${ }^{9-13,15,16,21}$ The data were pooled with substantial heterogeneity between treatment groups $\left(I^{2}=98 \%\right)$. There were no significant differences in time to radiological union between PEMF or LIPUS and placebo. (mean difference (MD) $=-13.32,95 \%$ $\mathrm{Cl}=-32.71$ to $6.06, \mathrm{p}=0.18$ ) (Figure 3a) Four studies comparing PEMF or LIPUS to placebo with regard to time to radiological union included only non-operatively treated fractures. ${ }^{9,10,12,21}$ After pooling the data, we found heterogeneous results that significantly favored PEMF or LIPUS treatment in non-operatively treated fractures. $\left(\mathrm{MD}=-26.65,95 \% \mathrm{Cl}=-50.38\right.$ to $\left.-2.91, \mathrm{p}=0.03, I^{2}=98 \%\right)$ (Figure $\left.3 \mathrm{~b}\right)$.

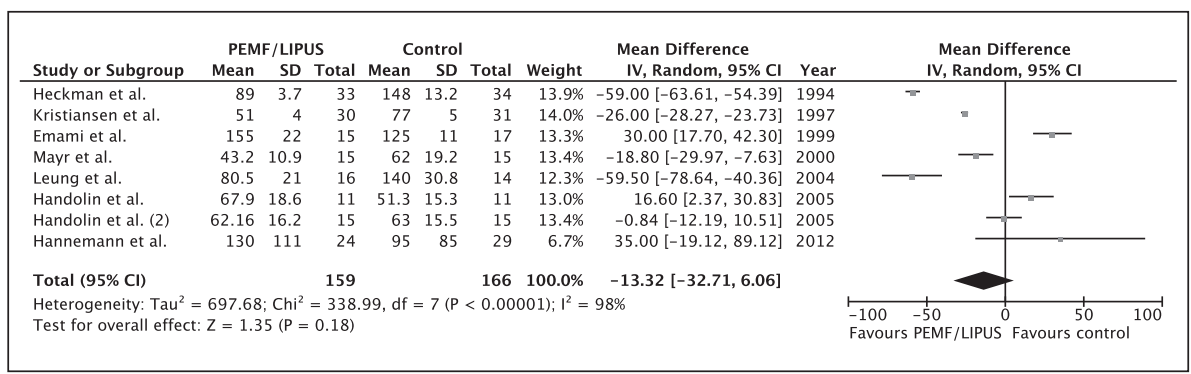

Figure 3a. Time until radiological union (PEMF/LIPUS vs. placebo).

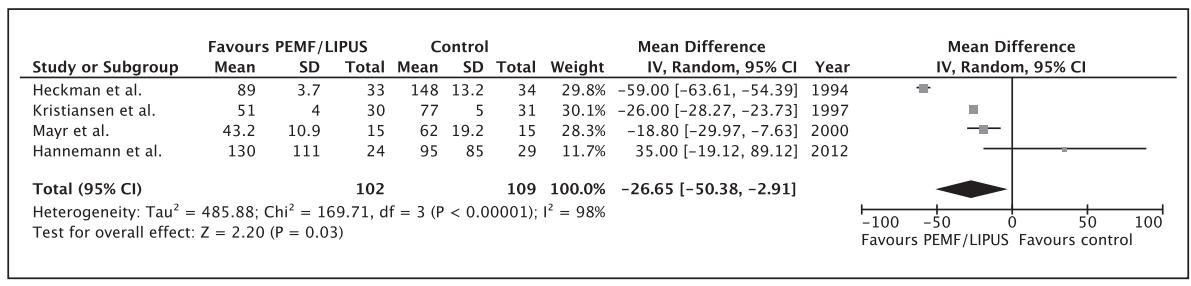

Figure 3b. Time until radiological union non-operatively treated fractures (PEMF/LIPUS vs. placebo).

\section{Time to radiological union upper and lower limb}

Three studies compared PEMF or LIPUS with placebo in fractures of the upper limb with regard to time to radiological union. ${ }^{10,12,21}$ Heterogeneous results $\left(I^{2}=69 \%\right)$ showed a significant difference in time to radiological union in favor of PEMF or LIPUS compared to placebo $(\mathrm{MD}=-20.23,95 \% \mathrm{Cl}-32.68$ to -7.77 , $\mathrm{p}=0.001$ ) (Figure 4a).

Five studies compared LIPUS and placebo in fractures of the lower limb with regard to time to radiological union..$^{9,11,13,15,16}$ The heterogeneous result $\left(I^{2}=99 \%\right)$ did not significantly differ between LIPUS or placebo. $(M D=-14.49,95 \% \mathrm{Cl}$ -55.96 to $26.97, p=0.49$ ) (Figure $4 b$ ). 


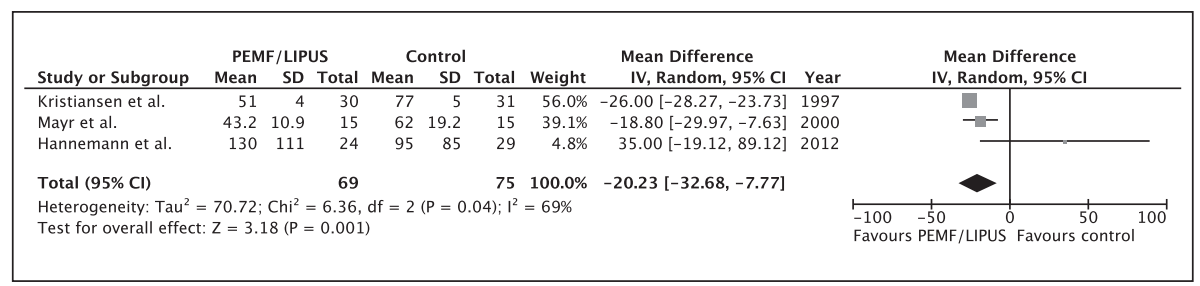

Figure 4a. Time until radiological union upper limb (PEMF/LIPUS vs. placebo).

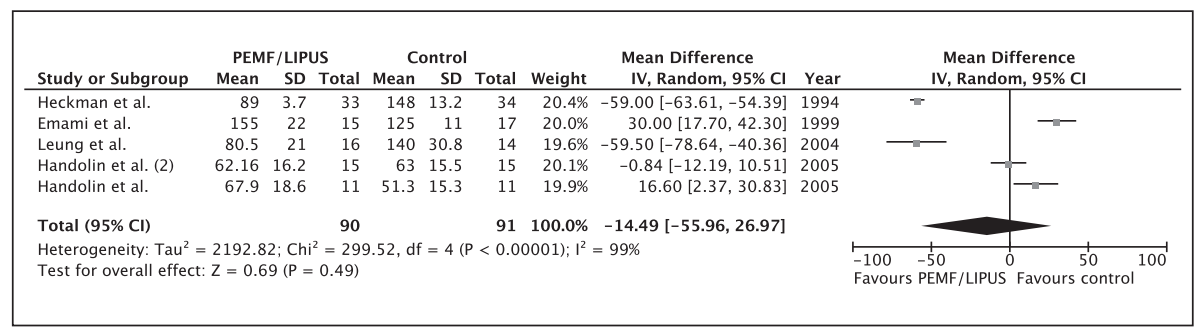

Figure 4b. Time until radiological union lower limb (PEMF/LIPUS vs. placebo).

Time to radiological union diaphyseal and metaphyseal fractures

After dividing the studies into two groups, diaphyseal fractures ${ }^{9,11,13}$ and metaphyseal fractures ${ }^{10,12,15,16,21}$, we found no significant differences in time to radiological union between PEMF or LIPUS and placebo regarding diaphyseal (MD = $-29.43,95 \% \mathrm{Cl}-89.99$ to $31.14, \mathrm{p}=0.34, I^{2}=99 \%$ ) or metaphyseal fractures $\left(\mathrm{MD}=-4.66,95 \% \mathrm{Cl}-22.78\right.$ to $\left.13.45, \mathrm{p}=0.61, I^{2}=93 \%\right)$ (Figure $\left.5 \mathrm{a}, 5 \mathrm{~b}\right)$.

\begin{tabular}{|c|c|c|c|c|c|c|c|c|c|c|c|}
\hline Study or Subgroup & \multicolumn{3}{|c|}{ PEMF/LIPUS } & \multicolumn{3}{|c|}{ Control } & \multicolumn{3}{|c|}{ Mean Difference } & \multicolumn{2}{|c|}{$\begin{array}{c}\text { Mean Difference } \\
\text { IV, Random, } 95 \% \mathrm{Cl}\end{array}$} \\
\hline Heckman et al. & 89 & 3.7 & 33 & 148 & 13.2 & 34 & $33.8 \%$ & $-59.00[-63.61,-54.39]$ & 1994 & $-\frac{-1}{7}$ & \\
\hline Emami et al. & 155 & 22 & 15 & 125 & 11 & 17 & $33.4 \%$ & $30.00[17.70,42.30]$ & 1999 & & -1 \\
\hline Leung et al. & 80.5 & 21 & 16 & 140 & 30.8 & 14 & $32.8 \%$ & $-59.50[-78.64,-40.36]$ & 2004 & 一- & \\
\hline Total $(95 \% \mathrm{Cl})$ & & & 64 & & & 65 & $100.0 \%$ & $-29.43[-89.99,31.14]$ & & & \\
\hline \multicolumn{10}{|c|}{$\begin{array}{l}\text { Heterogeneity: } \text { Tau }^{2}=2818.01 ; \mathrm{Chi}^{2}=177.63, \mathrm{df}=2(P<0.00001) ; \mathrm{I}^{2}=99 \% \\
\text { Test for overall effect: } Z=0.95(P=0.34)\end{array}$} & $\begin{array}{lll}-100 & -50 & 1 \\
\text { Favours } & \text { PEMF/LIPUS }\end{array}$ & 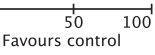 \\
\hline
\end{tabular}

Figure 5a. Time until radiological union diaphyseal fractures (PEMF/LIPUS vs. placebo).

\begin{tabular}{|c|c|c|c|c|c|c|c|c|c|c|c|}
\hline \multirow[b]{2}{*}{ Study or Subgroup } & \multicolumn{3}{|c|}{ PEMF/LIPUS } & \multicolumn{3}{|c|}{ Control } & \multicolumn{3}{|c|}{ Mean Difference } & \multirow{2}{*}{\multicolumn{2}{|c|}{$\begin{array}{c}\text { Mean Difference } \\
\text { IV, Random, } 95 \% \mathrm{Cl}\end{array}$}} \\
\hline & Mean & SD & Total & Mean & SD & Total & Weight & IV, Random, $95 \% \mathrm{CI}$ & Year & & \\
\hline Kristiansen et al. & 51 & 4 & 30 & 77 & 5 & 31 & $24.9 \%$ & $-26.00[-28.27,-23.73]$ & 1997 & - & \\
\hline Mayr et al. & 43.2 & 10.9 & 15 & 62 & 19.2 & 15 & $22.9 \%$ & $-18.80[-29.97,-7.63]$ & 2000 & $-\square$ & \\
\hline Handolin et al. & 67.9 & 18.6 & 11 & 51.3 & 15.3 & 11 & $21.7 \%$ & $16.60[2.37,30.83]$ & 2005 & & 一— \\
\hline Handolin et al. (2) & 62.16 & 16.2 & 15 & 63 & 15.5 & 15 & $22.8 \%$ & $-0.84[-12.19,10.51]$ & 2005 & & - \\
\hline Hannemann et al. & 130 & 111 & 24 & 95 & 85 & 29 & $7.7 \%$ & $35.00[-19.12,89.12]$ & 2012 & & \\
\hline Total $(95 \% \mathrm{Cl})$ & & & 95 & & & 101 & $100.0 \%$ & $-4.66[-22.78,13.45]$ & & & \\
\hline \multicolumn{10}{|c|}{$\begin{array}{l}\text { Heterogeneity: } \operatorname{Tau}^{2}=341.23 ; \mathrm{Chi}^{2}=55.60, \mathrm{df}=4(\mathrm{P}<0.00001) ; \mathrm{I}^{2}=93 \% \\
\text { Test for overall effect: } Z=0.50(\mathrm{P}=0.61)\end{array}$} & $\begin{array}{lll}-100 & -50 \\
\text { Favours } & \text { PEMF/LIPUS }\end{array}$ & $\begin{array}{l}50 \\
\text { Favours control }\end{array}$ \\
\hline
\end{tabular}

Figure 5b. Time until radiological union metaphyseal fractures (PEMF/LIPUS vs. placebo). 


\section{Chapter 7}

\section{Secondary outcomes}

Time to clinical union

Six studies compared PEMF or LIPUS to placebo with regard to time to clinical union. ${ }^{9,11,13,17,18,21}$ After pooling the data, no significant differences were found between groups (MD $=-13.01,95 \% \mathrm{Cl}=-26.92$ to $0.89, \mathrm{p}=0.07, \mathrm{I}^{2}=96 \%$ ) (Figure 6a). When analyzing non-operatively and operatively treated fractures separately, we found no significant differences in non-operatively treated fractures $\left(\mathrm{MD}=-9.65,95 \% \mathrm{Cl}=-33.85\right.$ to $\left.14.55, \mathrm{p}=0.43, \mathrm{I}^{2}=97 \%\right)$ or in operatively treated fractures $\left(\mathrm{MD}=-15.50,95 \% \mathrm{Cl}-39.25\right.$ to $\left.8.25, \mathrm{p}=0.20, \mathrm{I}^{2}=94 \%\right)$ (Fig. 6b, 6c).

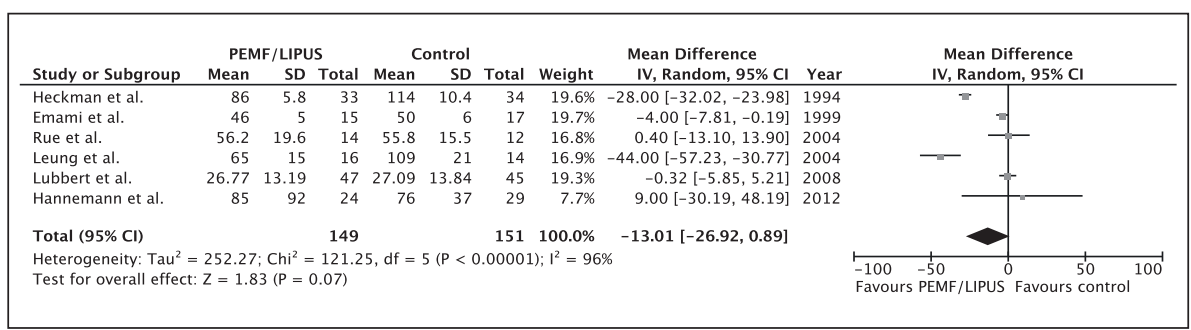

Figure 6a. Time until clinical union (PEMF/LIPUS vs. placebo).

\begin{tabular}{|c|c|c|c|c|c|c|c|c|c|c|}
\hline \multirow[b]{2}{*}{ Study or Subgroup } & \multicolumn{3}{|c|}{ PEMF/LIPUS } & \multicolumn{3}{|c|}{ Control } & \multicolumn{3}{|c|}{ Mean Difference } & \multirow{2}{*}{$\begin{array}{l}\text { Mean Difference } \\
\text { IV, Random, } 95 \% \mathrm{Cl}\end{array}$} \\
\hline & Mean & SD & Total & Mean & SD & Total & Weight & IV, Random, $95 \% \mathrm{CI}$ & Year & \\
\hline Heckman et al. & 86 & 5.8 & 33 & 114 & 10.4 & 34 & $40.3 \%$ & $-28.00[-32.02,-23.98]$ & 1994 & 들 \\
\hline Lubbert et al. & 26.77 & 13.19 & 47 & 27.09 & 13.84 & 45 & $39.9 \%$ & $-0.32[-5.85,5.21]$ & 2008 & 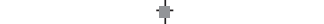 \\
\hline Hannemann et al. & 85 & 92 & 24 & 76 & 37 & 29 & $19.7 \%$ & $9.00[-30.19,48.19]$ & 2012 & \\
\hline Total $(95 \% \mathrm{Cl})$ & & & 104 & & & 108 & $100.0 \%$ & $-9.65[-33.85,14.55]$ & & \\
\hline \multicolumn{10}{|c|}{$\begin{array}{l}\text { Heterogeneity: } \text { Tau }^{2}=373.57 ; \mathrm{Chi}^{2}=64.88, \mathrm{df}=2(P<0.00001) ; 1^{2}=97 \% \\
\text { Test for overall effect: } Z=0.78(P=0.43)\end{array}$} & $\begin{array}{lllll}-100 & -50 & 0 & 50 & 100 \\
\text { Favours } & \text { PEMF/LIPUS Favours control }\end{array}$ \\
\hline
\end{tabular}

Figure 6b. Time until clinical union non-operatively treated fractures (PEMF/LIPUS vs. placebo).

\begin{tabular}{|c|c|c|c|c|c|c|c|c|c|c|}
\hline \multirow[b]{2}{*}{ Study or Subgroup } & \multicolumn{3}{|c|}{ PEMF/LIPUS } & \multicolumn{3}{|c|}{ Control } & \multicolumn{3}{|c|}{ Mean Difference } & \multirow{2}{*}{$\begin{array}{c}\text { Mean Difference } \\
\text { IV, Random, } 95 \% \mathrm{CI}\end{array}$} \\
\hline & Mean & SD & Total & Mean & SD & Total & Weight & IV, Random, $95 \% \mathrm{Cl}$ & Year & \\
\hline Emami et al. & 46 & 5 & 15 & 50 & 6 & 17 & $35.6 \%$ & $-4.00[-7.81,-0.19]$ & 1999 & 可 \\
\hline Rue et al. & 56.2 & 19.6 & 14 & 55.8 & 15.5 & 12 & $32.2 \%$ & $0.40[-13.10,13.90]$ & 2004 & \\
\hline Leung et al. & 65 & 15 & 16 & 109 & 21 & 14 & $32.3 \%$ & $-44.00[-57.23,-30.77]$ & 2004 & 一— \\
\hline Total $(95 \% \mathrm{Cl})$ & & & 45 & & & 43 & $100.0 \%$ & $-15.50[-39.25,8.25]$ & & \\
\hline \multicolumn{10}{|c|}{$\begin{array}{l}\text { Heterogeneity: } \mathrm{Tau}^{2}=409.32 ; \mathrm{Chi}^{2}=33.52, \mathrm{df}=2(\mathrm{P}<0.00001) ; \mathrm{I}^{2}=94 \% \\
\text { Test for overall effect: } Z=1.28(\mathrm{P}=0.20)\end{array}$} & $\begin{array}{lcccc}-100 & -50 & 0 & 1 & \\
\text { Favours } & \text { PEMF/LIPUS Favours control } & 100\end{array}$ \\
\hline
\end{tabular}

Figure 6c. Time until clinical union operatively treated fractures (PEMF/LIPUS vs. placebo).

\section{Time to clinical union upper and lower limb}

Two studies compared PEMF or LIPUS with placebo in fractures of the upper limb with regard to time to clinical union. ${ }^{17,21}$ No significant differences were 
found between the groups $(\mathrm{MD}=-0.14,95 \% \mathrm{Cl}=-5.61$ to $5.34, \mathrm{p}=0.96$, $I^{2}=0 \%$ ). (Fig. 7a) When analyzing four studies comparing PEMF or LIPUS with placebo in fractures of the lower limb with regard to time to clinical union, heterogeneous results that significantly favored PEMF or LIPUS were found $(M D=-18.73$, $95 \% \mathrm{Cl}-36.25$ to $-1.21, \mathrm{p}=0.04, I^{2}=97 \%$ ) (Figure $7 \mathrm{~b}$ ). ${ }^{9,11,13,18}$

\begin{tabular}{|c|c|c|c|c|c|c|c|c|c|c|}
\hline \multirow[b]{2}{*}{ Study or Subgroup } & \multicolumn{3}{|c|}{ PEMF/LIPUS } & \multicolumn{3}{|c|}{ Control } & \multirow[b]{2}{*}{ Weight } & \multicolumn{2}{|l|}{ Mean Difference } & \multirow{2}{*}{$\begin{array}{c}\text { Mean Difference } \\
\text { IV, Random, } 95 \% \mathrm{Cl}\end{array}$} \\
\hline & Mean & SD & Total & Mean & SD & Total & & IV, Random, $95 \% \mathrm{CI}$ & Year & \\
\hline Lubbert et al. & 26.77 & 13.19 & 47 & 27.09 & 13.84 & 45 & $98.0 \%$ & $-0.32[-5.85,5.21]$ & 2008 & \\
\hline Hannemann et al. & 85 & 92 & 24 & 76 & 37 & 29 & $2.0 \%$ & $9.00[-30.19,48.19]$ & 2012 & \\
\hline Total $(95 \% \mathrm{Cl})$ & & & 71 & & & 74 & $100.0 \%$ & $-0.14[-5.61,5.34]$ & & \\
\hline \multicolumn{10}{|c|}{$\begin{array}{l}\text { Heterogeneity: } \mathrm{Tau}^{2}=0.00 ; \mathrm{Chi}^{2}=0.21, \mathrm{df}=1(\mathrm{P}=0.64) ; \mathrm{I}^{2}=0 \% \\
\text { Test for overall effect: } Z=0.05(P=0.96)\end{array}$} & 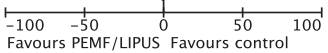 \\
\hline
\end{tabular}

Figure 7a. Time until clinical union upper limb (PEMF/LIPUS vs. placebo).

\begin{tabular}{|c|c|c|c|c|c|c|c|c|c|c|}
\hline \multirow[b]{2}{*}{ Study or Subgroup } & \multicolumn{3}{|c|}{ PEMF/LIPUS } & \multicolumn{3}{|c|}{ Control } & \multicolumn{3}{|c|}{ Mean Difference } & \multirow{2}{*}{$\begin{array}{l}\text { Mean Difference } \\
\text { IV, Random, } 95 \% \mathrm{CI}\end{array}$} \\
\hline & Mean & SD & Total & Mean & SD & Total & Weight & IV, Random, $95 \% \mathrm{CI}$ & Year & \\
\hline Heckman et al. & 86 & 5.8 & 33 & 114 & 10.4 & 34 & $26.6 \%$ & $-28.00[-32.02,-23.98]$ & 1994 & $=$ \\
\hline Emami et al. & 46 & 5 & 15 & 50 & 6 & 17 & $26.7 \%$ & $-4.00[-7.81,-0.19]$ & 1999 & $=$ \\
\hline Rue et al. & 56.2 & 19.6 & 14 & 55.8 & 15.5 & 12 & $23.3 \%$ & $0.40[-13.10,13.90]$ & 2004 & -1 \\
\hline Leung et al. & 65 & 15 & 16 & 109 & 21 & 14 & $23.4 \%$ & $-44.00[-57.23,-30.77]$ & 2004 & -1 \\
\hline Total $(95 \% \mathrm{Cl})$ & & & 78 & & & 77 & $100.0 \%$ & $-18.73[-36.25,-1.21]$ & & \\
\hline \multicolumn{10}{|c|}{$\begin{array}{l}\text { Heterogeneity: } \mathrm{Tau}^{2}=295.85 ; \mathrm{Chi}^{2}=95.20, \mathrm{df}=3(\mathrm{P}<0.00001) ; \mathrm{I}^{2}=97 \% \\
\text { Test for overall effect: } Z=2.10(\mathrm{P}=0.04)\end{array}$} & 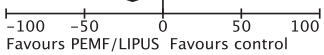 \\
\hline
\end{tabular}

Figure 7b. Time until clinical union lower limb fractures (PEMF/LIPUS vs. placebo).

Time to clinical union diaphyseal and metaphyseal fractures

Four studies compared PEMF or LIPUS with placebo in diaphyseal fractures with regard to time to clinical union; heterogeneous results that significantly favored PEMF or LIPUS were found (MD $=-18.27,95 \% \mathrm{Cl}-34.59$ to $-1.95, \mathrm{p}=0.03$, $I^{2}=97 \%$ ). (Figure 8a). ${ }^{9,11,13,18}$ No significant differences were found regarding metaphyseal fractures ( $\mathrm{MD}=1.31,95 \% \mathrm{Cl}-11.45$ to $14.08, \mathrm{p}=0.84, \mathrm{I}^{2}=0 \%$ ) (Figure 8b).

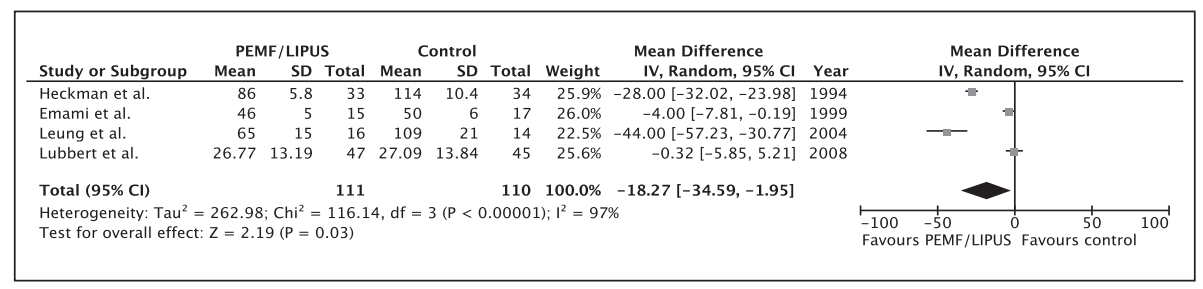

Figure 8a. Time until clinical union diaphyseal fractures (PEMF/LIPUS vs. placebo). 


\section{Chapter 7}

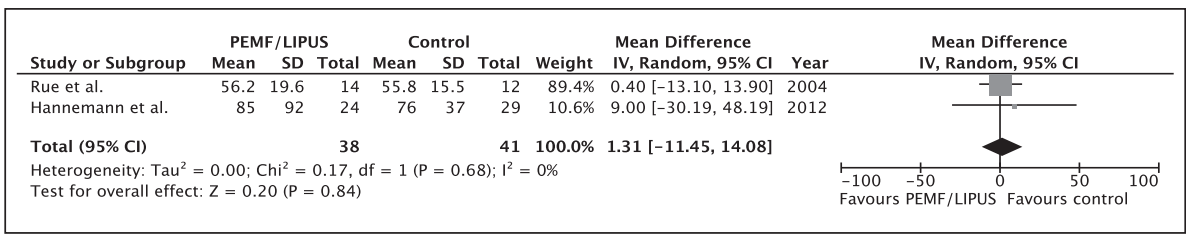

Figure 8b. Time until clinical union metaphyseal fractures (PEMF/LIPUS vs. placebo).

\section{Number of nonunions}

With regard to the number of nonunions, data from all thirteen studies could be pooled. ${ }^{9-21}$ Analysis revealed no significant differences between LIPUS or PEMF (28 events of nonunion in 355 patients) and placebo (35 events of nonunion in 382 patients) with regard to the number of nonunions in each group (Risk Ratio $=$ $0.95,95 \% \mathrm{Cl}=0.59$ to $1.54, \mathrm{p}=0.84, I^{2}=19 \%$ ) (Figure 9a). When analyzing non-operatively and operatively treated fractures separately, we found no significant differences in both groups. (non-operatively treated fractures: $M D=1.18$, $95 \% \mathrm{Cl}=0.38$ to $3.70, \mathrm{p}=0.77, \mathrm{I}^{2}=0 \%$; operatively treated fractures: $\mathrm{MD}=0.91$, $95 \% \mathrm{Cl}=0.53$ to $1.54, \mathrm{p}=0.72, I^{2}=51 \%$ ) (Figure 9b, 9c).

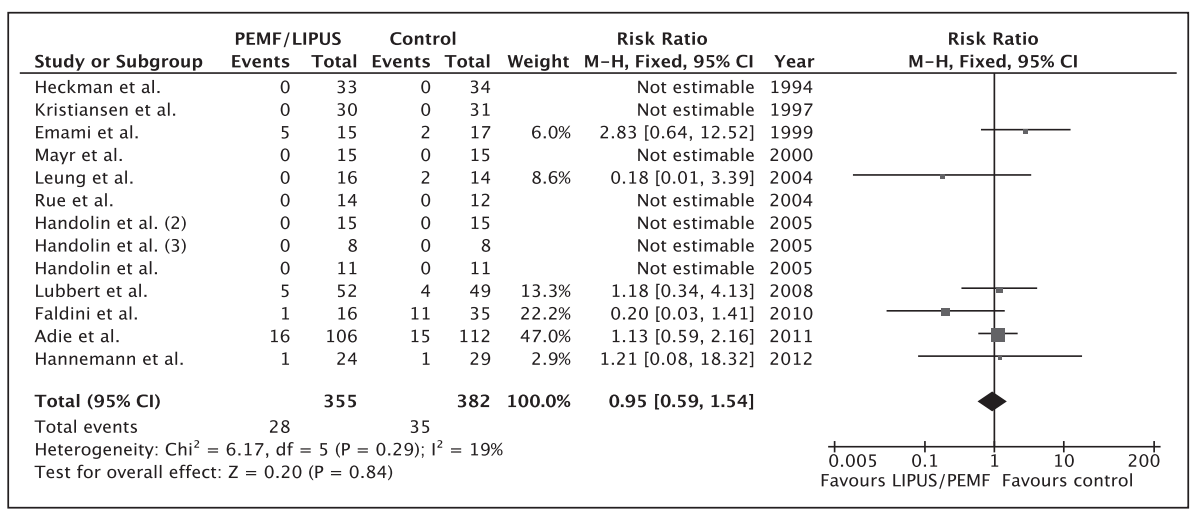

Figure 9a. Number of nonunions at 6 months (PEMF/LIPUS vs. placebo).

\begin{tabular}{|c|c|c|c|c|c|c|c|c|}
\hline \multirow{2}{*}{ Study or Subgroup } & \multicolumn{2}{|c|}{ PEMF/LIPUS } & \multicolumn{2}{|c|}{ Control } & Weight & $\begin{array}{c}\text { Risk Ratio } \\
\text { M-H, Fixed, } 95 \% \mathrm{Cl}\end{array}$ & Year & $\begin{array}{c}\text { Risk Ratio } \\
\text { M-H, Fixed, } 95 \% \mathrm{Cl}\end{array}$ \\
\hline & 0 & 33 & 0 & 34 & & Not estimable & 1994 & \\
\hline Kristiansen et al. & 0 & 30 & 0 & 31 & & Not estimable & 1997 & \\
\hline Mayr et al. & 0 & 15 & 0 & 15 & & Not estimable & 2000 & \\
\hline Lubbert et al. & 5 & 52 & 4 & 49 & $82.0 \%$ & $1.18[0.34,4.13]$ & 2008 & \\
\hline Hannemann et al. & 1 & 24 & 1 & 29 & $18.0 \%$ & $1.21[0.08,18.32]$ & 2012 & $=$ \\
\hline Total $(95 \% \mathrm{Cl})$ & & 154 & & 158 & $100.0 \%$ & $1.18[0.38,3.70]$ & & \\
\hline Total events & 6 & & 5 & & & & & \\
\hline $\begin{array}{l}\text { Heterogeneity: } \mathrm{Chi}^{2}= \\
\text { Test for overall effect }\end{array}$ & $\begin{array}{l}0.00, \mathrm{df} \\
Z=0.29\end{array}$ & $\begin{array}{l}=1(P= \\
(P=0 .\end{array}$ & $\begin{array}{l}=0.99) ; 1^{2} \\
.77)\end{array}$ & $2=0 \%$ & & & & $\begin{array}{ccccc}0.005 & 0.1 & 1 & 10 & 200 \\
\text { Favours } & \text { PEMF/LIPUS Favours control }\end{array}$ \\
\hline
\end{tabular}

Figure 9b. Number of nonunions at 6 months non-operatively treated fractures

PEMF/LIPUS vs. placebo). 


\begin{tabular}{|c|c|c|c|c|c|c|c|c|}
\hline \multirow[b]{2}{*}{ Study or Subgroup } & \multicolumn{2}{|c|}{ PEMF/LIPUS } & \multicolumn{2}{|c|}{ Control } & \multirow[b]{2}{*}{ Weight } & \multicolumn{2}{|l|}{ Risk Ratio } & \multirow{2}{*}{$\begin{array}{c}\text { Risk Ratio } \\
\text { M-H, Fixed, } 95 \% \mathrm{Cl}\end{array}$} \\
\hline & Events & Total & Events & Total & & M-H, Fixed, $95 \% \mathrm{Cl}$ & Year & \\
\hline Emami et al. & 5 & 15 & 2 & 17 & $7.2 \%$ & $2.83[0.64,12.52]$ & 1999 & \\
\hline Leung et al. & 0 & 16 & 2 & 14 & $10.2 \%$ & $0.18[0.01,3.39]$ & 2004 & \\
\hline Rue et al. & 0 & 14 & 0 & 12 & & Not estimable & 2004 & \\
\hline Handolin et al. (2) & 0 & 15 & 0 & 15 & & Not estimable & 2005 & \\
\hline Handolin et al. (3) & 0 & 8 & 0 & 8 & & Not estimable & 2005 & \\
\hline Handolin et al. & 0 & 11 & 0 & 11 & & Not estimable & 2005 & \\
\hline Faldini et al. & 1 & 16 & 11 & 35 & $26.5 \%$ & $0.20[0.03,1.41]$ & 2010 & (a) \\
\hline Adie et al. & 16 & 106 & 15 & 112 & $56.1 \%$ & $1.13[0.59,2.16]$ & 2011 & \\
\hline Total $(95 \% \mathrm{Cl})$ & & 201 & & 224 & $100.0 \%$ & $0.91[0.53,1.54]$ & & \\
\hline \multirow{2}{*}{\multicolumn{8}{|c|}{$\begin{array}{l}\text { Heterogeneity: } \mathrm{Chi}^{2}=6.17, \mathrm{df}=3(\mathrm{P}=0.10) ; \mathrm{I}^{2}=51 \% \\
\text { Test for overall effect: } Z=0.36(P=0.72)\end{array}$}} & \\
\hline & & & & & & & & 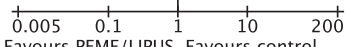 \\
\hline
\end{tabular}

Figure 9c. Number of nonunions at 6 months operatively treated fractures (PEMF/LIPUS vs. placebo).

\section{Number of nonunions upper and lower limb}

Data from all thirteen studies could be divided into fractures of the upper limb ${ }^{10,12,17,21}$ or lower limb. ${ }^{9,11,13-16,18-20}$ Comparing PEMF or LIPUS with placebo with regard to the number of nonunions, no significant differences in the upper limb (Risk Ratio $=1.18,95 \% \mathrm{Cl}=0.38$ to $3.70, \mathrm{p}=0.77, I^{2}=0 \%$ ) or in the lower limb (Risk Ratio $=0.91,95 \% \mathrm{Cl} 0.53$ to $1.54, \mathrm{p}=0.72, I^{2}=51 \%$ ) were found. (Figure 10a, 10b).

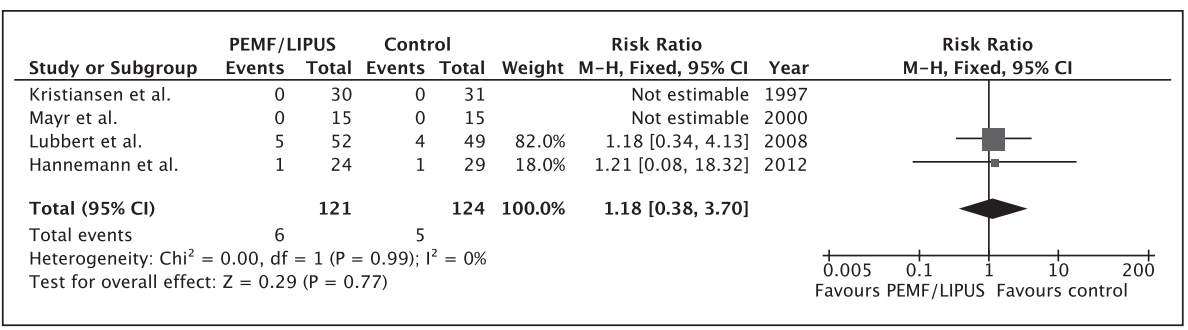

Figure 10a. Number of nonunions at 6 months upper limb (PEMF/LIPUS vs. placebo).

\begin{tabular}{|c|c|c|c|c|c|c|c|c|}
\hline Study or Subgroup & \multicolumn{2}{|c|}{ PEMF/LIPUS } & Control & $\begin{array}{l}\text { rol } \\
\text { Total }\end{array}$ & Weight & $\begin{array}{c}\text { Risk Ratio } \\
\text { M-H, Fixed, } 95 \% \mathrm{Cl}\end{array}$ & Year & $\begin{array}{c}\text { Risk Ratio } \\
\text { M-H, Fixed, } 95 \% \mathrm{Cl}\end{array}$ \\
\hline Heckman et al. & 0 & 33 & 0 & 34 & & Not estimable & 1994 & \\
\hline Emami et al. & 5 & 15 & 2 & 17 & $7.2 \%$ & $2.83[0.64,12.52]$ & 1999 & \\
\hline Leung et al. & 0 & 16 & 2 & 14 & $10.2 \%$ & $0.18[0.01,3.39]$ & 2004 & \\
\hline Rue et al. & 0 & 14 & 0 & 12 & & Not estimable & 2004 & \\
\hline Handolin et al. & 0 & 11 & 0 & 11 & & Not estimable & 2005 & \\
\hline Handolin et al. (2) & 0 & 15 & 0 & 15 & & Not estimable & 2005 & \\
\hline Handolin et al. (3) & 0 & 8 & 0 & 8 & & Not estimable & 2005 & \\
\hline Faldini et al. & 1 & 16 & 11 & 35 & $26.5 \%$ & $0.20[0.03,1.41]$ & 2010 & - \\
\hline Adie et al. & 16 & 106 & 15 & 112 & $56.1 \%$ & $1.13[0.59,2.16]$ & 2011 & \\
\hline Total $(95 \% \mathrm{Cl})$ & & 234 & & 258 & $100.0 \%$ & $0.91[0.53,1.54]$ & & \\
\hline Total events & 22 & & 30 & & & & & \\
\hline $\begin{array}{l}\text { Heterogeneity: } \mathrm{Chi}^{2}= \\
\text { Test for overall effect }\end{array}$ & $\begin{array}{l}6.17, \mathrm{df} \\
Z=0.36\end{array}$ & $\begin{array}{l}=3(P= \\
(P=0 .\end{array}$ & $\begin{array}{l}=0.10) ; 1^{2} \\
72)\end{array}$ & $2^{2}=51 \%$ & & & & $\begin{array}{ccccc}0.005 & 0.1 & 1 & 10 & 200 \\
\text { Favours } & \text { PEMF/LIPUS Favours control }\end{array}$ \\
\hline
\end{tabular}

Figure 10b. Number of nonunions at 6 months lower limb (PEMF/LIPUS vs. placebo). 


\section{Chapter 7}

Number of nonunions in diaphyseal and metaphyseal fractures

When subdividing studies comparing PEMF or LIPUS with placebo in acute diaphyseal fractures ${ }^{9,11,13,17,20}$ (Risk Ratio $=1.17,95 \% \mathrm{Cl}=0.70$ to $1.95, \mathrm{p}=0.56$, $I^{2}=0 \%$ ) and acute metaphyseal fractures respectively ${ }^{10,12,14-16,19,21}$ (Risk Ratio = $0.32,95 \% \mathrm{Cl}=0.07$ to $1.43, \mathrm{p}=0.13, \mathrm{I}^{2}=13 \%$ ), no significant differences were found with regard to number of nonunions (Figure 11a, 11b).

\begin{tabular}{|c|c|c|c|c|c|c|c|c|}
\hline \multirow{2}{*}{$\begin{array}{l}\text { Study or Subgroup } \\
\text { Heckman et al. }\end{array}$} & \multicolumn{2}{|c|}{ PEMF/LIPUS } & \multicolumn{2}{|c|}{ Control } & \multicolumn{3}{|c|}{ Risk Ratio } & $\begin{array}{c}\text { Risk Ratio } \\
\text { M-H, Fixed, 95\% Cl }\end{array}$ \\
\hline & 0 & 33 & 0 & 34 & & Not estimable & 1994 & \\
\hline Emami et al. & 5 & 15 & 2 & 17 & $8.1 \%$ & $2.83[0.64,12.52]$ & 1999 & \\
\hline Leung et al. & 0 & 16 & 2 & 14 & $11.4 \%$ & $0.18[0.01,3.39]$ & 2004 & $\leftarrow$ \\
\hline Lubbert et al. & 5 & 52 & 4 & 49 & $17.7 \%$ & $1.18[0.34,4.13]$ & 2008 & \\
\hline Adie et al. & 16 & 106 & 15 & 112 & $62.8 \%$ & $1.13[0.59,2.16]$ & 2011 & \\
\hline Total $(95 \% \mathrm{Cl})$ & & 222 & & 226 & $100.0 \%$ & $1.17[0.70,1.95]$ & & \\
\hline Total events & 26 & & 23 & & & & & \\
\hline $\begin{array}{l}\text { Heterogeneity: } \mathrm{Chi}^{2}= \\
\text { Test for overall effect }\end{array}$ & $\begin{array}{l}2.95, \mathrm{df} \\
Z=0.58\end{array}$ & $\begin{array}{l}=3(P= \\
(P=0 .\end{array}$ & $\begin{array}{l}=0.40) ; 1^{2} \\
56)\end{array}$ & ${ }^{2}=0 \%$ & & & & $\begin{array}{ccccc}0.01 & 0.1 & 1 & 10 & 100 \\
\text { Favours } & \text { PEMF/LIPUS } & \text { Favours control }\end{array}$ \\
\hline
\end{tabular}

Figure 11a. Number of nonunions at 6 months diaphyseal fractures (PEMF/LIPUS vs. placebo).

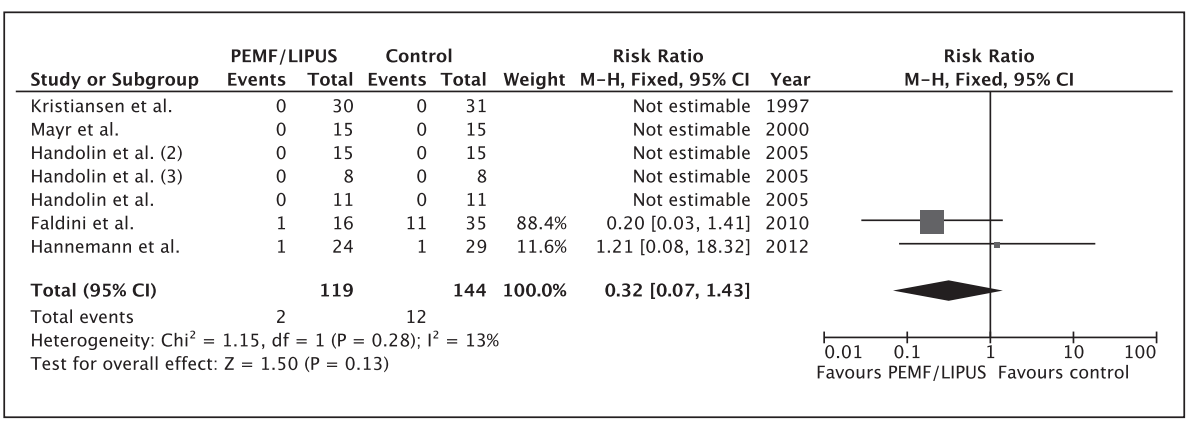

Figure 11b. Number of nonunions at 6 months metaphyseal fractures (PEMF/LIPUS vs. placebo).

\section{DisCUSSION}

\section{Key findings}

This systematic review suggests that current evidence from randomized trials is insufficient to conclude a benefit of LIPUS or PEMF bone growth stimulation in reducing the incidence of nonunions when used for treatment in acute fractures. With regard to time to radiological union, we found heterogeneous but significant results that suggest that the use of PEMF or LIPUS in acute fractures may be beneficial, however only in non-operatively treated fractures. The use of bone growth stimulation can accelerate the time to radiological union with approximately 27 days. Furthermore, treatment with PEMF or LIPUS may be effective in 
the upper limb, to shorten the time to radiological union with 20 days. Concerning time to clinical union current evidence suggest that the use of LIPUS can be beneficial, especially in acute diaphyseal fractures, by reducing the time to clinical union with approximately 18 days.

\section{Strengths and limitations}

The findings of our study are strengthened by the broad literature search and valid methodological assessment of all included trials. Furthermore, we contacted several authors to provide previously unreported data, necessary for pooling of comparable outcome measurements. ${ }^{13,17,21}$ Still, some of the included trials had methodological limitations such as small population samples, per protocol analysis and inadequate concealment of treatment allocation.

Pooled data for outcome parameter time to radiological union showed substantial heterogeneity $\left(I^{2}=97 \%\right)$. We consider the variability in criteria for radiological union to be the main factor for variation in outcome generating substantial heterogeneity. In four studies, union was defined as trabecular bridging of 3 out of 4 cortices. ${ }^{9,11,13,20}$ In two studies, union was defined as bridging of 4 out of 4 cortices. ${ }^{10,21}$ Three studies defined union as fading of the fracture line on the radiographs ${ }^{14-16}$ and in one study union was defined as trabecular bridging of $70 \%$ of the fracture surface. ${ }^{19}$ Therefore, conclusions drawn from this heterogeneous outcome must be interpreted with caution. For outcome parameter time to clinical union, serious heterogeneity $\left(I^{2}=94 \%\right)$ is also considered to be caused by variability in criteria for clinical union. The studies investigating lower extremity fractures mainly used the criterion full weight bearing as indicator for clinical healing $9,11,13,18$, while the study by Hannemann et al. investigating upper extremity fractures used pain at manipulation of the fracture site, range of motion and grip strength as criteria for determining clinical union. ${ }^{21}$

Only three trials reported on the effects of PEMF in acute fractures. ${ }^{19-21}$ This raises the question of publication bias. One study reported significantly faster healing in the active group treated with PEMF. ${ }^{19}$ However, because of the low amount of publications, significant heterogeneity according to the outcome parameters and the lack of detailed description of the electromagnetic intervention in one study ${ }^{20}$, the potential effects of PEMF cannot be clarified significantly.

\section{Previous research}

The interest in applying physical forces for accelerated bone healing dates back to the 1950s when several animal studies investigated the effect of high-intensity 


\section{Chapter 7}

ultrasound on callus formation and reported adverse effects. ${ }^{22}$ After adjustment of the signal intensity, results from several trials reporting faster callus formation in fractures caused international interest in the use of low-intensity pulsed ultrasound (LIPUS) as a potential method to accelerate bone healing. ${ }^{23,24}$

The first double-blind study concerning PEMF in tibia delayed unions showed a significantly increased healing rate in the intervention group compared to the control group. ${ }^{25}$ Several randomized clinical trials have investigated the effectiveness of LIPUS and PEMF therapy to treat delayed unions and nonunions and concluded that long-bone healing up to $87 \%$ could be achieved when using LIPUS or PEMF for delayed unions or nonunions. ${ }^{26-28}$ Since 1990 several trials have been conducted to test whether LIPUS and PEMF can be used to promote healing in acute fractures. ${ }^{3,4}$

Two previous systematic reviews investigating the use of LIPUS or PEMF in acute fractures were inconclusive about the clinical relevance of LIPUS and PEMF., A possible explanation may be the limited number of studies included and the large heterogeneity in outcome measures. Since then a substantial number of new studies have been published including a systematic review and meta-analysis in 2012. ${ }^{17,19-21,29}$ The authors of this review selected 23 studies that used LIPUS on a variety of bone injuries, including fresh fractures, malunions or nonunions in all types of bones. They were able to pool the fresh fractures and concluded that LIPUS stimulates the radiographic bone healing in fresh fractures. However, they did not consider the type of fracture (metaphyseal or diaphyseal fractures) or the site of fractures (upper or lower limb) for the meta-analysis. Therefore, we believe that our review and meta-analysis currently provides the best available evidence to support clinical decision-making by adding methodological quality, performing a subgroup-analysis and incorporating recently published data. ${ }^{30}$

\section{Recommendations for future research}

Further studies on the acceleration of fracture healing using PEMF and LIPUS should take in to account the need for large clinical trials using an intention-to-treat analysis, proper blinding and adequate concealment of treatment allocation. Although union is a continuous process of bone reconstruction and there is no commonly accepted cut-off point for union of fractures, a valid and uniform measuring method to define radiological union for various fractures should be considered in future trials. ${ }^{31,32}$ This may help in reducing substantial heterogeneity in outcome parameters as stated above. Since the widespread use of PEMF and 
LIPUS bone growth stimulation in orthopedics has its impact on total healthcare costs, cost-effectiveness and cost-utility analyses should also be part of future trials. $^{33}$

\section{Conclusions}

Based on trials with substantial methodological quality, this study suggests that bone growth stimulation with PEMF or LIPUS decreases healing time to radiological union for acute fractures undergoing non-operative treatment and fractures of the upper limb. LIPUS bone growth stimulation can be beneficial in the treatment of acute diaphyseal fractures to accelerate the time to clinical union. Concerning the overall rate of nonunions in acute fractures, current evidence from randomized trials has not demonstrated sufficient advantage to warrant routine use of PEMF or LIPUS. 


\section{Chapter 7}

\section{References}

1. van der Molen AB, Groothoff JW, Visser GJ, Robinson PH, Eisma WH. Time off work due to scaphoid fractures and other carpal injuries in The Netherlands in the period 1990 to 1993. J Hand Surg Br 1999;24:193-8.

2. Bonafede $M$, Espindle D, Bower AG. The direct and indirect costs of long bone fractures in a working age US population. J Med Econ 2013;16:169-78.

3. Griffin XL, Costello I, Costa ML. The role of low intensity pulsed ultrasound therapy in the management of acute fractures: a systematic review. J Trauma 2008;65:1446-52.

4. Walker NA, Denegar CR, Preische J. Low-intensity pulsed ultrasound and pulsed electromagnetic field in the treatment of tibial fractures: a systematic review. J Athl Train 2007; 42:530-5.

5. Moher D, Liberati A, Tetzlaff J, Altman DG, Group P. Preferred reporting items for systematic reviews and meta-analyses: the PRISMA statement. Bmj 2009;339:b2535.

6. Higgins J, Altman DG. Assessing risk of bias in included studies. Cochrane Handbook for Systematic Reviews of Interventions: Cochrane Book Series 2008:187-241.

7. Landis JR, Koch GG. The measurement of observer agreement for categorical data. biometrics 1977:159-74.

8. Higgins JP, Thompson SG. Quantifying heterogeneity in a meta-analysis. Stat Med 2002; 21:1539-58.

9. Heckman JD, Ryaby JP, McCabe J, Frey JJ, Kilcoyne RF. Acceleration of tibial fracturehealing by non-invasive, low-intensity pulsed ultrasound. The Journal of bone and joint surgery American volume 1994;76:26-34.

10. Kristiansen TK, Ryaby JP, McCabe J, Frey JJ, Roe LR. Accelerated healing of distal radial fractures with the use of specific, low-intensity ultrasound. A multicenter, prospective, randomized, double-blind, placebo-controlled study. The Journal of bone and joint surgery American volume 1997;79:961-73.

11. Emami A, Petren-Mallmin M, Larsson S. No effect of low-intensity ultrasound on healing time of intramedullary fixed tibial fractures. J Orthop Trauma 1999;13:252-7.

12. Mayr E, Rudzki MM, Rudzki M, Borchardt B, Hausser H, Ruter A. [Does low intensity, pulsed ultrasound speed healing of scaphoid fractures?]. Handchir Mikrochir Plast Chir 2000;32:115-22.

13. Leung KS, Lee WS, Tsui HF, Liu PP, Cheung WH. Complex tibial fracture outcomes following treatment with low-intensity pulsed ultrasound. Ultrasound Med Biol 2004;30: 389-95.

14. Handolin L, Kiljunen V, Arnala I, et al. No long-term effects of ultrasound therapy on bioabsorbable screw-fixed lateral malleolar fracture. Scand J Surg 2005;94:239-42.

15. Handolin L, Kiljunen V, Arnala I, et al. Effect of ultrasound therapy on bone healing of lateral malleolar fractures of the ankle joint fixed with bioabsorbable screws. J Orthop Sci 2005;10:391-5. 


\section{The effects of LIPUS and PEMF in acute fractures}

16. Handolin L, Kiljunen V, Arnala I, Pajarinen J, Partio EK, Rokkanen P. The effect of low intensity ultrasound and bioabsorbable self-reinforced poly-L-lactide screw fixation on bone in lateral malleolar fractures. Archives of orthopaedic and trauma surgery 2005;125:317-21.

17. Lubbert PH, van der Rijt RH, Hoorntje LE, van der Werken C. Low-intensity pulsed ultrasound (LIPUS) in fresh clavicle fractures: a multi-centre double blind randomised controlled trial. Injury 2008;39:1444-52.

18. Rue JP, Armstrong DW, 3rd, Frassica FJ, Deafenbaugh M, Wilckens JH. The effect of pulsed ultrasound in the treatment of tibial stress fractures. Orthopedics 2004;27:1192-5.

19. Faldini C, Cadossi M, Deianira L, Betti E, Chiarello E, Giannini S. Electromagnetic bone growth stimulation in patients with femoral neck fractures treated with screws: prospective randomized double-blind study. Current Orthopaedic Practice 2010;21:282-87.

20. Adie S, Harris IA, Naylor JM, et al. Pulsed electromagnetic field stimulation for acute tibial shaft fractures: a multicenter, double-blind, randomized trial. The Journal of bone and joint surgery American volume 2011;93:1569-76.

21. Hannemann PF, Gottgens KW, van Wely BJ, et al. The clinical and radiological outcome of pulsed electromagnetic field treatment for acute scaphoid fractures: A randomised double-blind placebo-controlled multicentre trial. The Journal of bone and joint surgery British volume 2012;94:1403-8.

22. Ardan NI, Jr., Janes JM, Herrick JF. Changes in bone after exposure to ultrasonic energy. Minnesota medicine 1954;37:415-20.

23. Borsalino G, Bagnacani M, Bettati E, et al. Electrical stimulation of human femoral intertrochanteric osteotomies. Double-blind study. Clinical orthopaedics and related research 1988:256-63.

24. Azuma Y, Ito M, Harada Y, Takagi H, Ohta T, Jingushi S. Low-intensity pulsed ultrasound accelerates rat femoral fracture healing by acting on the various cellular reactions in the fracture callus. Journal of bone and mineral research: the official journal of the American Society for Bone and Mineral Research 2001;16:671-80.

25. Sharrard WJ. A double-blind trial of pulsed electromagnetic fields for delayed union of tibial fractures. The Journal of bone and joint surgery British volume 1990;72:347-55.

26. Bassett CA, Mitchell SN, Gaston SR. Treatment of ununited tibial diaphyseal fractures with pulsing electromagnetic fields. The Journal of bone and joint surgery American volume 1981;63:511-23.

27. Nolte PA, van der Krans A, Patka P, Janssen IM, Ryaby JP, Albers GH. Low-intensity pulsed ultrasound in the treatment of nonunions. J Trauma 2001;51:693-702; discussion -3.

28. Schofer MD, Block JE, Aigner J, Schmelz A. Improved healing response in delayed unions of the tibia with low-intensity pulsed ultrasound: results of a randomized shamcontrolled trial. BMC Musculoskelet Disord 2010;11:229. 


\section{Chapter 7}

29. Bashardoust Tajali S, Houghton P, MacDermid JC, Grewal R. Effects of low-intensity pulsed ultrasound therapy on fracture healing: a systematic review and meta-analysis. American journal of physical medicine \& rehabilitation / Association of Academic Physiatrists 2012;91:349-67.

30. Poolman RW, Abouali JA, Conter HJ, Bhandari M. Overlapping systematic reviews of anterior cruciate ligament reconstruction comparing hamstring autograft with bonepatellar tendon-bone autograft: why are they different? The Journal of bone and joint surgery American volume 2007;89:1542-52.

31. Bhandari M, Fong K, Sprague S, Williams D, Petrisor B. Variability in the definition and perceived causes of delayed unions and nonunions: a cross-sectional, multinational survey of orthopaedic surgeons. The Journal of bone and joint surgery American volume 2012;94:e1091-6.

32. Corrales LA, Morshed S, Bhandari M, Miclau T, 3rd. Variability in the assessment of fracture-healing in orthopaedic trauma studies. The Journal of bone and joint surgery American volume 2008;90:1862-8.

33. Button ML, Sprague S, Gharsaa O, Latouche S, Bhandari M. Economic evaluation of bone stimulation modalities: A systematic review of the literature. Indian J Orthop 2009;43: 168-74. 
The effects of LIPUS and PEMF in acute fractures 


\section{Chapter 8}

\section{GENERAL DISCUSSION}



This thesis has assessed the addition of pulsed electromagnetic fields (PEMF) bone growth stimulation to the conservative treatment of minimally displaced and undisplaced scaphoid waist fractures. In two separate randomized, doubleblind, placebo-controlled multicenter trials, we tested the hypothesis that the use of PEMF could significantly accelerate time to union and reduce the number of nonunions. Since delayed healing and prolonged immobilization of scaphoid fractures may have severe socioeconomic consequences for the mainly young, working population affected, we also investigated functional outcomes and costeffectiveness in a prospective trial.

Further, we evaluated the reliability and validity of conventional radiographic examination and multiplanar reconstruction computed tomography in diagnosing scaphoid waist fracture union. This is important as the definition of bony union is dependent on the modality used to assess it, and its consistent identification is determined by the precision and accuracy of the different imaging techniques. Therefore, these studies also provided a quality control for one of the major outcome parameters of the multicenter trials.

A considerable amount of clinical and basic research has been conducted on electrophysical bone growth stimulation. However, level I and II evidence supporting the use of bone growth stimulation (particularly electromagnetic bone growth stimulation) in the treatment of acute fractures is limited. To put the results of our prospective trials into perspective and determine the role and place of electrophysical bone growth stimulation in the treatment of acute fractures, we also performed a systematic review and meta-analysis of the effects of low-intensity pulsed ultrasound (LIPUS) and pulsed electromagnetic fields (PEMF) bone growth stimulation in acute fractures.

\section{Clinical and radiological outcomes of PEMF treatment FOR ACUTE SCAPHOID FRACTURES}

In chapter 2 we randomly assigned 53 patients from 3 different medical centers with a unilateral scaphoid fracture to conservative treatment with either PEMF bone growth stimulation as an adjunct to cast immobilization or a placebo. Followup lasted one year, with the clinical and radiological outcomes assessed at 4, 6, 9, 12, 24 and 52 weeks. Neither time to full radiological consolidation nor functional outcomes differed significantly between groups. This was the first trial to investigate the effect of PEMF on time to union and functional outcome in fresh scaphoid fractures. Previous studies by Adams, Frykman and Taleisnik and 


\section{Chapter 8}

Frykman et al. reported healing rates of $69 \%$ to $80 \%$ in scaphoid nonunions treated with cast immobilization and PEMF. ${ }^{1,2}$ The only previous study on the effects of electrophysical bone growth stimulation in fresh scaphoid fractures is that by Mayr et al. ${ }^{3}$ In their prospective, double-blind, randomized clinical trial on the effects of LIPUS on the healing speed of acute scaphoid fractures, they randomized 28 patients with 30 acute undisplaced fractures of the scaphoid waist to LIPUS or placebo. The median healing time of the fractures was 43 days \pm 11 days in the LIPUS group versus $62 \pm 19$ days in the control group $(p<0.01)$. These results confirmed those of Heckman et al. and Kristiansen et al., showing that the addition of low-intensity ultrasound stimulation to a conservative treatment regime significantly accelerated healing in fresh tibial and distal radius fractures, respectively. ${ }^{4,5}$ It is worth noting that a significant number of participants from the studies by Heckman et al. and Kristiansen et al. were either excluded due to protocol violation or lost to follow-up ( $20 \%$ and $25 \%$, respectively). Still, that we were not able to confirm the results of these studies is striking. It is unclear whether the discrepancy can be attributed to differences in the effects at cellular level of PEMF versus LIPUS bone growth stimulation.

In our first trial multicenter trial, healing of the scaphoid fractures was assessed using conventional radiographic imaging. In the study by Mayr et al., union was assessed by means of CT scans every 2 weeks. As described in chapter 3, we found a moderate weighted average inter-observer agreement for radiological union at 6 weeks after injury for the conventional radiographs $(\kappa=0.583(95 \%$ Cl 0.371-0.795; $p<0.001)$ ). Others, however, have reported limited reliability of conventional scaphoid series for radiographic signs of union. ${ }^{6}$ Still, numerous recent studies on the treatment of scaphoid waist fractures have likewise used standard radiographic imaging techniques to determine radiological healing. ${ }^{7-9}$

In addition to the lack of significant differences in radiological outcomes between the PEMF and the placebo group in our first multicenter trial, no significant differences between treatment arms were observed during follow-up with respect to the clinical parameters of union. However, clinical signs of union, too, have limited reliability, and are identified in the literature based on many different criteria. ${ }^{10,11}$ Unfortunately, no significant differences were found for range of motion and grip strength, both of which are important predictors of outcome after wrist injuries. ${ }^{12}$ 


\section{The Role of PEMF AND LIPUS bone Growth Stimulation IN THE TREATMENT OF ACUTE FRACTURES}

There is evidence that the addition of PEMF or LIPUS bone growth stimulation in the conservative treatment of acute fractures is effective. In their systematic review on the effects of LIPUS and PEMF in the treatment of tibial fractures, Walker, Denegar and Preische concluded that LIPUS accelerates the healing of acute tibial fractures and PEMF increases the proportion of previously ununited tibial fractures that heal without additional (surgical) intervention. ${ }^{13}$ However, the lack of uniform outcome criteria for healing prevented the authors from comparing the effects of the two modalities.

Chapter 7 presented a systematic review and meta-analysis based on pooled data from 13 trials. We found that bone growth stimulation technology may be of benefit to patients with an acute fracture, especially when treated nonoperatively. ${ }^{14}$ However, there is not enough evidence to recommend the ubiquitous application of electrophysical bone growth stimulation technologies in the nonoperative treatment of acute fractures. We also concluded that studies reporting on the results of PEMF are underrepresented. The results of our systematic review and meta-analysis may therefore be more applicable to LIPUS than to PEMF bone growth stimulation. Furthermore, a significant number of the analyses were characterized by heterogeneous outcomes, resulting from the lack of uniform criteria for union. Still, our systematic review and meta-analysis revealed that time to radiographic union in conservatively treated fractures was significantly shorter when it included bone growth stimulation.

In addition to the abovementioned clinical studies on the effects of LIPUS and PEMF, numerous basic research studies support the potential efficacy of PEMF in the treatment of fresh fractures. The in-vitro effects of PEMF on cell proliferation and differentiation of osteoblasts, resulting in increased mineralization, have been described extensively in the literature. ${ }^{15,16}$ These effects have also been observed in animal model studies, where a significant increase in callus mineralization and new bone formation has been observed after PEMF treatment. ${ }^{17,18}$ Using a PEMF signal with the same characteristics as in our multicenter trial, Jansen et al. demonstrated that PEMF exposure of differentiating human bone marrow-derived stromal cells stimulates the expression of specific osteogenic genes, such as bone morphogenetic protein 2 (BMP-2) and osteocalcin, both important for new bone formation and mineralization. ${ }^{19}$ 


\section{Chapter 8}

\section{The ROle OF PEMF IN the tREATMENT OF ACUTE MiNimAlLy DiSPLACED AND NONDISPLACED SCAPHOID FRACTURES}

There is evidence that CT scans are more reliable and accurate in diagnosing scaphoid fracture union than conventional imaging techniques. ${ }^{20,21}$ However, only two studies to date provided evidence regarding inter-observer agreement on the use of CT scans for diagnosis of fracture union in undisplaced and minimally displaced scaphoid waist fractures. ${ }^{21,22}$ Buijze et al. used single-plane sagittal images to assess scaphoid waist fracture union, ${ }^{21}$ while Geoghegan et al. addressed the reproducibility of CT scans for fracture union at 4 weeks after start of treatment. ${ }^{22}$ Therefore, in chapter 4 we examined inter-observer reliability and accuracy of multiplanar reconstruction $\mathrm{CT}$ scans for scaphoid waist fracture union at 6, 12 and 24 weeks after start of treatment. We concluded that computed tomography is a reliable and accurate tool for assessing union or nonunion in scaphoid fractures. ${ }^{23}$ Given this result, in the study reported on in chapter 5 we used CT scans to assess union during follow-up in a new trial on the effects of PEMF bone growth stimulation in acute scaphoid fractures. The aim was to further underpin the results of our first trial on PEMF in acute scaphoid fractures. In the course of 2010 and 2011, we conducted a double-blind, prospective multicenter trial including 102 patients with a unilateral minimally displaced or nondisplaced scaphoid fracture. Patients were randomly assigned to PEMF (with the same signal characteristics as used in the previous trial and the in-vitro study by Jansen et al. ${ }^{19}$ ) or placebo. We hypothesized that PEMF would significantly reduce time to union as well as the number of nonunions. Radiological healing was assessed by means of multiplanar reconstruction CT, using the technique described in our study on the accuracy and precision of this modality. ${ }^{23}$ In addition to radiological outcome parameters, we assessed clinical and functional outcomes as primary outcome parameters.

Results revealed that neither time to clinical union, based on the proportion of patients reaching the criteria for clinical union, nor time to radiological union differed significantly between the PEMF and the placebo group. However, post hoc log-rank subgroup analysis revealed that undisplaced transverse waist fractures proceeded to radiologically confirmed union earlier in the PEMF group. Since this study was not primarily designed to detect differences between subgroups, this finding should be interpreted with restraint. Still, the significant effect of PEMF on healing in a subgroup of stable scaphoid waist fractures was striking. 


\section{StabiLITY OF SCAPHOID FRACTURES AS A PREDICTOR FOR OUTCOME OF CONSERVATIVE TREATMENT}

Given the substantial interfragmentary motion in scaphoid nonunions, there is evidence that fracture stability is a predictor for the development of nonunion. ${ }^{24}$ Previous research has also indicated that the location of the scaphoid fracture is related to particular patterns of instability in scaphoid nonunions. ${ }^{25} \mathrm{~A}$ study assessing fracture displacement with MRI showed that a significant number of displaced fractures failed to unite, while none of the nondisplaced fractures developed nonunion. ${ }^{26}$ Moreover, a recent meta-analysis on the management of displaced scaphoid waist fractures concluded that displaced fractures are four times more likely to develop nonunion than undisplaced fractures. ${ }^{27}$ There is evidence that the majority of undisplaced scaphoid fractures unite after 4 weeks of plaster cast immobilization. ${ }^{22}$

In addition to displacement, fracture translation and the amount of bone contact between fracture fragments have been suggested as further predictors of union, although inter- and intra-observer agreement on the definition of these aspects is poor. ${ }^{22}$ We therefore conclude that fracture displacement and the amount of bone contact between fragments or fracture union soon after initiation of treatment are strongly correlated with eventual union. Further, there is circumstantial evidence that the amount of bone contact between fracture fragments and the amount of early trabecular bridging are correlated with the speed of healing. This is based on clinical findings that the majority of scaphoid fractures with moderate displacement or distraction of fracture fragments initially proceed to a stage of partial union, and eventually (after a prolonged period) progress to full union. ${ }^{28}$

We suspect that the same principles may be responsible for our finding that PEMF accelerates union in a subgroup of nondisplaced, transverse stable scaphoid waist fractures. In vitro studies have shown that the strongest effects of PEMF stimulation are observed in the period of bone healing, prior to the stage of mineralization. ${ }^{19,29}$ Therefore, PEMF may be more effective in stable, undisplaced transverse waist fractures with maximum bone contact between fracture fragments, which proceed earlier to this stage of bone healing than distracted or oblique waist fractures that reach this stage only later, since bone growth stimulation is usually administered for a limited period of time (e.g. 6 weeks in our trial). This interpretation is supported by Mayr et al.'s findings on the effects of LIPUS bone growth stimulation in acute scaphoid fractures, which healed 


\section{Chapter 8}

significantly faster in the intervention group among stable, undisplaced waist fractures of the scaphoid. ${ }^{3,30}$

Thus, PEMF and LIPUS may have effects only in a narrow time window during fracture healing and in a specific subtype of fractures. This may limit the generalizability of the clinical use of PEMF. Therefore, adequate fracture imaging and classification is needed to select the most suitable patients prior to the start of the treatment.

\section{Cost-effectiveness of PEMF treatment for acute scaphoid fractures}

Data on the number of workdays lost due to scaphoid fractures are limited. The most detailed study published to date considered time off work due to scaphoid fractures and other carpal injuries in the Netherlands between 1990 and 1993. ${ }^{31}$ On average, patients were able to resume their previous work activities after 144 days. In a randomized trial on the cost-effectiveness of operative versus conservative treatment of acute scaphoid fractures, the median time off work for the patients treated conservatively was 74 days. ${ }^{32}$ In comparison, in our study in chapter 6 on the functional outcomes and cost-effectiveness of PEMF in the treatment of acute scaphoid fractures, the average numbers of workdays lost in the PEMF and the placebo group were 9.8 and 12.9 days, respectively. These figures are considerably lower than those reported in the two abovementioned studies. Those studies, however, used standard scaphoid series radiographs to assess fracture healing, whereas our study used follow-up CT scans. As follow-up scaphoid radiographs do not always provide reliable or accurate information on fracture healing, a time frame of 8 to 12 weeks (and even up to 20 weeks) of plaster cast immobilization is frequently used. ${ }^{8,32-34}$ In our study, immobilization of the wrist was discontinued after 6 weeks in $42 \%$ of patients, as the use of CT scans simplified the assessment of fracture union and therefore also the decision to cease plaster cast immobilization. It is highly likely that this facilitated the resumption of former activities, thus reducing the number of workdays lost.

Furthermore, $55 \%$ of patients in our study performed manual work, compared to the majority of patients in Van der Molen et al. ${ }^{31}$ Less than $2 \%$ of patients in that study were able to resume work with an immobilized wrist, compared to $49 \%$ in our study. This suggests that the patient's occupation is the key factor influencing time off work among patients with an immobilized wrist due to carpal injury. In accordance with other authors, we found that non-manual workers took less time off work than manual workers. ${ }^{32}$ 
Given that the number of total workdays lost in both groups was remarkably small compared to previous studies, the average workdays lost in the PEMF group (9.82 days) did not differ significantly from that in the placebo group (12.91 days) ( $p=0.651)$. Since PEMF treatment involves considerably higher healthcare costs, its total cost to society is higher than that of standard conservative treatment, despite the small but not statistically significant difference in lost workdays. Therefore, in terms of cost-effectiveness PEMF can be considered an inferior treatment option for scaphoid fractures compared to care as usual.

\section{Conclusions}

This thesis set out to establish whether PEMF bone growth stimulation has added value in the conservative treatment of acute scaphoid fractures. For this purpose we conducted two separate randomized, double-blind, placebo-controlled trials. We concluded that the addition of PEMF did not accelerate bone healing, neither in terms of clinical nor radiological criteria. Furthermore, in terms of cost-effectiveness PEMF treatment can be considered inferior to conservative treatment, as it leads to higher costs with no improvement in functional outcome or general health-related quality of life.

However, based on our systematic review and meta-analysis of randomized controlled trials comparing PEMF or LIPUS with placebo for acute fractures, we concluded that PEMF/LIPUS can be beneficial in treating acute fractures. These treatment modalities have the potential to significantly accelerate both time to radiological union (for fractures treated nonoperatively and acute upper limb fractures) and time to clinical union (for acute diaphyseal fractures). Still, current evidence from randomized trials is insufficient to warrant routine use of PEMF or LIPUS in the conservative treatment of fractures to reduce the number of nonunions.

\section{Future PERSPECTIVES}

Evidence has accumulated in recent years that operative treatment of undisplaced and minimally displaced scaphoid fractures leads to faster return to work and sports, but also to significantly higher complication rates compared to conservative treatment in a below-elbow plaster cast. ${ }^{35}$ Furthermore, there is no evidence that operative treatment of minimally displaced and undisplaced scaphoid waist fractures significantly decreases the number of nonunions. ${ }^{35}$ 


\section{Chapter 8}

Research shows, however, that the majority of undisplaced scaphoid waist fractures unite within 4 weeks when treated conservatively in a below-elbow cast. ${ }^{22}$ For this reason, the most accurate and reliable diagnostic technique should be used prior to start of the treatment to select those scaphoid fractures best suited for conservative or operative treatment.

Moreover, in order to minimize the duration of immobilization, the early effects of conservative treatment of undisplaced and minimally displaced scaphoid fractures should be monitored to determine whether treatment can be discontinued. This thesis has provided evidence that MRCT is more suitable for this task than conventional radiographic imaging.

The aforementioned studies addressing scaphoid fracture displacement and stability suggest that the outcomes of conservative treatment of scaphoid waist fractures can be predicted by multiplanar imaging techniques such as MRI or CT. Yet, there is evidence that even CT scanning is unable to adequately predict the stability or instability of scaphoid waist fractures, given that a significant number of fractures with unstable fracture patterns during arthroscopic evaluation show no malalignment on CT scans. ${ }^{36}$ Early dynamic sequential multiplanar computed tomography of scaphoid fractures may be helpful in determining the stability of the fracture; however, this technique has not yet been described in literature. Therefore, its feasibility with respect to scaphoid fractures should be investigated.

This thesis has contributed to the empirical pursuit of alternatives to surgery in order to further decrease the period of disability due to immobilization of undisplaced and minimally displaced scaphoid fractures. Specifically, it has demonstrated that the addition of PEMF bone growth stimulation to conservative treatment is justifiable neither with regard to accelerating the speed of healing, nor with regard to reducing the number of nonunions. However, it has also provided evidence that bone growth stimulation techniques such as PEMF or LIPUS can affect the time to radiological healing in non-operatively treated fractures. Furthermore, it has brought to light circumstantial evidence that fracture characteristics may influence the effects of pulsed electromagnetic fields bone growth stimulation on time to healing.

We identified a subgroup of patients with stable, transverse scaphoid waist fractures that proceeded to union earlier with PEMF treatment. However, this subgroup analysis should be considered underpowered in relation to the required sample size based on our initial power analysis. A study focusing on this subgroup of stable scaphoid waist fractures would therefore be desirable. Given that 
$38 \%$ of all fractures in our study were classified as stable, undisplaced transverse waist fractures, at least 265 patients with this type of scaphoid waist fracture should be considered for inclusion based on the abovementioned power analysis. Whether this is feasible remains unclear.

Moreover, further research is needed on the interaction between bone and its physical surroundings. Since bone healing is a complex process in which blood supply and mechanical stability play an important role, it is essential to investigate these interactions in vivo rather than in vitro. In addition, uncertainty concerning the ideal intensity and exposure length of the PEMF signal might further contribute to its lack of effect in the treatment of fresh fractures. In future research, therefore, we will address the efficacy of different PEMF signal exposure lengths in a standardized mouse femur osteotomy model. This will help to clarify the existing uncertainty regarding the signal characteristics and minimal required exposure time of PEMF bone growth stimulation for acute fractures.

It would be feasible to evaluate the fracture healing process of scaphoid fractures using high-resolution imaging techniques in order to detect small changes in morphometric properties. Recently, a high-resolution peripheral quantitative computed tomography (HR-pQCT) scanner has been developed that allows for visualization of the trabecular structure of peripheral bone in vivo with a significantly better spatial resolution than conventional CT imaging. ${ }^{37}$ We expect this technique to facilitate visualization of changes in bone stiffness and histomorphometrical parameters of scaphoid fractures due to bone growth stimulation. Therefore, in an upcoming single-center, randomized, double-blind, placebo-controlled trial we will assess the effect of PEMF treatment of acute scaphoid fractures by detecting changes in trabecular bone parameters by means of HR-pQCT. Based on the results of this trial, we will be able to draw further conclusions on the efficacy of PEMF in the treatment of acute scaphoid fractures. 


\section{Chapter 8}

\section{REFERENCES}

1. Adams BD, Frykman GK, Taleisnik J. Treatment of scaphoid nonunion with casting and pulsed electromagnetic fields: a study continuation. The Journal of hand surgery 1992; 17:910-4.

2. Frykman GK, Taleisnik J, Peters G, et al. Treatment of nonunited scaphoid fractures by pulsed electromagnetic field and cast. The Journal of hand surgery 1986;11:344-9.

3. Mayr E, Rudzki MM, Rudzki M, Borchardt B, Hausser H, Ruter A. [Does low intensity, pulsed ultrasound speed healing of scaphoid fractures?]. Handchirurgie, Mikrochirurgie, plastische Chirurgie: Organ der Deutschsprachigen Arbeitsgemeinschaft fur Handchirurgie: Organ der Deutschsprachigen Arbeitsgemeinschaft fur Mikrochirurgie der Peripheren Nerven und Gefasse 2000;32:115-22.

4. Heckman JD, Ryaby JP, McCabe J, Frey JJ, Kilcoyne RF. Acceleration of tibial fracturehealing by non-invasive, low-intensity pulsed ultrasound. The Journal of bone and joint surgery American volume 1994;76:26-34.

5. Kristiansen TK, Ryaby JP, McCabe J, Frey JJ, Roe LR. Accelerated healing of distal radial fractures with the use of specific, low-intensity ultrasound. A multicenter, prospective, randomized, double-blind, placebo-controlled study. The Journal of bone and joint surgery American volume 1997;79:961-73.

6. Dias JJ, Taylor M, Thompson J, Brenkel IJ, Gregg PJ. Radiographic signs of union of scaphoid fractures. An analysis of inter-observer agreement and reproducibility. The Journal of bone and joint surgery British volume 1988;70:299-301.

7. Dias JJ, Wildin CJ, Bhowal B, Thompson JR. Should acute scaphoid fractures be fixed? A randomized controlled trial. The Journal of bone and joint surgery American volume 2005;87:2160-8.

8. McQueen MM, Gelbke MK, Wakefield A, Will EM, Gaebler C. Percutaneous screw fixation versus conservative treatment for fractures of the waist of the scaphoid: a prospective randomised study. The Journal of bone and joint surgery British volume 2008; 90:66-71.

9. Vinnars B, Pietreanu M, Bodestedt A, Ekenstam F, Gerdin B. Nonoperative compared with operative treatment of acute scaphoid fractures. A randomized clinical trial. The Journal of bone and joint surgery American volume 2008;90:1176-85.

10. Waizenegger M, Barton NJ, Davis TR, Wastie ML. Clinical signs in scaphoid fractures. J Hand Surg Br 1994;19:743-7.

11. Corrales LA, Morshed S, Bhandari M, Miclau T, 3rd. Variability in the assessment of fracture-healing in orthopaedic trauma studies. The Journal of bone and joint surgery American volume 2008;90:1862-8.

12. Chung KC, Haas A. Relationship between patient satisfaction and objective functional outcome after surgical treatment for distal radius fractures. Journal of hand therapy: official journal of the American Society of Hand Therapists 2009;22:302-7; quiz 8. 


\section{General discussion}

13. Walker NA, Denegar CR, Preische J. Low-intensity pulsed ultrasound and pulsed electromagnetic field in the treatment of tibial fractures: a systematic review. J Athl Train 2007;42:530-5.

14. Hannemann PF, Mommers EH, Schots JP, Brink PR, Poeze M. The effects of low-intensity pulsed ultrasound and pulsed electromagnetic fields bone growth stimulation in acute fractures: a systematic review and meta-analysis of randomized controlled trials. Archives of orthopaedic and trauma surgery 2014;134:1093-106.

15. Wiesmann H, Hartig M, Stratmann U, Meyer U, Joos U. Electrical stimulation influences mineral formation of osteoblast-like cells in vitro. Biochimica et biophysica acta 2001; 1538:28-37.

16. Martino CF, Belchenko D, Ferguson V, Nielsen-Preiss S, Qi HJ. The effects of pulsed electromagnetic fields on the cellular activity of SaOS-2 cells. Bioelectromagnetics 2008;29:125-32.

17. Taylor KF, Inoue N, Rafiee B, Tis JE, McHale KA, Chao EY. Effect of pulsed electromagnetic fields on maturation of regenerate bone in a rabbit limb lengthening model. Journal of orthopaedic research: official publication of the Orthopaedic Research Society 2006;24:2-10.

18. Inoue N, Ohnishi I, Chen D, Deitz LW, Schwardt JD, Chao EY. Effect of pulsed electromagnetic fields (PEMF) on late-phase osteotomy gap healing in a canine tibial model. Journal of orthopaedic research: official publication of the Orthopaedic Research Society 2002;20:1106-14.

19. Jansen JH, van der Jagt OP, Punt BJ, et al. Stimulation of osteogenic differentiation in human osteoprogenitor cells by pulsed electromagnetic fields: an in vitro study. BMC musculoskeletal disorders 2010;11:188.

20. Hackney LA, Dodds SD. Assessment of scaphoid fracture healing. Current reviews in musculoskeletal medicine 2011;4:16-22.

21. Buijze GA, Wijffels MM, Guitton TG, Grewal R, van Dijk CN, Ring D. Interobserver reliability of computed tomography to diagnose scaphoid waist fracture union. The Journal of hand surgery 2012;37:250-4.

22. Geoghegan JM, Woodruff MJ, Bhatia R, et al. Undisplaced scaphoid waist fractures: is 4 weeks' immobilisation in a below-elbow cast sufficient if a week 4 CT scan suggests fracture union? The Journal of hand surgery, European volume 2009;34:631-7.

23. Hannemann PF, Brouwers L, van der Zee D, et al. Multiplanar reconstruction computed tomography for diagnosis of scaphoid waist fracture union: a prospective cohort analysis of accuracy and precision. Skeletal Radiol 2013.

24. Leventhal EL, Wolfe SW, Moore DC, Akelman E, Weiss AP, Crisco JJ. Interfragmentary motion in patients with scaphoid nonunion. The Journal of hand surgery 2008;33:1108-15.

25. Moritomo H, Murase T, Oka K, Tanaka H, Yoshikawa H, Sugamoto K. Relationship between the fracture location and the kinematic pattern in scaphoid nonunion. The Journal of hand surgery 2008;33:1459-68. 


\section{Chapter 8}

26. Bhat M, McCarthy M, Davis TR, Oni JA, Dawson S. MRI and plain radiography in the assessment of displaced fractures of the waist of the carpal scaphoid. The Journal of bone and joint surgery British volume 2004;86:705-13.

27. Singh HP, Taub N, Dias JJ. Management of displaced fractures of the waist of the scaphoid: meta-analyses of comparative studies. Injury 2012;43:933-9.

28. Singh HP, Forward D, Davis TR, Dawson JS, Oni JA, Downing ND. Partial union of acute scaphoid fractures. J Hand Surg Br 2005;30:440-5.

29. Aaron RK, Ciombor DM. Acceleration of experimental endochondral ossification by biophysical stimulation of the progenitor cell pool. Journal of orthopaedic research: official publication of the Orthopaedic Research Society 1996;14:582-9.

30. Herbert TJ, Fisher WE. Management of the fractured scaphoid using a new bone screw. The Journal of bone and joint surgery British volume 1984;66:114-23.

31. van der Molen AB, Groothoff JW, Visser GJ, Robinson PH, Eisma WH. Time off work due to scaphoid fractures and other carpal injuries in The Netherlands in the period 1990 to 1993. J Hand Surg Br 1999;24:193-8.

32. Vinnars B, Ekenstam FA, Gerdin B. Comparison of direct and indirect costs of internal fixation and cast treatment in acute scaphoid fractures: a randomized trial involving 52 patients. Acta orthopaedica 2007;78:672-9.

33. Bond CD, Shin AY, McBride MT, Dao KD. Percutaneous screw fixation or cast immobilization for nondisplaced scaphoid fractures. The Journal of bone and joint surgery American volume 2001;83-A:483-8.

34. Desai VV, Davis TR, Barton NJ. The prognostic value and reproducibility of the radiological features of the fractured scaphoid. J Hand Surg Br 1999;24:586-90.

35. Ibrahim T, Qureshi A, Sutton AJ, Dias JJ. Surgical versus nonsurgical treatment of acute minimally displaced and undisplaced scaphoid waist fractures: pairwise and network meta-analyses of randomized controlled trials. The Journal of hand surgery 2011;36: 1759-68 e1.

36. Buijze GA, Jorgsholm P, Thomsen NO, Bjorkman A, Besjakov J, Ring D. Diagnostic performance of radiographs and computed tomography for displacement and instability of acute scaphoid waist fractures. The Journal of bone and joint surgery American volume 2012;94:1967-74.

37. Engelke K, Libanati C, Liu Y, et al. Quantitative computed tomography (QCT) of the forearm using general purpose spiral whole-body CT scanners: accuracy, precision and comparison with dual-energy X-ray absorptiometry (DXA). Bone 2009;45:110-8. 
General discussion 


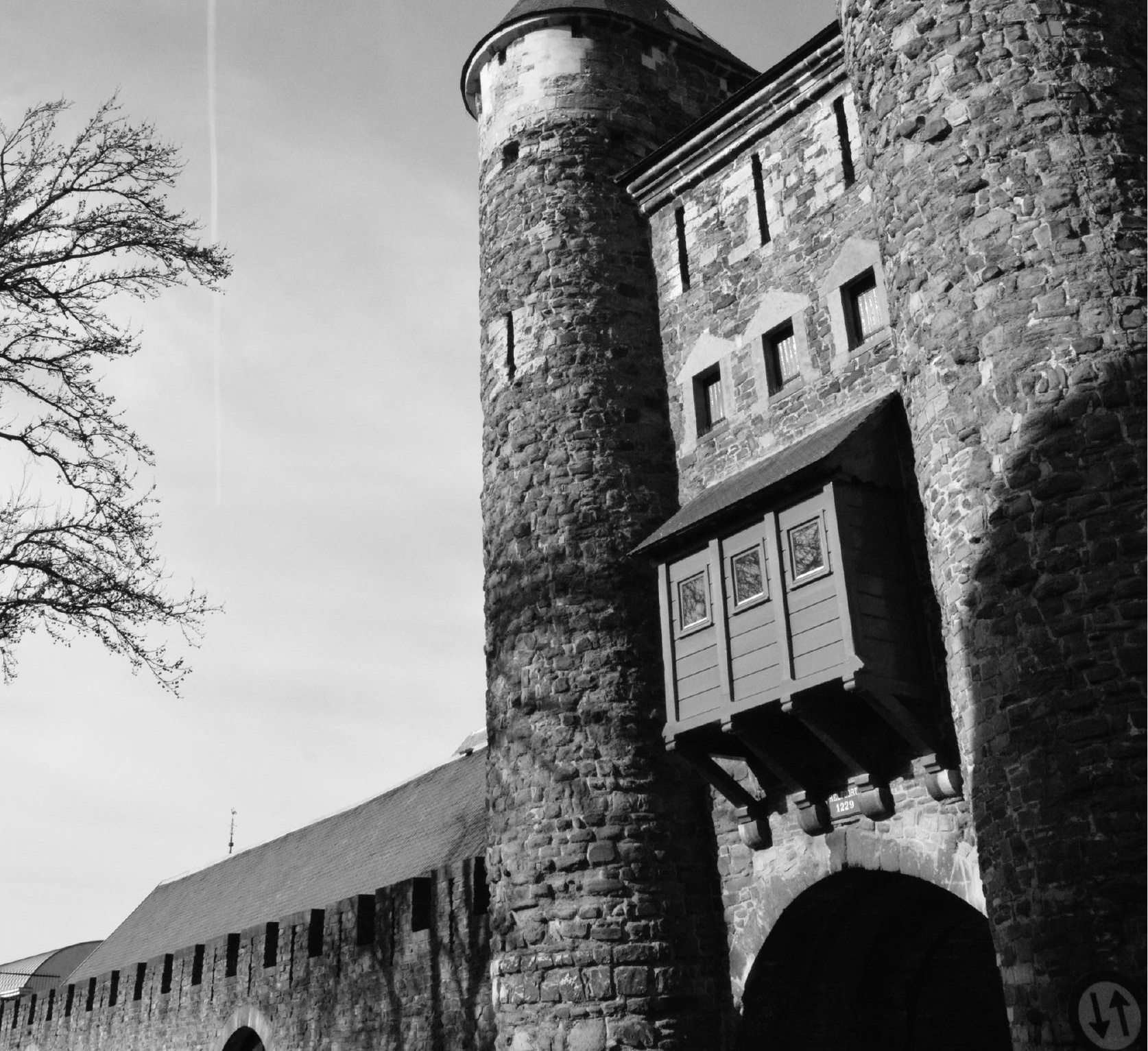


Chapter 9

SUMMARY 

Scaphoid fractures are relatively common among young, active people and failed or delayed treatment can have severe health related, economical and social consequences.

In this thesis, the influence of pulsed electromagnetic field (PEMF) bone growth stimulation on the healing of acute scaphoid fractures has been addressed. We hypothesized that the use of pulsed electromagnetic field therapy would significantly improve healing in acute scaphoid fractures. Our research objective was to determine whether PEMF bone growth stimulation would accelerate fracture healing both clinically and radiologically. Furthermore, we tried to determine whether the use of PEMF in acute scaphoid fractures would reduce the number of nonunions and whether it would improve functional outcome, when used as an adjunct to conservative treatment. The reliability and accuracy of different diagnostic modalities to prove scaphoid fracture healing have also been investigated.

In chapter 1, fracture healing of the scaphoid including the factors that contribute to the development of complicated or failed healing and different treatment options of scaphoid fractures are being described. Furthermore, the history, principles and possible applicability of electrophysical bone growth stimulation and PEMF in particular are addressed.

In chapter 2, the first randomized, double-blind, placebo-controlled trial to test the hypothesis that the use of PEMF in acute scaphoid fractures can significantly accelerate time to union is being described. A total of 53 patients with undisplaced acute scaphoid fractures from three different Dutch medical centers were randomized to treatment with either a PEMF bone growth stimulator or a placebo. Clinical and radiological outcomes were assessed at four, six, nine, 12, 24 and 52 weeks after start of the treatment. Radiological follow up was performed by assessment of scaphoid series radiographs.

Neither time to clinical and radiological union, nor functional outcomes differed significantly between both groups and we therefore concluded that, based on this trial, PEMF had no additional value in the conservative treatment of acute scaphoid fractures.

Although standard scaphoid series radiographs are the first imaging tool of choice for diagnosis of scaphoid fractures, they do not always provide reliable and accurate information regarding the presence or absence of fracture union. In chapter 3, we investigated inter-observer agreement and validity of standard scaphoid series radiographs for the diagnosis of scaphoid fracture union and 


\section{Chapter 9}

nonunion in a prospective cohort analysis. Fleiss' kappa statistics were used concerning the opinions of four observers reviewing 47 sets of scaphoid series radiographs, regarding the time frame of 6 weeks after start of the conservative treatment of undisplaced scaphoid waist fractures. This time frame was chosen since a substantial part of undisplaced scaphoid waist fractures unite after 6 weeks of cast immobilization. Reliability concerning nonunion was better than for union and overall reliability was defined as moderate.

In order to put these results in perspective, we examined reliability and validity concerning scaphoid fracture union determined by multiplanar reconstruction CT at 6, 12 and 24 weeks after injury in chapter 4. Again, Fleiss' kappa statistics were used to determine inter-observer agreement concerning 44 sets of computed tomographic scans. Reliability concerning the diagnosis of nonunion and union were both substantial. Furthermore, sensitivity and specificity of multiplanar CT scan for diagnosis of union were better than for standard scaphoid series radiographs. For follow-up after a scaphoid fracture, computed tomography seems a reliable and accurate method to assess union or nonunion of the fracture. We concluded that CT scanning should be used early in follow-up of scaphoid fracture treatment.

The findings from chapters 2, 3 and 4 warranted a larger and improved trial on the efficacy of PEMF for acute scaphoid fractures. In chapter 5, we describe the randomized, double-blind, placebo-controlled multicenter trial, in which we hypothesized that PEMF bone growth stimulation would significantly shorten the time to union in acute scaphoid fractures and significantly reduce the number of scaphoid nonunions. A total of 102 patients from five different medical centers with undisplaced acute scaphoid fractures where randomly allocated to treatment with a PEMF bone growth stimulator or a placebo and assessed regarding functional and radiological outcomes. For assessment of radiological parameters of healing, multiplanar reconstruction computed tomographic scans were made at 6, 12, 24 and 52 weeks. Although overall time to clinical and radiological healing did not differ significantly between the PEMF group and the placebo group, we were able to select a group of patients with scaphoid fractures in a post-hoc subgroup analysis that may benefit from PEMF bone growth stimulation with regards to speed of healing. Log-rank analysis revealed a significantly shorter time to union in the active PEMF group for undisplaced transverse scaphoid waist fractures. However, since these subgroup analyses were underpowered when considering the minimum number of participants needed when applying our power analysis used for this trial, we confirmed the results of 
our study described in chapter 2 and concluded that the addition of PEMF to the conservative treatment of acute scaphoid fractures does not accelerate bone healing in general.

In chapter 6, a prospective economic evaluation of PEMF bone growth stimulation in acute scaphoid fractures was carried out from a social perspective, alongside the randomized trial described in chapter 5. All costs of PEMF treatment and care as usual for undisplaced scaphoid fractures, including medical costs and costs due to productivity loss were measured during one year. Furthermore, functional outcome and general health related quality of life were assessed using the EuroQol-5D and patient rated wrist and hand evaluation (PRWHE) questionnaires. No significant differences in the amount of lost workdays were observed between the two groups. Mean total costs for the active PEMF group were higher than mean total costs for standard conservative treatment. The desired effects of PEMF treatment for acute scaphoid fractures in terms of costeffectiveness were therefore not achieved. Moreover, no differences in functional outcomes and general health related quality of life were observed between both groups.

In chapter 7, available literature on bone growth stimulation for acute fractures has been reviewed. The aim of this systematic review and meta-analysis was to evaluate best available evidence from randomized controlled trials comparing pulsed electromagnetic field or low intensity pulsed ultrasound (LIPUS) bone growth stimulation with placebo for acute fractures. Two reviewers independently determined the strength of the included studies and assessed the risk of bias. Seven hundred and thirty-seven patients from 13 trials were included. Evidence from randomized trials included in this analysis revealed that PEMF and LIPUS significantly shorten time to radiological union for acute fractures undergoing non-operative treatment and acute fractures of the upper limb. However, based on this review, the routine use of both techniques for reduction of the proportion of fractures proceeding to nonunion is not supported by evidence.

In conclusion, evidence from this thesis has not demonstrated significant advantage from the use of pulsed electromagnetic field treatment to justify routine application of PEMF bone growth stimulation in acute scaphoid fractures. When using multiplanar CT scans for assessment of healing of scaphoid fractures - the diagnostic modality that in this thesis showed superior reliability and accuracy when compared to standard scaphoid series radiographs for determination of scaphoid fracture union - we conclude that neither time to full union, nor the 


\section{Chapter 9}

number of nonunions in scaphoid fractures is significantly influenced by the use of PEMF. Since the length of unemployment in patients treated with PEMF is not significantly shorter than in patients treated conservatively in a below-elbow cast, PEMF treatment for acute scaphoid fractures is an inferior treatment compared to care as usual, when considering cost-effectiveness. However, the effects of PEMF in a subgroup of undisplaced, stable scaphoid waist fractures account for the need to further investigate the effects of PEMF on healing in acute fractures in prospective, focused in vivo studies. 


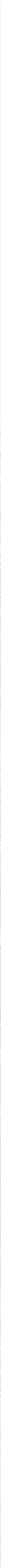




\section{Chapter 10}

\section{NEDERLANDSE SAMENVATTING (SUMMARY IN DUTCH)}



Scaphoïdfracturen zijn relatief veelvoorkomende fracturen onder jonge, actieve mensen waarbij falende of te laat geïnitieerde behandeling tot ernstige gezondheidsgerelateerde, economische of sociale problemen kan leiden. In dit proefschrift wordt de invloed van pulsed electromagnetic field (PEMF) botgroeistimulatie op de genezing van acute scaphoïdfracturen beschreven. Onze hypothese was dat het gebruik van PEMF botgroeistimulatie de genezing van verse scaphoïdfracturen significant zou bevorderen. Het doel van ons onderzoek was derhalve om vast te stellen of PEMF botgroeistimulatie de periode tot fractuurgenezing kon verkorten, zowel op basis van radiologische criteria, alsmede op basis van klinische criteria van genezing. Daarnaast probeerden we vast te stellen of door het inzetten van PEMF botgroeistimulatie in de behandeling van scaphoïdfracturen het aantal nonunions gereduceerd kon worden, alsmede een verbeterde functionele uitkomst van pols en hand verkregen kon worden. Daarnaast hebben we de betrouwbaarheid en nauwkeurigheid van de verschillende radiologische technieken onderzocht om aan te tonen dat scaphoïdfracturen al dan niet genezen zijn.

In hoofdstuk 1 wordt het genezingsproces van scaphoïdfracturen beschreven, alsmede de factoren die bijdragen aan gecompliceerde of falende genezing en de verschillende behandelopties. Daarnaast worden de geschiedenis, de principes en de mogelijke toepasbaarheid beschreven van (elektrische) botgroeistimulatie en PEMF in het bijzonder.

In hoofdstuk 2 wordt de eerste dubbelblinde, placebo-gecontroleerde gerandomiseerde studie beschreven waarin de hypothese wordt getoetst dat PEMF botgroeistimulatie de tijd tot volledige genezing van scaphoïdfracturen significant kan verkorten. Drieënvijftig patiënten uit drie verschillende centra met een onverplaatste of minimaal verplaatste scaphoïdfractuur werden gerandomiseerd voor behandeling met een PEMF botgroeistimulator danwel een placebo. Klinische en radiologische uitkomsten werden na vier, zes, negen, twaalf, vierentwintig en tweeënvijftig weken na start van de behandeling bepaald. Radiologische genezing gedurende follow-up werd bepaald met behulp van standaard scaphoïdserie röntgenfoto's.

Zowel tijd tot volledige radiologische en klinische genezing, alsmede functionele uitkomst verschilden niet significant tussen beide groepen. We concludeerden derhalve dat, gebaseerd op deze trial, PEMF botgroeistimulatie geen aanvullende waarde heeft bij de conservatieve behandeling van acute scaphoïdfracturen. 


\section{Chapter 10}

Alhoewel standaard röntgenfoto's nog altijd de eerste keuze zijn voor het aantonen van scaphoïdfracturen, verschaffen ze niet altijd betrouwbare en nauwkeurige informatie aangaande aan- of afwezige genezing van scaphoïdfracturen. In hoofdstuk 3 hebben we de inter-waarnemer betrouwbaarheid en validiteit bepaald van standaard scaphoïdserie röntgenfoto's voor het vaststellen van fractuurgenezing van scaphoïdfracturen in een prospectieve cohort analyse. De interwaarnemer overeenstemming van vier verschillende waarnemers werd bepaald, die elk zevenenveertig standaard scaphoïdseries beoordeelden aangaande genezing van scaphoïdfracturen zes weken na start van een conservatieve behandeling middels gipsimmobilisatie. Het tijdsbestek van zes weken werd gekozen omdat een substantieel deel van alle onverplaatste scaphoïdfracturen na zes weken is geconsolideerd. De inter-waarnemer betrouwbaarheid voor nonunion (uitblijvende genezing) was beter dan voor union (genezing) en de overall inter-waarnemer betrouwbaarheid werd als matig gedefinieerd.

Om deze resultaten in perspectief te plaatsen hebben we eveneens de betrouwbaarheid en validiteit bepaald van multiplanar reconstructie computer tomografie (MRCT) scans aangaande de genezing van scaphö̈dfracturen zes, twaalf en vierentwintig weken na ontstaan van de fractuur in hoofdstuk 4. De inter-waarnemer overeenstemming werd bepaald voor vierenveertig sets van MRCT scans. Zowel voor union alsmede nonunion kon de inter-waarnemer betrouwbaarheid worden bestempeld als substantieel. Daarnaast bleek dat sensitiviteit en specificiteit van MRCT scans voor het bepalen van union beter was dan van standaard scaphoïd röntgenfoto's. In de follow-up na een scaphoïdfractuur lijkt de CT scan dan ook een betrouwbare en nauwkeurige methode om genezing van scaphoïdfracturen aan te tonen of uit te sluiten. We adviseren derhalve om de CT scan te gebruiken in de vroege fase van de follow-up na scaphoïdfractuur behandeling.

De bevindingen uit hoofdstuk 2, 3 en 4 rechtvaardigden een grotere en verbeterde trial betreffende de werkzaamheid van PEMF botgroeistimulatie voor acute scaphö̈dfracturen. In hoofdstuk 5 beschrijven we de gerandomiseerde, dubbelblinde, placebo-gecontroleerde multicentrische trial waarin we de hypothese hebben getoetst dat PEMF botgroeistimulatie de tijdsperiode tot genezing van scaphoïdfracturen significant kan verkorten en het aantal nonunions kan reduceren. Honderdtwee patiënten uit vijf verschillende centra met een onverplaatste acute scaphoïdfractuur werden gerandomiseerd voor behandeling met een PEMF botgroeistimulator, danwel een placebo waarbij functionele en radiologische uitkomsten van beide groepen werden vergeleken. Radiologische uitkomsten werden bepaald door middel van multiplanar reconstructie CT scans 
die zes, twaalf, vierentwintig en tweeënvijftig weken na start van de behandeling werden gemaakt. Alhoewel er geen significant overall verschil werd waargenomen tussen beide groepen betreffende tijdsduur tot volledige klinische en radiologische genezing, konden we een subgroep van patiënten selecteren door middel van een post-hoc analyse die aangaande snelheid van genezing mogelijk zou kunnen profiteren van PEMF botgroeistimulatie. Een log-rank analyse liet zien dat bij onverplaatste dwarse taillefracturen de tijdsduur tot volledige genezing significant korter was in de groep die met de PEMF botgroeistimulator werd behandeld dan in de placebo groep. Afgaande op het minimum aantal patiënten dat volgens de power analyse geïncludeerd diende te worden, moeten deze bevindingen wel met enige terughoudendheid worden geïnterpreteerd. We concluderen derhalve dat de resultaten die we zagen in de studie die we in hoofdstuk 2 beschrijven, ook door deze studie bevestigd kunnen worden en dat de toevoeging van PEMF botgroeistimulatie overall niet leidt tot snellere genezing van scaphoïdfracturen.

In hoofdstuk 6 beschrijven we de prospectieve economische evaluatie van PEMF botgroeistimulatie voor acute scaphoïdfracturen die we vanuit een sociaal perspectief hebben uitgevoerd, analoog aan de trial die we in hoofdstuk 5 hebben beschreven. Alle kosten aangaande PEMF botgroeistimulatie en gebruikelijke zorg voor onverplaatste scaphoïdfracturen zijn gedurende een jaar na ontstaan van de fractuur bepaald, waarbij naast alle medische kosten ook kosten van productiviteitsverlies door de fractuur zijn bepaald. Daarnaast werden functionele uitkomst en gezondheidsgerelateerde kwaliteit van leven bepaald met behulp van de EuroQol-5D en patient rated wrist and hand evaluation (PRWHE) vragenlijsten. Er werd geen significant verschil gezien in verloren werkdagen tussen de PEMF en de placebo groep. De totale kosten van behandeling waren hoger voor de PEMF groep dan voor de groep die zonder PEMF werd behandeld. De gewenste effecten van PEMF aangaande kosteneffectiviteit van de behandeling van scaphoïdfracturen werden derhalve niet bereikt. Verder werden geen verschillen aangaande functionele uitkomst en gezondheidsgerelateerde kwaliteit van leven gezien tussen beide groepen.

In hoofdstuk 7 zijn de uitkomsten van botgroeistimulatie voor acute fracturen in de beschikbare literatuur systematisch beoordeeld. Het doel van deze systematische review en meta-analyse was om het best beschikbare bewijs voor effectiviteit van pulsed electromagnetic field (PEMF) en low intensity pulsed ultrasound (LIPUS) botgroeistimulatie voor acute fracturen te vergelijken. Twee onafhankelijke beoordelaars bepaalden de sterkte en het risico op bias 


\section{Chapter 10}

voor elk van de geïncludeerde studies. Uit dertien trials werden 737 patiënten geïncludeerd. Uit de resultaten van de geïncludeerde gerandomiseerde trials bleek dat PEMF en LIPUS de tijd tot volledige radiologische genezing van conservatief behandelde fracturen en fracturen van de bovenste extremiteit significant kunnen verkorten. Echter, om het aantal nonunions terug te dringen is op basis van deze review onvoldoende bewijs geleverd om deze technieken routinematig in te zetten in de behandeling van deze fracturen.

Concluderend kunnen we stellen dat dit proefschrift bewijst dat het gebruik van PEMF botgroeistimulatie in het algemeen geen significant voordeel oplevert bij de behandeling van acute scaphoïdfracturen en derhalve de routinematige inzet van deze techniek niet gerechtvaardigd kan worden. Als we multiplanar reconstructie CT scans gebruiken voor de beoordeling van de mate van genezing van de scaphoïdfracturen - de techniek die volgens dit proefschrift een betere betrouwbaarheid en validiteit toont dan de standaard röntgenfoto voor deze bepaling - kunnen we concluderen dat noch tijd tot volledige genezing, noch het aantal scaphoïd nonunions significant wordt beïnvloed door de inzet van PEMF botgroeistimulatie. Gezien het feit dat de duur van arbeidsongeschiktheid onder patiënten die behandeld zijn met een PEMF botgroeistimulator niet korter is dan onder patiënten die uitsluitend met een gips zijn behandeld, kunnen we stellen dat de behandeling met PEMF botgroeistimulatie een minder effectieve behandeling is voor scaphoïdfracturen dan de standaard conservatieve behandeling op basis van kosteneffectiviteit. Echter, de geobserveerde positieve effecten van PEMF botgroeistimulatie op de tijd tot genezing in een subgroep van onverplaatste, stabiele scaphoïd taillefracturen dragen bij aan de noodzaak om de invloed van PEMF botgroeistimulatie op het genezingsproces van acute fracturen verder doelgericht in vivo te onderzoeken. 
Nederlandse samenvatting 


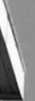

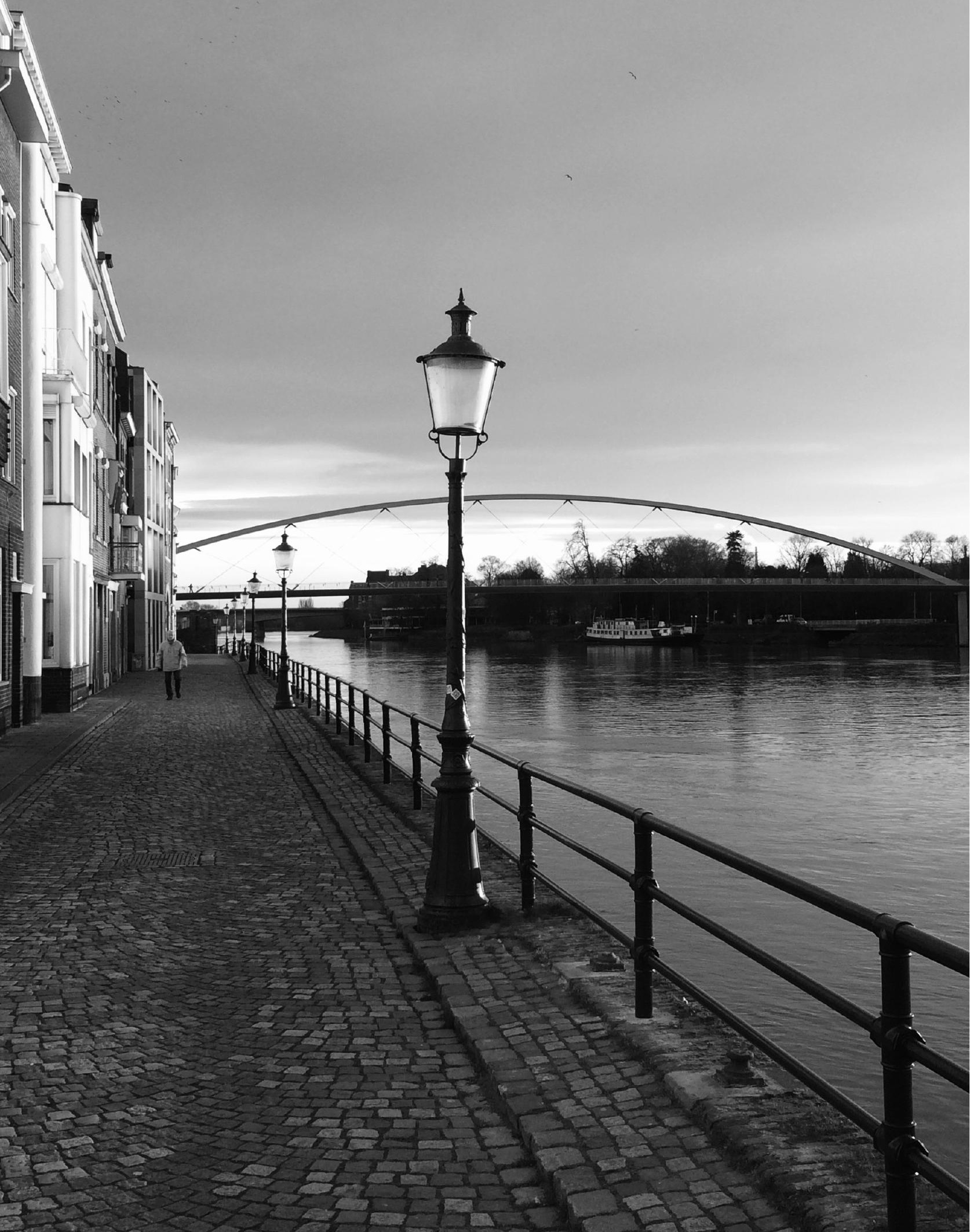




\section{Chapter 11}

VALORIZATION 



\section{INTRODUCTION}

The scientific work in this thesis was funded by the Netherlands Organisation for Health Research and Development (ZonMw), as part of a research programme focused on healthcare efficiency. This programme aims to provide an evidence base for innovative proposed interventions in order to facilitate their implementation. The idea is that if the innovations studied are actually introduced in practice, then the research results from this programme will lead to tangible efficiency gains. These gains may take the form of implementation of efficient interventions, but also cessation of interventions that have proven to be inefficient from a societal perspective. As part of this programme, this thesis therefore represents a form of valorization in itself. Further areas of valorization are discussed in more detail below.

\section{Social AND ECONOMIC ReleVANCE OF THE THESIS}

Hand and wrist injuries, accounting for approximately $20 \%$ of all visits to Dutch emergency departments, are the most expensive of all injury types presenting at emergency departments. ${ }^{1}$ Strikingly, the resulting loss of productivity is the largest contributor to the health-related cost of these injuries. Population-based research has shown that the majority of all costs due to hand and wrist injuries occur in patients of working age (20 to 64 years), therefore contributing significantly to high productivity costs as a result of prolonged absence from work. ${ }^{1}$ Therefore, hand and wrist injuries represent a considerable economic burden. Among these hand and wrist injuries, acute scaphoid fractures can result in fracture nonunion and/or carpal malalignment, leading to persistent pain and loss of wrist movement and function. These consequences, in turn, lead to a significantly increased risk of symptomatic post-traumatic osteoarthritis, with severe healthrelated and social consequences. ${ }^{2}$

Although non-operative treatment remains the standard in the Netherlands, there is an increasing trend towards operative treatment of scaphoid fractures. Operative treatment of undisplaced and minimally displaced scaphoid waist fractures has been shown to lead to earlier return to work and sport. ${ }^{3}$ However, it also has a significantly higher risk of complications than conservative treatment. ${ }^{4}$ Furthermore, there is no evidence that operative treatment of undisplaced or minimally displaced scaphoid fractures increases union rates. ${ }^{5}$ For this reason, routine surgical treatment of minimally displaced and undisplaced scaphoid fractures does not seem to be justified by the available literature. 


\section{Chapter 11}

This necessitates further research on the non-invasive treatment of scaphoid fractures. Since electromagnetic field stimulation has been shown to induce and stimulate fracture healing in vivo, we hypothesized that this non-invasive technique would accelerate and improve healing without the risk of concomitant complications, thereby yielding both social and economic benefits. This thesis has demonstrated that pulsed electromagnetic field (PEMF) bone growth stimulation does not induce these effects in undisplaced and minimally displaced scaphoid fractures, and its use is therefore not recommended in general. In addition, this thesis presented recommendations for appropriate imaging techniques for follow-up of scaphoid fracture treatment. This, too, is important, as inadequate assessment of scaphoid healing and undetected lack of progression towards scaphoid union may have severe consequences in terms of functional outcome as well as direct and indirect costs.

\section{TARGET POPULATION}

A large survey among Canadian trauma surgeons revealed that $45 \%$ of surgeons incorporated bone growth stimulators into their treatment regimes for long-bone fractures. ${ }^{6}$ Data on the number of orthopedic trauma surgeons using bone growth stimulation in daily practice in the Netherlands are not available, but are expected to be similar. The results of this thesis, and its recommendations for treatment and follow-up of scaphoid fractures, will be of interest to clinicians involved in clinical decision-making on the treatment of scaphoid fractures. Given the high incidence of these fractures, the number of clinicians involved in treating them is relatively large. ${ }^{7}$

\section{KNOWLEDGE UTILIZATION}

The research group's knowledge in the area of bone growth stimulation for acute fractures and fracture healing in general will be valorized through its application in studies focused on induction of fracture repair and high-resolution imaging techniques for bone healing. Further, evaluation of the changes in bone turnover marker serum levels as a result of PEMF bone growth stimulation will help us to understand the effects of PEMF in acute fractures. The expected insights into the optimal signal characteristics and exposure time of PEMF bone growth stimulation will help to reduce the burden of delayed fracture healing for society and the economy. In addition, it may be feasible to apply these techniques in the treatment of other acute fractures. 


\section{INNOVATION AND FUTURE}

The clinical effects of PEMF bone growth stimulation have featured in the literature since $1977 .{ }^{\circ}$ An invention can only be considered an innovation if it is widely adopted in practice and has an impact on society. In other words: innovation also implies the large-scale implementation of a novel application of existing scientific knowledge. However, the number of studies reporting on the efficacy of PEMF bone growth stimulation in acute fractures is very limited. ${ }^{9}$ Given this dearth of evidence, the use of PEMF in the treatment of acute fractures is not recommended. However, if the required evidence is forthcoming in the future, this technology could come to be used on a larger scale. The studies described in this thesis are the first to evaluate the effect of PEMF in acute scaphoid fractures. Although the desired effects in terms of cost-effectiveness and efficacy were not achieved, our studies offer new insights into the applicability of PEMF in acute fractures, and the data obtained will serve as the basis for further research. 


\section{Chapter 11}

\section{REFERENCES}

1. de Putter CE, Selles RW, Polinder S, Panneman MJ, Hovius SE, van Beeck EF. Economic impact of hand and wrist injuries: health-care costs and productivity costs in a population-based study. The Journal of bone and joint surgery American volume 2012;94:e56.

2. Davis TR. Prediction of outcome of non-operative treatment of acute scaphoid waist fracture. Annals of the Royal College of Surgeons of England 2013;95:171-6.

3. McQueen MM, Gelbke MK, Wakefield A, Will EM, Gaebler C. Percutaneous screw fixation versus conservative treatment for fractures of the waist of the scaphoid: a prospective randomised study. The Journal of bone and joint surgery British volume 2008; 90:66-71.

4. Ibrahim T, Qureshi A, Sutton AJ, Dias JJ. Surgical versus nonsurgical treatment of acute minimally displaced and undisplaced scaphoid waist fractures: pairwise and network meta-analyses of randomized controlled trials. The Journal of hand surgery 2011;36: 1759-68 e1.

5. Alshryda S, Shah A, Odak S, Al-Shryda J, Ilango B, Murali SR. Acute fractures of the scaphoid bone: Systematic review and meta-analysis. The surgeon: journal of the Royal Colleges of Surgeons of Edinburgh and Ireland 2012;10:218-29.

6. Busse JW, Morton E, Lacchetti C, Guyatt GH, Bhandari M. Current management of tibial shaft fractures: a survey of 450 Canadian orthopedic trauma surgeons. Acta orthopaedica 2008;79:689-94.

7. Duckworth AD, Jenkins PJ, Aitken SA, Clement ND, Court-Brown CM, McQueen MM. Scaphoid fracture epidemiology. The journal of trauma and acute care surgery 2012; 72:E41-5.

8. Bassett CA, Pilla AA, Pawluk RJ. A non-operative salvage of surgically-resistant pseudarthroses and non-unions by pulsing electromagnetic fields. A preliminary report. Clinical orthopaedics and related research 1977:128-43.

9. Hannemann PF, Mommers EH, Schots JP, Brink PR, Poeze M. The effects of low-intensity pulsed ultrasound and pulsed electromagnetic fields bone growth stimulation in acute fractures: a systematic review and meta-analysis of randomized controlled trials. Archives of orthopaedic and trauma surgery 2014;134:1093-106. 
Valorization 
APPENDIX

DANKWOORD

LIST OF PUBLICATIONS

CURRICULUM VITAE 



\section{DANKWOORD}

Toen ik in 2008 naar Maastricht kwam om verder aan mijn carrière als chirurg en traumachirurg in het bijzonder te werken, had ik gehoopt dat ik ooit aan dit stukje tekst zou mogen beginnen. En zie daar... De basis voor dit proefschrift is dan ook op dat moment gelegd. Ondanks het feit dat het geen eenvoudige klus is geweest, heb ik met veel plezier gewerkt aan de totstandkoming van dit proefschrift. Zonder de hulp van tal van mensen die direct of indirect hun bijdrage hebben geleverd, was dit echter niet gelukt. Een aantal mensen wil ik dan ook in het bijzonder bedanken.

In de eerste plaats wil ik mijn promotor bedanken. Beste professor Brink, beste Peter, ik ben je ontzettend dankbaar dat je je hebt ingespannen om mijn komst vanuit Nijmegen naar Maastricht te stimuleren en dat je mij hebt geënthousiasmeerd om dit onderzoek verder uit te werken tot hetgeen het is geworden. Belemmeringen zie jij als uitdagingen en geen brug is te ver om je doel te bereiken. Het is deze volhardendheid die er ook uiteindelijk toe heeft geleid dat ZonMw de subsidieaanvraag voor het onderzoek, hetgeen de basis was voor dit proefschrift, heeft gehonoreerd. Zonder deze subsidie was de totstandkoming van dit proefschrift waarschijnlijk nooit gelukt.

Daarnaast heb ik veel respect voor de liefde die jij hebt voor het vak en de manier waarop je dat uitstraalt naar anderen. Je kritische blik, je immense ervaring en ongeëvenaarde handvaardigheid zijn voor mij drijfveren om het vak ooit te kunnen uitoefenen op de manier zoals jij dat doet. Het zal een eer zijn om in jouw voetsporen te mogen treden als je de scalpel vaarwel zegt.

Beste dr. Poeze, beste Martijn, wat een genot om met jou als copromotor aan dit proefschrift te hebben mogen werken. Je bent een wetenschapper in hart en nieren met een ongelofelijke kennis van zaken. Jouw deur stond altijd wagenwijd open en advies en feedback werden altijd zeer gedegen, weldoordacht en scherpzinnig geleverd. Ik heb ontzettend veel van je geleerd, waarvoor mijn dank. Daarnaast ben je een inspirerende collega op de werkvloer en beschouw ik je als een echte vriend bij wie je altijd welkom bent voor een gesprek en een kop koffie. Ik kijk uit naar verdere samenwerking met je.

Zonder de inspanningen van de founding fathers van dit onderzoek, Andries Werre en Karel Kolkman, zou dit proefschrift nooit tot stand zijn gekomen. Andries en Karel, dank dat jullie mij de kans hebben gegeven om dit onderzoek, jullie kindje, uit te bouwen tot hetgeen het geworden is. Ik hoop dat het eindresultaat voldoet aan jullie verwachtingen. 


\section{Appendix}

Gerrit van Niftrik en Harrie Boogers, ontzettend bedankt voor jullie bereidheid om namens Ossatec op deze wijze een bijdrage te leveren aan dit onderzoek. Zonder de botgroeistimulatoren die jullie beschikbaar hebben gesteld was dit onderzoek uiteraard onmogelijk geweest. Omdat onderzoek meestal meer vragen dan antwoorden oplevert ben ik blij dat we onze samenwerking op wetenschappelijk gebied nog verder gaan uitbreiden. Beste Michelle Lavalette, dank voor de secure manier waarop je het datamanagement hebt gedaan!

Beste mede traumachirurgen, Jan Verbruggen, Paul Breedveld en Guido Stollenwerck, dank voor de intensieve en prettige samenwerking die we hopelijk nog jaren zullen voortzetten. Jan, je kundigheid in het vak is nog altijd een bron van inspiratie. Ik hoop dat we nog veel samen mogen opereren. Beste Paul, je bent de beste kamergenoot die een chirurg zich kan wensen. Je doet me denken aan een profeet wiens woorden, die nooit overvloedig zijn, doordrenkt zijn van wijsheid en inzicht. Ik hoop dat ik nog lang om advies kan vragen bij je.

Beste Guido, je enthousiasme en doortastendheid maken onze samenwerking voor de traumapatiënt bijzonder prettig.

Vakgroep chirurgie AZM en Michael Jacobs in het bijzonder, dank voor de prettige samenwerking de afgelopen jaren. Het werkt bijzonder inspirerend om van een in goede harmonie functionerende groep deel uit te mogen maken.

Beste dr. Hoofwijk, beste Ton, je staat aan het allereerste begin van mijn carrière en hebt een duidelijke stempel gedrukt op mijn professionele waarden. Je inspanningen om de liefde voor wetenschappelijk onderzoek over te brengen op mij zijn niet zonder resultaat gebleken. Ik ben trots dat ik eindelijk aan mijn opleider het resultaat mag laten zien van vele jaren intensief wetenschappelijk werk.

Veel dank ben ik verschuldigd aan onze SEH PA's, Sacha en Ed. Zonder jullie niet aflatende enthousiasme om patiënten te includeren hadden we nooit deze aantallen gehaald. Ik ben blij dat jullie onderdeel uitmaken van ons "traumateam".

Zonder de inzet van alle gipsmeesters in Maastricht, Arnhem, Boxmeer, Nijmegen en Zwolle zou dit onderzoek nooit afgerond zijn. In het bijzonder dank aan het Maastrichtse clubje, Anniek, Chris, Daniëlle, John, Mario en Marie-Louise. We gaan elkaar nog veel zien! 
Beste Manfred, waar zou ik zijn gebleven zonder jouw inspanningen vanuit Boxmeer? Dank voor je inzet. Ik hoop dat we elkaar nog vaak zullen treffen in de toekomst.

Beste Hilde, dank voor je hulp vanuit Nijmegen om de data te organiseren. Het maakte ons leven in elk geval wat makkelijker.

Het doen van multicenter onderzoek is alleen mogelijk door de inspanning van velen. Ik wil dan ook iedereen die in de deelnemende ziekenhuizen in Arnhem en Zwolle direct of indirect betrokken is geweest bedanken.

Zonder de hulp van de collega's van de afdeling radiologie had ik een groot deel van dit proefschrift nooit kunnen schrijven. Rene, Annika, Ed, Dennis en Daan dank voor jullie inspanningen. Ik hoop dat er nog vele publicaties zullen voortkomen uit onze samenwerking.

Beste semi-artsen, beste Lars, Koen, Martin, Elwin en Judith, dank voor jullie inspanningen. Zonder jullie (monniken)werk was er geen bruikbare database geweest. Onder andere hiermee hebben jullie een fundamentele bijdrage geleverd aan de totstandkoming van vele artikelen en dus ook dit proefschrift. Ik wens jullie veel succes toe met jullie carrières en hoop ooit ook te verschijnen op jullie promoties.

Kevin, dank voor je bijdrage aan het onderzoek in het prille begin.

Beste Alison, dank voor de zeer professionele manier waarop je het gebruik van de Engelse taal kritisch hebt beoordeeld in alle publicaties.

Dank aan de leden van de beoordelingscommissie, prof. Van der Hulst, prof. Arora, dr. Buijze en prof. Van Rhijn voor de kritische beoordeling van het manuscript.

John Derwall, dank voor de fraaie cover en de lay-out van het definitieve proefschrift.

Pap en mam, dank voor jullie vertrouwen, steun en begrip. Ik ben trots dat ik dit met jullie mag meemaken.

De afgelopen jaren heb ik naast mijn drukke werkzaamheden ontzettend veel tijd geïnvesteerd in dit proefschrift waardoor het contact met vrienden en familie 


\section{Appendix}

op een lager pitje is komen te staan. Omdat promoveren bijzonder is, maar andere dingen in het leven veel belangrijker zijn, weet ik zeker dat we dit de komende jaren goed zullen maken. Dank voor jullie geduld en begrip.

Beste Bart, wat fijn dat je paranimf bent. Wanneer kunnen we de rollen omdraaien?

Beste Antoine, ik heb altijd gehoopt dat mijn broer me op het moment van verdedigen zou kunnen bijstaan, ook al is de parallel tussen onze vakken ver te zoeken. Daarom is het wat mij betreft bijzonder dat mijn enige broer dit samen met mij wil doen.

Tot slot wil ik de allerbelangrijkste persoon bedanken zonder wie ik de hoop al lang had opgegeven dat dit proefschrift ook maar uit 1 pagina zou bestaan. Sandra, lieve schat, wat heb jij moeten doorstaan met je promoverende mannetje. Al die uren, avonden, maanden en jaren achter de computer of in artikelen gedoken heb ik de afgelopen periode veel te weinig aandacht kunnen besteden aan de liefde van mijn leven. Ik ben gelukkig dat onze paden ons ooit kruisten en dat ik onder alle omstandigheden kan rekenen op jouw onvoorwaardelijke steun en liefde. Nu ben jij aan de beurt. 


\section{LIST OF PUBLICATIONS}

Hannemann PFW, Essers BAB, Schots JPM, Dullaert K, Poeze M, Brink PRG. Functional outcome and cost-effectiveness of pulsed electromagnetic fields in the treatment of acute scaphoid fractures: a cost-utility analysis. Submitted (2015)

Disseldorp DJG, Poeze M, Hannemann PFW, Brink PRG. Is bone grafting necessary in the treatment of malunited distal radius fractures? Submitted (2014)

Hannemann PFW, Brouwers L, Dullaert K, Van der Linden ES, Poeze M, Brink PRG. Determining scaphoid waist fracture union by conventional radiographic examination: an analysis of reliability and validity. Arch Orthop Trauma Surg. 2015 Feb;135(2):291-6

Hannemann PFW, Van Wezenbeek MR, Kolkman KA, Twiss ELL, Berghmans CHJ, Dirven PAMGM, Brink PRG, Poeze M. CT scan-evaluated outcome of pulsed electromagnetic fields in the treatment of acute scaphoid fractures. A randomised, multicentre, double-blind, placebo-controlled trial. Bone Joint J. 2014 Aug; 96-B(8):1070-6

Hannemann PFW, Mommers EHH, Schots J, Brink PRG, Poeze M. The effects of low-intensity pulsed ultrasound and pulsed electromagnetic fields bone growth stimulation in acute fractures: a systematic review and meta-analysis of randomized controlled trials. Arch Orthop Trauma Surg. 2014 Aug; 134(8):1093-106

Hannemann PFW, Brouwers L, Brink PRG. Nonunion of the pisiform bone in a 9-year-old boy. Hand 2014; feb. DOI 10.1007/s11552-014-9613-2

Theunissen BHJJ, Lardenoye S, Hannemann PFW, Gerritsen K, Brink PRG, Poeze $M$. Fast Track by physician assistants shortens waiting and turnaround times of trauma patients in an emergency department. Eur J Trauma Emerg Surg 2013; sept. DOI 10.1007/s00068-013-0324-0

Hannemann PFW, Brouwers L, Van der Zee D, Stadler A, Göttgens KWA, Weijers R, Poeze M, Brink PRG. Multiplanar reconstruction computed tomography for diagnosis of scaphoid waist fracture union: a prospective cohort analysis of accuracy and precision. Skeletal Radiol 2013 Oct; 42(10):1377-82 


\section{Appendix}

Hannemann PFW, Göttgens KWA, Van Wely BJ, Kolkman KA, Werre AJ, Poeze $M$, Brink PRG. The clinical and radiological outcome of pulsed electromagnetic field treatment for acute scaphoid fractures: A randomised double-blind placebo-controlled multicentre trial. J Bone Joint Surg Br. 2012 Oct; 94(10):1403-8

Hannemann PFW, Brink PRG. Scaphoid fractures. Diagnosis by computed tomography $(\mathrm{CT})$ compared with magnetic resonance imaging (MRI). Orthop. trauma dir. 2011;03:29-30

Hannemann PFW, Göttgens KWA, Van Wely BJ, Kolkman KA, Were AJ, Poeze $M$, Brink PRG. Pulsed Electromagnetic Fields in the treatment of fresh scaphoid fractures. A Multicenter, prospective, double-blind, placebo controlled, randomized trial. BMC Musculoskeletal Disord. 2011 May 6;12:90

Fransen SAF, Hannemann PFW. A dog's groomer with a painfull hand. Case report. Dutch Journal of Medicine (Ned Tijdschr geneeskd.) 2010;154:A1718

Hannemann PFW, Lassen K, Nimmo S, Ljungqvist O, Nygren J, Soop M, Faeron K, Andersen J, Revhaug A, Von Meyenfeldt MF, Dejong CHC, Spies C. Patterns in current anaesthesiologic perioperative practice for colonic resections: A survey in five northern European countries. Acta Anaesthesiol Scand. 2006 oct; 50(9): $1152-60$

Lassen K, Dejong CHC, Ljungqvist O, Faeron K, Andersen J, Hannemann PFW, Von Meyenfeldt MF, Hausel J, Nygren J, Revhaug A. Nutritional support and oral intake after gastric resection in five northern European countries. Dig Surg. 2005 nov;22(5):346-52

Lassen K, Hannemann PFW, Ljungqvist O, Faeron K, Dejong CHC, Von Meyenfeldt MF, Andersen J, Revhaug A. Patterns in current perioperative practice: Survey of colorectal surgeons in five northern European countries. BMJ 2005 Jun 18; 330(7505):1420-1

Hannemann PFW, Hoofwijk AGM, van den Akker LHJM. Ruptured iliac aneurysm presenting as acute cardiac failure and massive leg swelling. EJVES 2001 Jan $1(1): 5-6$ 


\section{Curriculum vitae}

Pascal Hannemann was born in Heerlen, the Netherlands, on September 13, 1974. After graduating from high school in 1992 (Atheneum, Sint Antonius Doctor College Rolduc, Kerkrade), he studied medicine at the university of Leiden. He obtained his medical degree in 1998.

In November 1998, he started his clinical career as a resident in general surgery at the Maasland hospital (now Orbis Medical Centre) in Sittard, under supervision of dr. A.G.M. Hoofwijk. In March 2001 he started his surgical training at the Maastricht University Medical Centre under supervision of prof. dr. M.J.H.M. Jacobs and subsequently at the Orbis Medical Centre in Sittard under supervision of dr. A.G.M. Hoofwijk.

In March 2007, Pascal Hannemann registered as a specialist in general surgery and started his training in trauma surgery with a fellowship at the Canisius Wilhelmina Hospital in Nijmegen. In May 2008 he started as a junior specialist at the Maastricht University Medical Centre, further developing his knowledge and experience in trauma surgery. The work on this thesis started in 2010, after receiving a grant from the Netherlands Organisation for Health Research and Development for exploration of effectiveness of the technique described in this thesis. In 2010, he became consultant senior staff member at the department of trauma surgery of the Maastricht University Medical Centre, where he specialized in upper extremity trauma. 
